Portland State University

PDXScholar

7-27-1993

\title{
This Looks Like an Old Point: Time and Projectile Points in the Tualatin Valley, Oregon
}

\author{
Linda Lani Freidenburg
}

Portland State University

Follow this and additional works at: https://pdxscholar.library.pdx.edu/open_access_etds

Part of the Anthropology Commons

Let us know how access to this document benefits you.

\section{Recommended Citation}

Freidenburg, Linda Lani, "This Looks Like an Old Point: Time and Projectile Points in the Tualatin Valley, Oregon" (1993). Dissertations and Theses. Paper 4660.

https://doi.org/10.15760/etd.6544

This Thesis is brought to you for free and open access. It has been accepted for inclusion in Dissertations and Theses by an authorized administrator of PDXScholar. Please contact us if we can make this document more accessible: pdxscholar@pdx.edu. 
AN ABSTRACT OF THE THESIS OF Linda Lani Freidenburg for the Master of Arts in Anthropology presented July 27, 1993.

Title: This Looks Like an Old Point: Time and Projectile Points in the Tualatin Valley, Oregon.

\section{APPROVED BY MEMBERS OF THE THESIS COMMITTEE:}
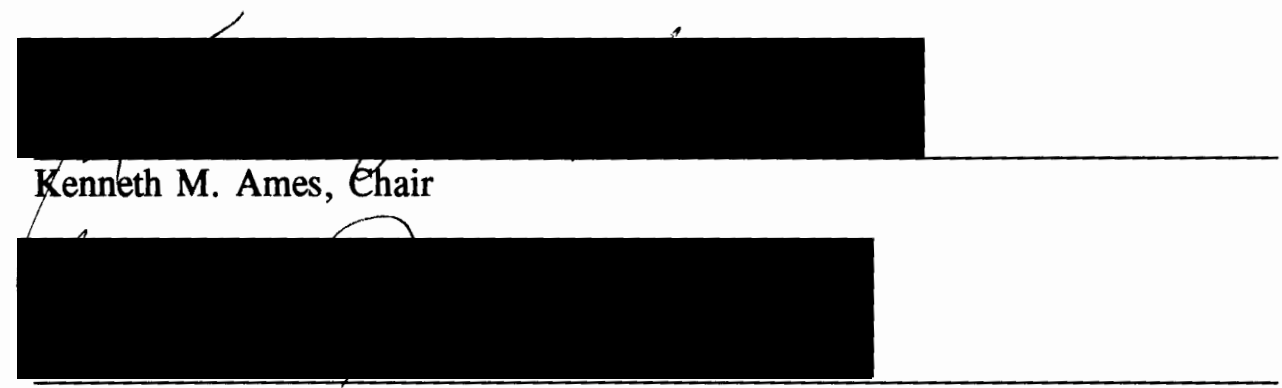

Marc R. Feldesman

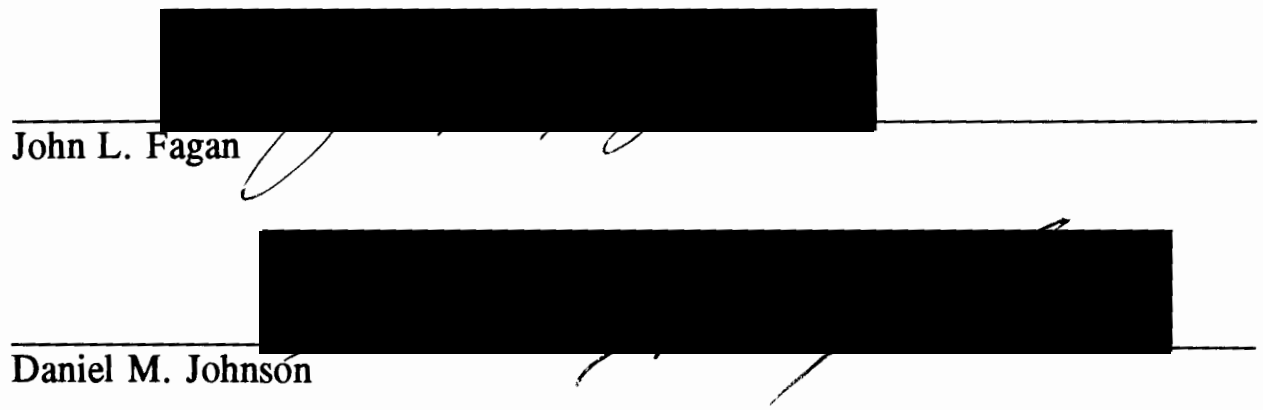

Little is known about the time depth of human occupation in the Tualatin Valley. Archaeological investigations have produced no absolute dates for the few sites tested. Projectile points collected from the Ibach and Heynderickx farms in the Tualatin Valley show similarities to early point styles from sites in the Pacific Northwest dating from 6,000 to 10,000 years ago. To determine how old the Ibach and Heynderickx sites are, the undated collections of 107 Ibach points and 119 Heynderickx points are compared to two established 
chronological projectile point sequences, which had been constructed using the relative dating technique of frequency seriation. These sequences are further anchored with radiocarbon dates which extend back 6,000 years. On the basis of the comparison of Ibach and Heynderickx projectile point types to the seriated point types, it is suggested that the Tualatin Valley sites evidence occupation times at least as early as 6,000 years ago and possibly earlier. 


\section{TO THE OFFICE OF GRADUATE STUDIES:}

The members of the Committee approve the thesis of Linda Lani Freidenburg presented July 27, 1993.

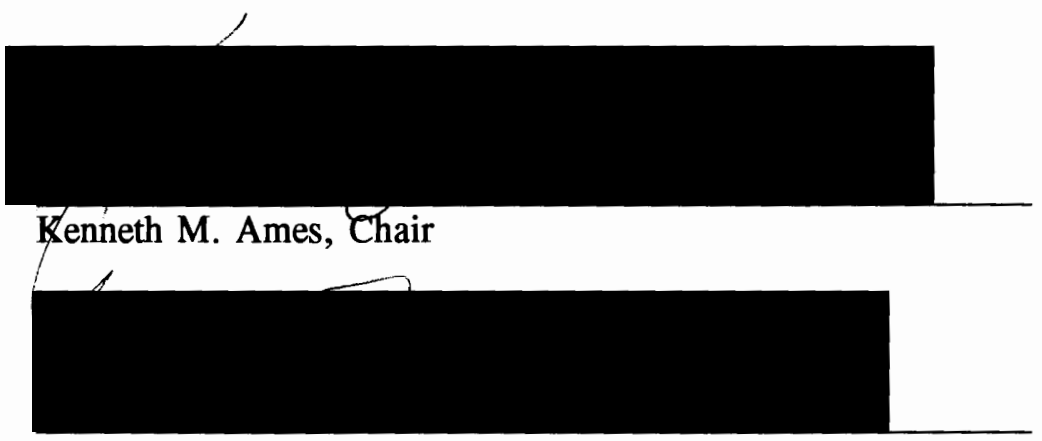

Marc R. Feldesman
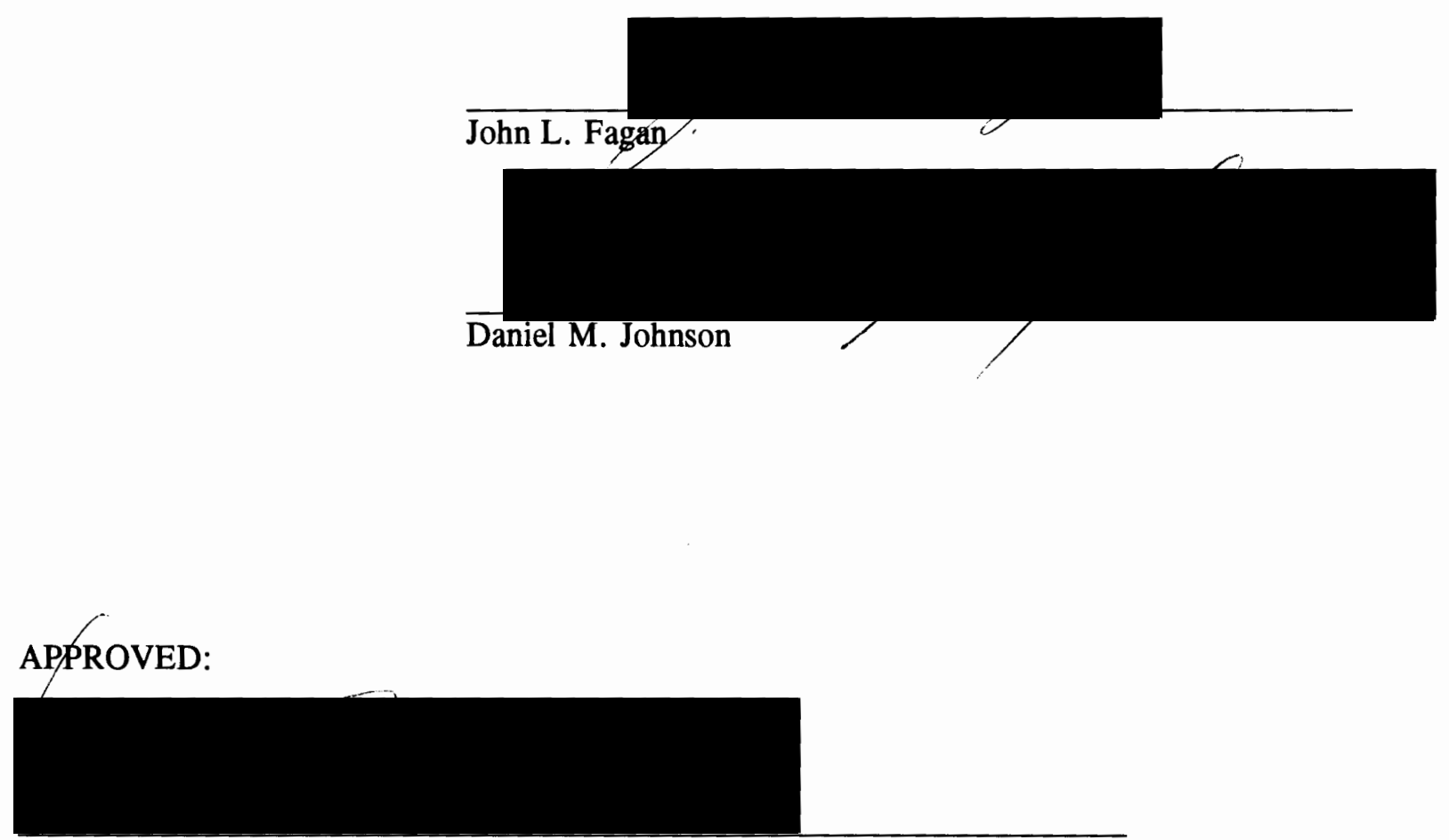

Marc R. Feldesman, Chair, Department of Anthropology

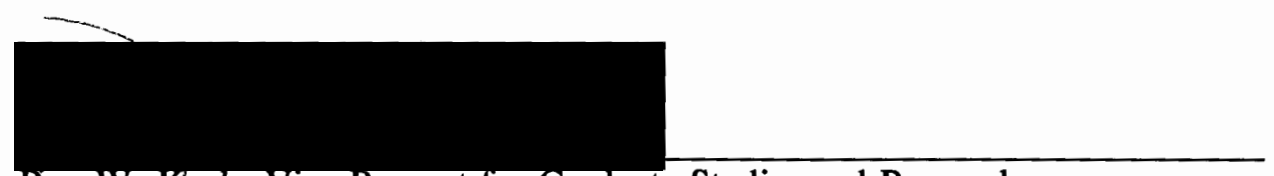

Roy W. Koch, Vice Provost for Graduate Studies and Research 
THIS LOOKS LIKE AN OLD POINT: TIME AND PROJECTILE POINTS

IN THE TUALATIN VALLEY, OREGON

by

LINDA LANI FREIDENBURG

A thesis submitted in partial fulfillment of the

requirements for the degree of

MASTER OF ARTS

in

ANTHROPOLOGY

Portland State University

1993 


\section{ACKNOWLEDGEMENTS}

I thank the Heynderickx and Ibach families for donating their artifacts to the Washington County Museum and the museum staff for granting easy access for research to these artifacts. I am indebted to Richard Pettigrew for his work in the Portland Basin and at the Hager's Grove sites and to Kathryn Toepel for her investigations at the Flanagan site. I thank also the members of my committee, who so willingly agreed to read and critique my work and who in good humor accommodated schedule changes. Finally, I especially thank Connie Cash who kept everything and everybody organized.

I would also like to acknowledge that over the lifespan of this thesis project there have been so many people who have encouraged me, bribed me, cheered me on, gave up on me, had faith in me, set deadlines, and knew I would finish even when I was uncertain. I thank each of you -- family, friends, strangers -- for your contribution. 
TABLE OF CONTENTS

PAGE

ACKNOWLEDGEMENTS $\ldots \ldots \ldots \ldots \ldots \ldots \ldots \ldots \ldots \ldots \ldots \ldots$ iii

LIST OF TABLES $\ldots \ldots \ldots \ldots \ldots \ldots \ldots \ldots \ldots \ldots \ldots \ldots \ldots$

LIST OF FIGURES $\ldots \ldots \ldots \ldots \ldots \ldots \ldots \ldots \ldots \ldots \ldots \ldots$

CHAPTER

I INTRODUCTION $\ldots \ldots \ldots \ldots \ldots \ldots \ldots \ldots \ldots \ldots$

The Physical Landscape $\ldots \ldots \ldots \ldots \ldots \ldots$

The Heynderickx and Ibach Artifact Collections ........ 7

The Farms as Sites $\ldots \ldots \ldots \ldots \ldots$

Previous Archaeological Research in the Tualatin Valley .......99

II MARKING TIME: THE THEORETICAL PERSPECTIVE . . . . . . . . 12

Classification, Seriation, and Typology Selection . . . . . . . 12

Projectile Points and Projectile Point Attributes . . . . . . . . . 16

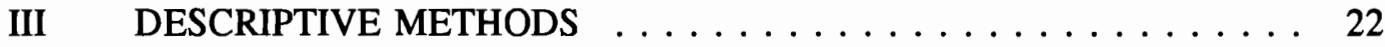

The Portland Basin Typology . . . . . . . . . . . . . . . . 22

Projectile Point Attributes

Projectile Point Types

The Flanagan Site Typology . . . . . . . . . . . . . . 26

Projectile Point Attributes

Projectile Point Types

Synthesis: Describing the Heynderickx and Ibach Projectile Points 30 
IV RESULTS.

Summary Description of the Study Collections ............................. 32

Tualatin Valley Points in Pettigrew's Typology .............................. 37

Stemmed Points

Stemless Points

Tualatin Valley Points in Toepel's Typology

Stemless Points

Stemmed Points

Comments Regarding Using Toepel's and Pettigrew's Typologies

V DISCUSSION

Tualatin Valley Sites in the Portland Basin Chronology 86

Pettigrew's Seriation Process

Portland Basin Projectile Point Type Patterns

Tualatin Valley Sites in the Portland Basin Chronology

Tualatin Valley Sites in the Hager's Grove Chronology

Tualatin Valley Sites in the Flanagan Site Chronology 95

Toepel's Seriation Process

Flanagan Site Projectile Point Type Patterns

Tualatin Valley Sites in the Flanagan Site Chronology

Conclusion

REFERENCES CITED

\section{APPENDICES}
A SAMPLE PROJECTILE POINT WORKSHEET WITH DEFINITIONS 106
B TABLES OF PROJECTILE POINT ATTRIBUTES AND TYPES 


\section{LIST OF TABLES}

I Projectile Point Attribute Definitions in Toepel Typology . . . . . . . 27

II $\quad$ Heynderickx Projectile Points $\ldots \ldots \ldots \ldots \ldots \ldots \ldots \ldots \ldots$

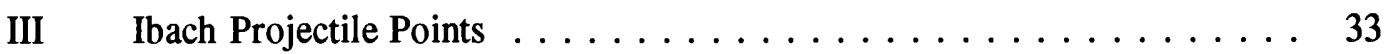

IV Comparative Data on Point Fragments . . . . . . . . . . . . . 34

V Projectile Points: Pettigrew Typology . . . . . . . . . . . . . . 39

VI Heynderickx Broad-necked Points . . . . . . . . . . . . . 48

VII Ibach Broad-necked Points $\ldots \ldots \ldots \ldots \ldots \ldots \ldots$

VIII Heynderickx Narrow-necked Points ... . . . . . . . . . . 52

IX Ibach Narrow-necked Points $\ldots \ldots \ldots \ldots \ldots \ldots$

X Heynderickx Side-notched Points $\ldots \ldots \ldots \ldots \ldots$

XI Ibach Side-notched Points $\ldots \ldots \ldots \ldots \ldots \ldots$

XII Heynderickx Stemless Points ... . . . . . . . . . . . . . . 59

XIII $\quad$ Ibach Stemless Points . . . . . . . . . . . . . . . . . 59

XIV Projectile Points: Toepel Typology ................... 65

XV Pettigrew Types: Projectile Point Percentages for Excavated Portland Basin

Points and Collected Tualatin Valley Points . . . . . . . . . 88

XVI Pettigrew Types: Projectile Point Percentages, Diagnostic Type Groups Only, Portland Basin Sites and Tualatin Valley Sites . . . . . . . . . . 90

XVII Distribution of Projectile Point Series by Site Component $(\mathrm{N}=226) \quad \ldots \quad . .97$

XVIII Distribution of Flanagan Projectile Point Series Per Site Component . . . 98 
XIX Tualatin Valley Projectile Points in Flanagan Site Typology . . . . . . . 98 


\section{LIST OF FIGURES}

FIGURE

PAGE

1. Map of the Study Area................................................................

2. Parts of a Projectile Point ............................................................ 17

3. Pettigrew's Projectile Point Attributes...............................................24

4. Toepel's Projectile Point Attributes..................................................28

5. Flanagan Site Projectile Point Key .......................................................29

6. Heynderickx Projectile Point Fragments ............................................35

7. Ibach Projectile Point Fragments...................................................

8. Heynderickx Projectile Points Typed as Pettigrew Type 1 .......................40

9. Ibach Projectile Points Typed as Pettigrew Type 1 ..................................41

10. Heynderickx and Ibach Projectile Points Typed as Pettigrew Type $2 \ldots \ldots . . . .43$

11. Heynderickx and Ibach Projectile Points Typed as Pettigrew Type $4 \ldots \ldots \ldots . . .43$

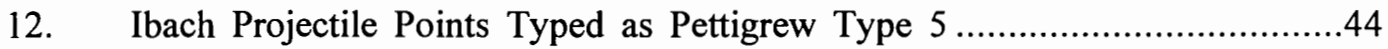

13. Heynderickx Projectile Points Typed as Pettigrew Type 5......................45

14. Heynderickx and Ibach Projectile Points Typed as Pettigrew Type Broadnecked, Unidentified .....................................................47

15. Heynderickx Projectile Points Typed as Pettigrew Type 7 and Type $8 \ldots . . .50$

16. Heynderickx Projectile Points Typed as Pettigrew Type 9......................50

17. Heynderickx and Ibach Projectile Points Typed as Pettigrew Type $10 \ldots \ldots . .51$

18. Heynderickx and Ibach Projectile Points Typed as Pettigrew Type Narrownecked, Unidentified .....................................................51

19. Heynderickx and Ibach Projectile Points Typed as Pettigrew Type $12 \ldots \ldots .54$ 
20. Heynderickx and Ibach Projectile Points Typed as Pettigrew Type 6a . . 57

21. Heynderickx and Ibach Projectile Points Typed as Pettigrew Type 6b . . 57

22. Heynderickx Projectile Points Typed as Pettigrew Type 6d and Type 14 . 60

23. Heynderickx Projectile Points Typed as Pettigrew Type 6, Unclassified . . 60

24. Ibach Projectile Points Typed as Pettigrew Type 6, Unclassified . . . . . 61

25. Heynderickx and Ibach Projectile Points Typed as Toepel Types SS1, SS2

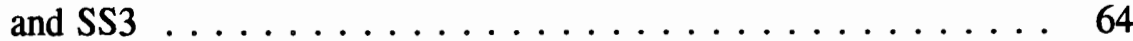

26. Heynderickx Projectile Points Typed as Toepel Type HS2 . . . . . . . 67

27. Ibach Projectile Points Typed as Toepel Type HS2 . . . . . . . 67

28. Heynderickx Projectile Points Typed as Toepel Type HS3 . . . . . . . 68

29. Ibach Projectile Points Typed as Toepel Type HS3 . . . . . . . . . . 69

30. Heynderickx and Ibach Projectile Points Typed as Toepel Type NN2 _. 73

31. Heynderickx Projectile Points Typed as Toepel Type NN3 . . . . . . . 73

32. Heynderickx and Ibach Projectile Points Typed as Toepel Type NN,

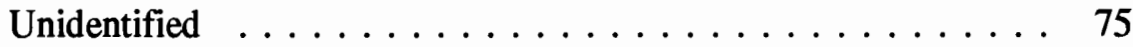

33. Heynderickx and Ibach Projectile Points Typed as Toepel Types MB1, MB2 and MB, Unidentified ................. 75

34. Ibach and Heynderickx Projectile Points Typed as Toepel Type MB3 _ . 77

35. Heynderickx and Ibach Projectile Points Typed as Toepel Type HB1 . . 77

36. Heynderickx Projectile Points Typed as Toepel Type HB2 . . . . . . . 79

37. Ibach Projectile Points Typed as Toepel Type HB2 . . . . . . . . . . 79

38. Heynderickx Projectile Points Typed as Toepel Type HB3 . . . . . . . . 81

39. Ibach Projectile Points Typed as Toepel Type HB3 . . . . . . . . . . 81

40. Ibach and Heynderickx Projectile Points Typed as Toepel HB, Unidentified 82 
41. Neck Width Relative Frequencies (\%) for Ibach Stemmed Points................91

42. Neck Width Relative Frequencies (\%) for Heynderickx Stemmed Points......91

43. Neck Width Relative Frequencies (\%) for 35MU9, Both Excavated

and Borrowed Collections....................................................... 92 


\section{CHAPTER I}

\section{INTRODUCTION}

Chronology equips archaeology with the temporal framework necessary for investigating cultural processes. Establishing temporal control is imperative. Whenever possible, archaeologists choose absolute chronometric methods, such as radiocarbon dating or thermoluminescence, for determining the age of things; however, when material is unavailable for absolute dating, they rely on relative dating techniques. Seriation, when used to chronologically order types (or styles) of a particular kind of artifact, is one such relative dating technique. The artifact most often used as a time-marker in seriations is the stone projectile point, due to its ubiquity in archaeological contexts throughout North America and to its morphological variability over time. Comparison of projectile point types from an undated site to projectile point types from one or more radiocarbon-dated sites, for example, provides a relative chronometric technique in the absence of more conclusive dating procedures.

In the Tualatin Valley, Oregon, archaeological investigations have produced no absolute dates. Of the 42 Tualatin Valley prehistoric sites listed with the Oregon State Historic Preservation Office, 27 have been merely surface-surveyed, 9 are documented as having been at least shovel or auger probed, and only 6 have been sampled with formal test excavations. None of these investigations has yielded dates from radiocarbon testing or other absolute dating procedures (Gilsen 1990). Furthermore, the number of projectile points recovered during testing has been sparse -- the greatest number of points from one site was 
seven -- which limited attempts to assign occupation times to these sites on the basis of projectile point types (Davis 1970, Ellis 1989, Ellis and Fagan 1990).

In the 1980s, the opportunity arose to use larger numbers of points for analysis when two farming families (Heynderickx and Ibach) living in different sections of the Tualatin Valley donated their collections of Native American artifacts to the Washington County Museum. Both farmers had gathered these artifacts from their land over the course of more than 50 years of farming activities. The Heynderickx farm is located near Hillsboro; the Ibach farm is in Tualatin. Similarities between projectile points in these collections and those linked with radiocarbon dates of 6000 to 8000 years ago in other parts of the Pacific Northwest prompted an initial hypothesis that the Tualatin Valley locations might also be as old.

This thesis assigns occupation ages to the Ibach and Heynderickx farm sites by using a seriational analysis of projectile points collected from them. To systematically evaluate the age of the Heynderickx and Ibach projectile points, I compare them with projectile point types incorporated in typologies pertaining to sites geographically and culturally close to the Tualatin Valley. Two such typologies are one constructed by Pettigrew (1977) for several Portland Basin sites and later applied to Hager's Grove in the Willamette Valley, and the other designed by Toepel (1985) for the Flanagan site, also in the Willamette Valley. Both the Portland Basin and Flanagan typologies are anchored with radiocarbon dates, which support the relative chronological ordering of projectile point types in each typology.

This thesis has six chapters. The first chapter, following this introduction, describes the physical landscape of the sites included in the Pettigrew and Toepel typologies and of the Heynderickx and Ibach farms, describes the types of artifacts found on the farms, and summarizes previous archaeological research in the Tualatin Valley. Chapter II first reviews 
archaeological classification and seriation of artifacts and then examines the use of projectile points as chronologically diagnostic artifacts. Chapter III outlines the descriptive procedures used by Pettigrew to define projectile point types in the Portland Basin sites and those used by Toepel to define the Flanagan site points. It also specifies how I described points in the Heynderickx and Ibach collections to enable comparisons with the point types as defined in the two typologies. Chapter IV presents the results of typing the Ibach and Heynderickx point collections using the Pettigrew and Toepel systems. Chapter V concludes with an analysis of the dating of the two Tualatin Valley sites.

\section{THE PHYSICAL LANDSCAPE}

The Tualatin Valley lies in the northwestern corner of the Willamette Valley, Oregon (Figure 1). The Willamette Valley itself forms the southern end of the structural depression known as the Puget-Willamette Trough and extends north from the Calapooya Mountains approximately 110 miles to the Columbia River and west from the Cascade Mountains to the Coast Range. For most of its length, the Willamette River flows through a broad, fairly level alluvial valley plain. Tributary rivers divide it into various hydrologic sub-basins, one of which is the Tualatin Valley. Just northeast of the Tualatin Valley is the Portland Basin, which forms the northern extremity of the Willamette Valley. The Portland Basin, at the confluence of the Willamette and Columbia rivers, is recognized as distinctive from the rest of the Willamette Valley and is often subsumed geographically and culturally under the Lower Columbia River system. The major sites discussed in this thesis (i.e, the Portland Basin sites, the Flanagan site, Hager's Grove sites, and the Ibach and Heyndericx farms) are in the Willamette Valley and are described below. (These sites are further described in Chapter V.)

The Portland Basin sites, which formed the basis of Pettigrew's original point 


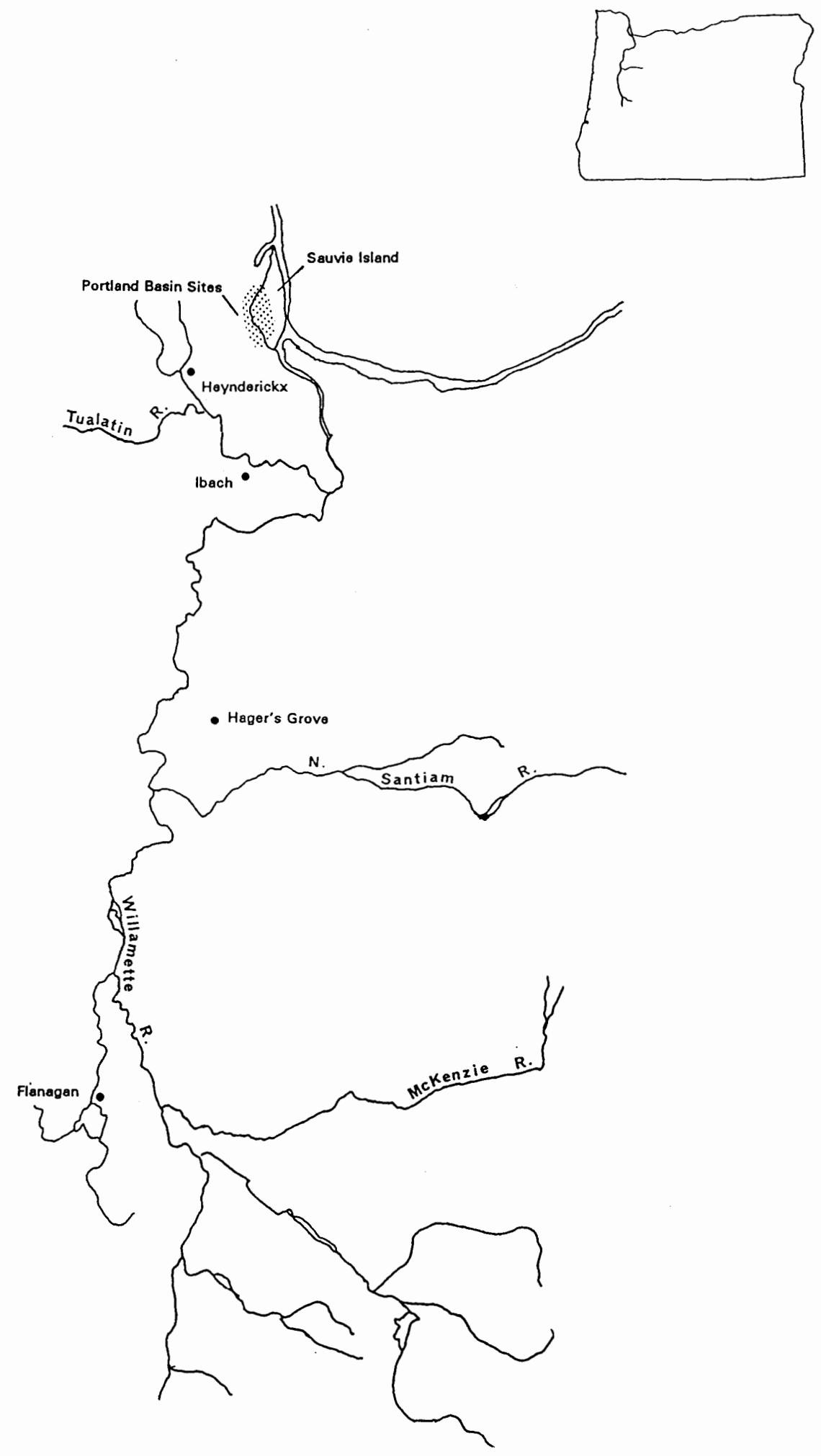

Figure 1. Map of the study area. (Adapted from Toepel 1985:10, Figure 2) 
typology, are located on Sauvie Island and on the mainland west of it. In this area, where Multnomah Channel splits away from the Willamette River and flows northward around Sauvie Island before meeting the Columbia, Pettigrew (1977) excavated portions of seven sites to gather samples of projectile points from which to construct his typology. Radiocarbon dates for these sites span roughly a 3000 -year period, from about 950 B.C. ${ }^{1}$ to circa A.D. 1870. Landforms vary from active floodplain to older terraces.

Hager's Grove, located in Salem at the intersection of the I-5 freeway and Highway 22, is a cluster of 3 sites situated on old abandoned braided channels of Mill Creek, a tributary of the Willamette River. Pettigrew (1980) excavated two of these sites and applied his Portland Basin projectile point typology to the points found here. The earliest radiocarbon date is about 1850 B.C., and the latest is around A.D. 1550 (Pettigrew 1980:61), a span of approximately 3500 years.

The Flanagan site (35 LA 218), source of the other typology (Toepel 1985) used here, is in the southern part of the Willamette Valley a few miles northwest of Eugene. The site is positioned on an abandoned floodplain of the Willamette River (Balster and Parsons 1968:8; Toepel 1985:30). Occupation dates based on radiocarbon results begin at about 3800 B.C. and end somewhere between A.D. 1550 and the time of contact, a span of nearly 6000 years.

The two projectile point collections forming the foundation of this thesis come from farms in the Tualatin Valley. The valley is nearly circumscribed by mountains: the Coast Range on the west, the Tualatin Mountains along the north and east, and the smaller Chehelam Mountains on the south. The valley floor is flat to gently rolling and is dotted with

'This radiocarbon date comes from an early level of 35MU9 (the Merrybell site). The site may be even older than this date, as culturally sterile dirt was not reached. However, since this level was not adequately sampled (only 5 of the $\mathbf{3 7 8}$ points came from it), Pettigrew used instead the date of about 200 B.C. from the cultural level above it to mark the earliest date of his projectile point analysis for the site. 
low hills. The Tualatin River rises in the Coast Range and meanders sluggishly across the valley gathering water from its tributaries before joining the Willamette River just south of Willamette Falls, West Linn and Oregon City.

The Tualatin Valley floor was configured most recently by the Bretz floods 12,000 to 15,000 years ago (Allen et al. 1986), which scoured the valley floor and then deposited thick layers of sediments. Tops of older remnant foothills escaped the effects of the floods (Allen et al. 1986; Green 1982). Subsequent erosional forces delineated the tributary stream beds and continue to contour the valley surfaces. In general, young alluvial soils border the Tualatin River and its tributaries, while older terraces lie between them and the older-yet foothills (Green 1982).

The Heynderickx farm is located in the south half of Section 16, T 1 north, R 3 west, Willamette Meridian. It is a 70-acre parcel running from Dairy Creek (just south and downstream of the confluence of East and West Forks of Dairy Creek) eastward about 240 yds. The land gently rises from an elevation of 150 feet above mean sea level (amsl) near the creek to a little over 170 feet amsl halfway across the property. This high area extends eastward before sloping down slightly to a intermittent streamlet flowing southwesterly across the eastern boundary of the farm.

The soils on the Heynderickx farm consist primarily of two types. The soil along Dairy Creek is a Chehalis series that forms in recent alluvium on level floodplains (Green 1982:16). The rest of the farm is primarily a Woodburn silt loam which "formed in old alluvium on low, broad valley terraces" (Green 1982:47). Most of the farm is on a terrace older than the active floodplain of Dairy Creek. Grain is the primary crop grown.

The Ibach farm was a 40-acre farm in the SW $1 / 4$ section of Section 26, Township 2 south, Range 1 west, Willamette Meridian. It was sold in the early 1980s. The eastern half 
of the farm (approximately 20 acres) has since been subdivided into house lots, while the western half has been bought by the city for development next year into a city park. The following description applies to the pre-development conditions since, based on Jane Ibach's account of the subdivision construction (personal communication, May 1991), I suspect the topographic and hydrologic situation may be radically changed.

The site of the Ibach farm contrasts in topography with the Heynderickx site. Whereas the Heynderickx farm lies in an area of extensive, nearly level and broad alluvial valleys north of Forest Grove and Hillsboro, the Ibach farm is located among the foothills that extend from the eastern edge of the Chehalam Mountains to the mouth of the Tualatin River. The farm sat on a northwest-facing slope with a creek flowing northwest across the property. Although the 1985 USGS topographical map denotes the creek as intermittent, Jane Ibach (personal communication, May 1991) said it was spring-fed and supplied water all year round. In fact, there were several springs on their farm.

The steeper east side of the farm was planted in orchards. This part of the property is primarily Hillsboro and Quatama soil series, the former formed on broad valley terraces and the latter formed in alluvium and lacustrine deposits (Green 1982). The bulk of the western section is more level and is primarily Aloha silt loam and Huberly silt loam, both poorly drained (Green 1982). Elevation ranges from approximately 270 feet amsl along the southern and eastern perimeter to 210 feet amsl in the northwest corner where the creek runs downslope.

\section{THE HEYNDERICKX AND IBACH ARTIFACT COLLECTIONS}

The Ibach and Heynderickx collections themselves differ dramatically in overall size and artifact diversity. Except for one ground stone tool, the Ibach collection consists of small 
flaked tools and tool fragments. There are 135 items in all; 107 of these I classified as projectile points (described in Chapter IV). The rest are scrapers, edge-modified or utilized flake tools, a knife, several unidentifiable biface fragments, two pieces of debitage, and a few non-artifactual stones. The ground stone tool is possibly what is called a bola stone. It is an oval cobble $(7.5 \mathrm{~cm}$ long) girdled by a groove parallel to its length with barely discernible narrow ground facets also along its length. All these items were found by Hilla Ibach as he went over his land with horse and plow. He stored them in a 3-pound coffee can, and artifacts and coffee can were donated to the Washinton County Museum. Although he found no other artifacts, their neighbors found many, including larger items such as bowls and pestles (Jane Ibach, personal communication, 1991).

The Heynderickx collection is more extensive. Although it consists of 134 small flaked lithic tools (a number comparable to the Ibach collection), it also includes over 60 other specimens: nearly half are mortars and bowls, the rest are pestles, cobble tools (such as hammerstones, net weights, spherical stones), an anvil stone, abrader, other unidentified artifacts, and a few non-artifactual stones. Of the 134 small flaked items, I classified 119 of these as projectile points (described in Chapter IV). The other 15 include knives, drills, scrapers, gravers, a biface blank, and three unclassifiable bifaces. These 134 small items had been arranged in glass frames for display and were donated that way to the Washington County Museum.

\section{THE FARMS AS SITES}

Both farmers who did the collecting of the artifacts are no longer alive. I tried to discover exactly where on their farms most or all of the items were found, but my talking to the families elicited no specific information. It is possible that each collection actually 
represents more than one site; it is equally possible that each does not. That the Heynderickx collection is so diverse and abundant and non-portable suggests an intense use of the area by Indians, perhaps over a long period of time. The Ibach farm collection is more problematic, as the artifacts collected are small and could all have been lost during hunts or other types of forays over the years. The neighbors, however, had an extensive collection of large and small artifacts, suggesting some settlement or encampment nearby. For the purpose of this thesis and until more definite information is available, I am assuming each collection is from one site.

\section{PREVIOUS ARCHAEOLOGICAL RESEARCH IN THE TUALATIN VALLEY}

Very little prehistoric archaeological investigation has been done in the Tualatin Valley since the first site was recorded in 1965. Several sites were found then during a survey preceding dam construction in Scoggin Valley in the mid-1960s (Cole 1965). From that time until now most of the sites recorded are a result of cultural resources compliance regulations, and, aside from a few isolated site reports, this has produced a clustered pattern of recorded sites in the Tualatin drainage. These clusters occur in the western valley in and west of Gaston, in the north between Rock and McKay creeks, and in the extreme southeast of the valley between the cities of Tualatin and Sherwood.

The earliest areas investigated were the two small Scoggin and Patton valleys on the western edge of the Tualatin Valley, where the Tualatin River begins. Cole's 1965 report listing several sites resulted in one of the few test excavations done to date. The site, 35WN4, was a midden with cultural material down to $60 \mathrm{~cm}$ (although the first $22 \mathrm{~cm}$ were fill). On the basis of artifact comparisons to other Willamette Valley sites (including the 7 projectile points he found), Davis (1970) suggests an occupation no earlier than 2000 years 
ago. Decker and Doyle (1976) recorded the next set of sites when they surveyed Patton Valley for a proposed dam. They dug a test pit at three sites and reported finding flakes and a few artifacts, but none below $20 \mathrm{~cm}$. In 1982 Melissa Cole, while doing a cultural resources inventory for Washington County, also observed and recorded sites in the town of Gaston and in Patton Valley. Other than a listing of artifacts found by the archaeologists or by private collectors and a listing of reports of extensive private artifact collections and reports of burials found years earlier, very little information about the prehistory or chronology of the area was gleaned from these early projects.

More recent investigations (i.e., in the last 6 years) have been in the north of the Tualatin Valley, in the area where the Heynderickx farm is located. In 1987 survey work for a gas pipeline produced 8 site listings (Hibbs and Ellis 1988). Follow-up test excavations occurred at one of these, the Pumpkin Ridge site, 35WN34. Ellis (1989) reported that the site covered 40 acres near Dairy Creek with surface material clustered in four places. Dating of the site relied on only two recovered projectile points, the only diagnostic tools found, and a radiocarbon sample collected from a feature. Unfortunately, this radiocarbon sample has not yet been processed (Ellis, personal communication 1993). The point styles indicate only that the site could have been occupied in the last 6000 years.

The third area of the valley to receive systematic archaeological attention is the Tualatin area. Brauner and Robbins (1976) recorded 3 sites based primarily on accounts from local artifact collectors. No testing followed. Survey for a road widening project revealed two prehistoric sites (Scott 1987a, 1987b) between Tualatin and Sherwood. Shovel testing produced flakes at one site (35WN31) and flakes and two unifacial tools at the other (35WN32), and cultural material did not extend beyond $20 \mathrm{~cm}$. Most recently, Jenkins and Soper (1989) in doing an inventory of sites in the Hedges Creek wetland area (just north of 
the Ibach farm) for the City of Tualatin found four prehistoric sites in addition to the one previously reported by Fagan (1987). All were shovel-tested and all produced lithic flakes and/or tools. Although they recommended all sites for further subsurface testing, only one site (35WN19) was subsequently tested (Ellis and Fagan 1990) in response to imminent construction disturbance. Two $1 \times 1$ meter test units produced 8 non-diagnostic tools and 80 flakes, most recovered in the top $10 \mathrm{~cm}$. The site was recommended for eligibility for listing in the National Register of Historic Places, but the recommendation was eventually denied.

The dearth of archaeological evidence in the Tualatin Valley is due in part to the paucity of thorough investigations as well as to the shallowness of the mostly plowzone sites found to date. In addition, urbanization of the valley has already destroyed much of the prehistoric cultural legacy and daily obliterates more. Against this background, the Heynderickx and Ibach collections of chronologically diagnostic projectile points -- several of them "old-looking" -- materialized as an excellent opportunity to assess the age of occupation in the Tualatin Valley. The next chapter explains the theoretical perspective of projectile point typology and seriation. 


\section{CHAPTER II}

\section{MARKING TIME: THE THEORETICAL PERSPECTIVE}

Before launching into a description of specific projectile point typologies, it is helpful to first step back to review the theoretical underpinnings of archaeological classification as used in this thesis. In this chapter I review the bases of archaeological classification and seriation and describe how projectile points have been used in typologies and employed as time-markers.

\section{CLASSIFICATION, SERIATION, AND TYPOLOGY SELECTION}

Classification is the grouping of like objects into classes based on criteria arbitrarily chosen by the classifier to suit a specific research question. Types are subsets of a class. Types, while falling under the general criteria of the class definition, are defined more specifically on the basis of attributes or variables ${ }^{2}$ which divide the class into subsets that show "internal cohesion and external isolation" (Doran and Hodson 1975:159). In other words, members of a type are more similar to one another than they are to members of another type. A typology is an arrangement of types. A good typology is one whose types are unambiguously dissimilar yet meaningful for the purpose of the typology.

The selection of attributes to define types depends on the objectives of the classification project. In terms of this thesis, the appropriate attributes defining types for the

\footnotetext{
${ }^{2}$ Unlike Cowgill (1982:31) and Spaulding (1977) who reserve variable to denote a condition or type of observation and attribute to describe the value of the variable, I use variable and attribute interchangeably for the condition and value for the specific reading of that condition.
} 
artifact class of projectile points are those capturing chronological changes, and these are discussed in the next section. How artifact types are used in seriations for relative dating purposes is presented below.

Seriation is a technique used to establish a relative chronology and is the basis of this thesis. Seriation is based on the assumption is that artifacts have styles ${ }^{3}$ (or physical characteristics) that wax and wane in popularity over time, and that the life of an individual type will begin with initial use, experience a certain period of growing popularity, and then fall out of fashion. Artifact classes, types or attributes that reflect these temporal changes and that are linked with particular time periods can be ordered in a relative dating sequence.

Two kinds of seriation are occurrence seriation and frequency seriation. Occurrence seriation is an ordering based only on the presence or absence of the phenomenon under study. For example, if projectile point types are the units being ordered, then proveniences A, B and C (or groups A,B,C) are arranged on horizontal axes so that when types $1,2,3$ or 4 are marked present in each provenience the distribution of each type is vertically contiguous. This ranking is considered chronological based on the underlying assumption that "the distribution of any historical or temporal class is continuous through time" (Dunnell 1970:308).

The type of seriation employed in this thesis is frequency seriation. It is similar to occurrence seriation except that instead of merely recording presence or absence of units, the relative frequency (percentage) of each unit is recorded. Here, the groups (or proveniences, etc.) are arranged horizontally not only to show a continuous distribution for each projectile point type, for example, but also to show that "each continuous distribution exhibits the form

\footnotetext{
${ }^{3}$ The word "styles" is used in a general sense here and not as an antithesis of "function." Following Brown (1982:183), I view projectile point morphological types as combining "both functional and stylistic features to a greater or lesser degree."
} 
of a unimodal curve in terms of the frequency of representation" (p. 309). This unimodal or battleship-shaped curve represents the "life-span" of each artifact type.

A chronology based on seriation does not of itself indicate the direction of time, i.e., which end of the vertical axis is earliest or which is latest. However, absolute dates associated with groups on the horizontal axes can provide the temporal framework for the relative chronology. Archaeologists can then set up sequences for a series of types within a site and also, by comparing chronological sequences from several sites in the same area, set up an intersite chronology.

Sequence comparison is the technique of taking a classified collection from an undated context and dating it by comparing it to an established chronological sequence. In my thesis I compare two undated collections of projectile points to two established chronological sequences based on seriated projectile point types. This type of comparison is not as strong, of course, as comparing dated collections, but it provides a legitimate means of establishing chronological control over collections lacking stratigraphy, associated dates or other contextual data.

The two typologies I selected for comparing my unstratified collections with exemplify these approaches. Toepel uses her typology to set up an intrasite seriation of Flanagan site projectile points; Pettigrew uses his typology to produce an intersite seriation of seven Portland Basin sites. Both use frequency seriation in conjunction with radiocarbon dates to set up projectile point typologies of perceived time-sensitive types. These site frequency patterns of projectile point types are what I use to compare the frequencies of similar types in the Ibach and Heynderickx collections.

Relative dating by artifact comparison assumes that change in a particular artifact in one area is reflected by similar change in the other and at about the same time. Dunnell 
(1970) cautions that a seriated order can be considered chronological only when the variation in the frequency distributions is due primarily to the time dimension and not to spatial, stylistic, or other factors. Assumptions here are that "the units ordered are of comparable duration ... and are from the same cultural tradition" (p. 305). In addition, an assumption in frequency seriation is that "[e]ach archaeological provenience included is assumed to constitute a representative sample of the artifact types in use at the time" (Thomas 1989:334). I chose the seriated typologies by Pettigrew and Toepel because both of them attempted to meet the specified conditions and because their sites are geographically and culturally close to the Heynderickx and Ibach sites. The Portland Basin sites are 10 to 15 miles overland from the Heynderickx site and less than 20 miles by land (and even easier access by river) from the Ibach site. Although resources were probably different in the two areas, there was social and economic trade at the time of historic contact which may have been long-term (Zenk 1976). The Flanagan site, although farther away, was chosen not only because of the ethnohistoric linguistic ties between the Kalapuyan people throughout the interior Willamette Valley, but also because the Tualatin Valley and greater Willamette Valley shared a similar interior valley environment; and people in close, similar environments likely fashioned similar subsistence and resource extraction tools.

Another reason for choosing these two tyologies is that both were applied to sites with substantial time depth. The Hager's Grove sites covered a 4000-year span, the Flanagan site had a 6000-year occupation span, and the Portland Basin sites spanned nearly 3000 years.

In the next section, I review some of the research aimed at eliciting projectile point attributes reflecting temporal changes, especially neck width, as both Toepel and Pettigrew lend that particular attribute weight. Finally, I summarize the attributes selected by Toepel and Pettigrew to define their projectile point types. 


\section{PROJECTILE POINTS AND PROJECTILE POINT ATTRIBUTES}

The class of stone projectile points is generally defined as relatively symmetrical, usually bifacially flaked, sharpened at the distal tip, and modified at the proximal end to facilitate hafting (Figure 2). Sometimes the haft is clearly delineated by notches or removal of stone to form a stem; in other instances, the haft is less obvious. Projectile points are the sharpened tips attached to shafts of arrows, atlatl darts, or spears, although they may also have served as hafted knives. The point is usually the only part of the tool or weapon to survive archaeologically.

Archaeologists wrestle, first, with choosing one or more attributes that reflect the time dimension as accurately as possible and, second, with deciding how best to measure or describe each attribute. One way of determining a point's age is to ascertain which type of propulsion device it was a part of; in particular, is it an early dart point or a later arrow point? Accepted as the single most dramatic change in projectile points seen archaeologically is the decrease over time in overall size (Lohse 1985; Thomas 1981). This change is assumed to reflect the shift from the use of atlatl darts to bows and arrows, with a concomitant downsizing of the point to parallel a presumed decrease in the diameter of the shaft.

Building on previous works (Baker and Kidder 1937; Forbis 1960; Fenenga 1953) that grappled with this issue, Corliss (1972) selected a single attribute -- width of the neck or "the distance between notches of points" (p. 1) -- to test this change. He expected a collection of dart points from early occupation levels to show a unimodal distribution for neck widths, and one including both dart and arrow points to exhibit a bimodal distribution. His assumptions were 1) that dart shafts had wider diameters than arrow shafts, 2) that the hafted portion of the point was modified to approximate the diameter of the shaft, and 3) that the introduction of the bow and arrow was relatively recent (i.e. about 2000 years ago, following Baker and 

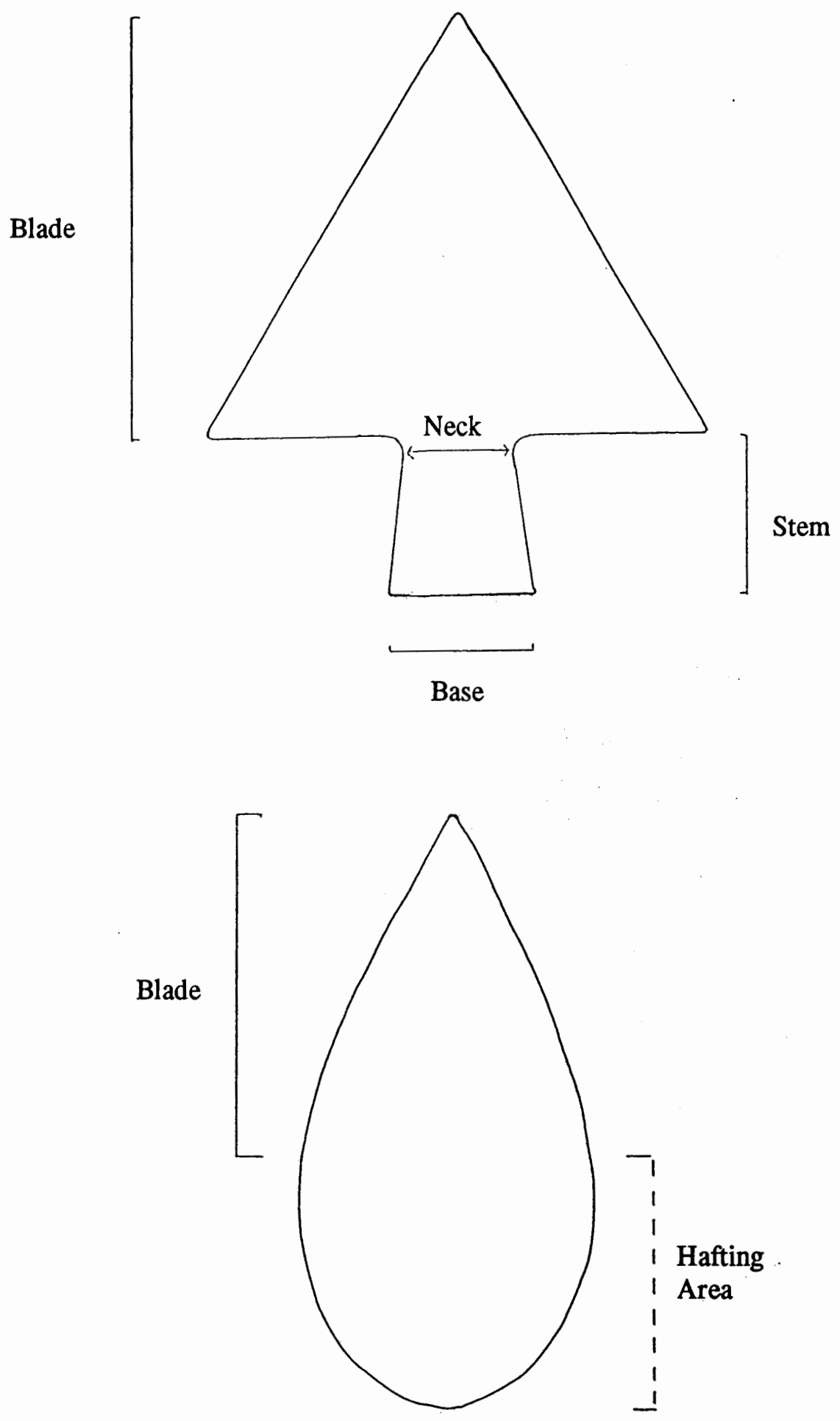

Figure 2. Parts of a projectile point. 
Kidder 1937). In measuring neck widths of 2712 points from 34 stratigraphically excavated sites and collections (some dating 7000 years ago), he found that in early levels neck widths indeed produced a unimodal histogram; in later levels, however, the distribution of neck widths actually produced several modes. Corliss notes that Fenenga, in his 1953 analysis of weights of 884 projectile points, also found similar results in his distributions; Corliss, like Fenenga, arbitrarily assumed the largest value to be darts and the intermediate modes to signify "early arrow points" (Corliss 1972:3).

This work by Corliss is often cited by archaeologists who, in setting up projectile point types, assign a fixed value to neck widths to differentiate between dart and arrow points. Most of them ignore one of the points in his research: that although dart point neck widths show unimodality, there is variation, often wide. For example, Corliss (1972:Figure 4, Figure 5) found that neck widths of dart points from early undisturbed stratigraphic levels of Hogup and Danger Caves ranged from 5 to $18 \mathrm{~mm}$, with a mean width of about $12 \mathrm{~mm}$. His work demonstrates that neck width measurements of points from naturally stratified levels are generally useful in detecting the introduction of the arrow. At no time does Corliss either state or imply that the value of the neck width measurement of one point determines whether it came from a dart or an arrow point.

On the other hand, Thomas (1978) approached the dart versus arrow identification differently. He posed the question: confronted with even one stone point, can a person presume to come to accurate conclusions about its function or the size of shaft to which it was once connected? He turned to actual hafted specimens -- 132 ethnographic and archaeological arrow specimens and 10 archaeological darts -- and measured the points themselves as well as the foreshafts to which the points were attached. Point measurements were length, width, thickness, neck width and weight. He found that dart foreshafts are significantly larger in 
diameter than arrow foreshafts (substantiating an assumption made by Corliss). However, while the size of arrowheads correlates positively (although not strongly) with foreshaft diameter, no single measurement (not even neck width) accounts for more than $40 \%$ of the variation. Surprisingly (or maybe not so surprising given the small sample size from wide geographic areas), none of the dart point measurements correlate significantly with foreshaft diameter or length. However, most importantly, Thomas noted that "dart points are demonstrably larger than arrowheads" (p. 470), and that each measured attribute between arrow and dart points is significant. Using discriminant analysis, Thomas concluded that for discriminating between arrow and dart points, the most important attribute is width, followed by thickness, neck width and, last, length. ${ }^{4}$ Finally, he derives two equations for classifying a point as either a dart or arrow point. Unfortunately, although this technique was successful $86 \%$ of the time overall in reclassifying these points, $30 \%$ of the dart tips were misclassified as arrowheads.

Because neck width plays an important part in the Pettigrew and Toepel typologies, it is interesting to note that Thomas found that for darts, mean neck width was $13.7 \mathrm{~mm}(+-$ 2.53); for arrows it was $10.0 \mathrm{~mm}(+-0.91)$. The range for darts was a conservative 10.3 $16.9 \mathrm{~mm}$, while the range for arrows was an even wider (or wilder) $5.1-20.9$. These compare with Pettigrew's $7.5 \mathrm{~mm}$ and Toepel's 7 and $9 \mathrm{~mm}$ divisions.

Another development affecting attribute selection is the recognition that formal characteristics of a projectile point may very likely change over its history of use (or use-life). Sizes, shapes and edge angles are altered by breakage and subsequent repairing, resharpening and general maintenance, or reshaping into a different tool. Several archaeologists (Hoffman

\footnotetext{
${ }^{4}$ In his study of Great Basin projectile points, Wiggin (1979) examined width, length, weight, neck width and stem thickness as discriminating factors for separating dart and arrow points. He found the best discriminating factors to be neck width and stem thickness.
} 
1985, Frison 1974, and Flenniken 1986, for example) have demonstrated that these actions can result in a projectile point "changing" types; that is, by the time it undergoes classification, a point starting its life as Type A may end up looking like Type C -- both variations in a use-life reduction sequence of a single "type." To nullify this factor, some archaeologists (e.g., Toepel 1985; Thomas 1981) have directed efforts to hone selection of attributes to those that are presumably most stable and least affected by use, yet exhibit time sensitivity. This attention has focused on the hafting dimension of the projectile point as being more resistant to repair and breakage than the blade portion (Hoffman 1985; Thomas 1981). (Pettigrew does not address use-life considerations.)

Out of this background of discussion and research and controversy over what are appropriate temporal attributes for projectile points, Corliss' work influenced both Pettigrew and Toepel to use neck width with its implied dart or arrow differentiation. Unlike Corliss but like Pettigrew, Toepel assigns a fixed neck width value to separate the smaller, presumably, arrow points from the larger, presumably, dart points. Like Pettigrew (1977:38), Toepel cites Corliss as substantiating her divisions: "...larger points with neck widths of greater than $9 \mathrm{~mm}$ were interpreted as dart points while points with neck widths of $8 \mathrm{~mm}$ and less were considered arrow tips (Corliss 1972, Figure 3)" (Toepel 1985:79). On the contrary, Corliss's Figure 3 is a graph of the range of neck width means for arrow and dart points of the sites he examined. A look at his Figures 4, 5, 6 and 7 reveals that actual neck widths of dart points may be as narrow as $5 \mathrm{~mm}$ (Corliss 1972), as noted above. Therefore, although both Pettigrew and Toepel appear to use the same approach as Corliss, their neck width treatment has no real basis in his results.

As discussed in greater detail in the next chapter, Pettigrew's and Toepel's approaches contrast in the rest of their selected attributes. Briefly, Pettigrew focuses on the presence of 
barbs and on stem shape for stemmed points, and other variably-applied descriptive terms to define his stemless types. Toepel constructs her typology with thought as to which part of the point is least susceptible to any breakage that would affect defining the point. She decides that the hafted or stemmed area is most stable, noting also that Flanagan points showed a lot of barb breakage, which would adversely affect typing points in Pettigrew's format. Her types are all defined metrically (i.e., quantitatively), whereas Pettigrew relies, except for neck width, on qualitative definitions.

It should also be noted that points without any notches around their perimeters (i.e., stemless points) generally tend to be left out of the discussion of attributes. Without easily discernible landmarks to delineate the blade portion from the hafted portion, these points suffer from typological neglect. Both Pettigrew and Toepel include stemless types in their typologies, with Toepel attempting to metrically capture dimensions of their shape and size.

In this chapter, I described the framework of archaeological classification and seriation that provides for relative dating of sites based on comparing artifact type sequences. When chronology is the purpose of the typology, then attributes defining types should be temporally sensitive. In the next chapter I ouline the specifc definitions of the Portland Basin and Flanagan site attributes and how I described the Ibach and Heynderickx collections. 


\section{CHAPTER III}

\section{DESCRIPTIVE METHODS}

In the previous section, I specified how selecting one or more attributes (characteristics) is the initial step toward defining an artifact type. Next is determining precisely how to measure or characterize each attribute. Making explicit how the attribute is measured or evaluated also encourages replication of results. Type definitions must effectively define a type to keep it discrete from the others. An artifact cannot belong to more than one type set.

In the following sections, I outline the attribute choices made by Pettigrew for the Portland Basin typology and by Toepel for the Flanagan site typology; specify how they measured or described these variables; and summarize briefly the types thus derived. (The reader will find more detail in Chapter IV.) Following that, I list descriptive procedures I followed and recorded on worksheets (see Appendix A) describing the projectile points in the two Tualatin Valley collections. I describe each point twice -- once in terms of the Portland Basin typology and again in terms of the Flanagan typology -- in order to effect valid seriation comparisons .

\section{THE PORTLAND BASIN TYPOLOGY}

\section{Projectile Point Attributes}

The Portland Basin typology consists of 16 projectile point types (named Type 1 through 16) and 4 variants of Type 6, for a total of 19 described types. Three variables are 
explicitly mentioned by Pettigrew (1977:38-40) as important attributes for defining projectile types. These explicit variables are 1) neck width, 2) shape of the blade-stem juncture, and 3) stem shape (Figure 3).

Neck width, as defined in Corliss (1972:11), is the only quantitative attribute Pettigrew uses. The other two attributes are nominal. The blade-stem juncture in a stemmed point is either barbed or shouldered: the point is barbed if any part of the blade crosses a line running horizontally through the projectile point neck and perpendicular to the longitudinal axis; it is shouldered if does not cross that horizontal line.

Stem shape is either diverging or it is non-diverging. Pettigrew defines a diverging stem as "narrowest at the neck" (1977:39). According to this definition, therefore, a stem with margins that either converge toward the base or are parallel is considered a nondiverging stem, while a stem with sides any wider than the neck is a diverging stem (p.39).

Although these three are the only attributes Pettigrew specifcally identifies, they define only 8 of the 19 types. Furthermore, they pertain to only non-side-notched stemmed points ${ }^{5}$. Discrimination among the remaining types in Pettigrew's typology is based on combinations of other characteristics not explicitly discussed but, which can be instead, inferred from type descriptions. These attributes are: side-notching; general outline form of the entire point (ovate, triangular, diamond-shaped or bipointed); absence of a stem; basal shape; and blade shape.

\footnotetext{
${ }^{5}$ Although Pettigrew follows Corliss in noting that side-notched points have measureable necks, Pettigrew (1977), unlike Corliss, keeps side-notched points separate from the series of narrow and broad-necked stemmed points. In a subsequent excavation at Hager's Grove in the Willamette Valley, he (1980) subdivides Type 12, a side-notched point, into narrow and broad-necked subtypes.
} 


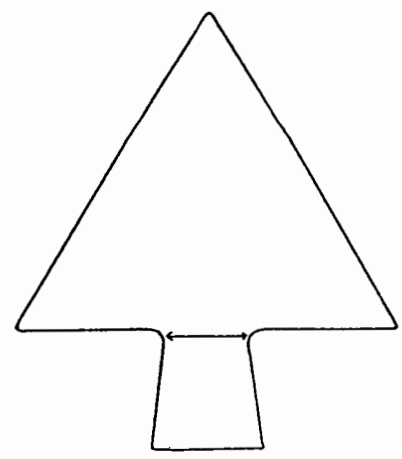

Neck Width

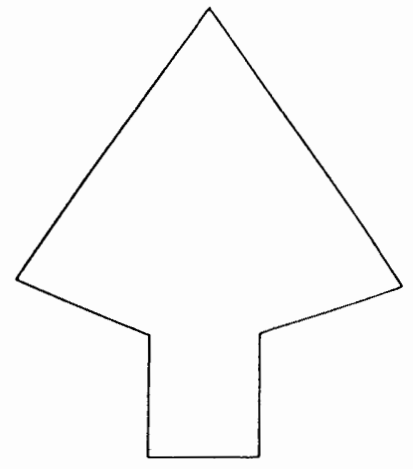

Shouldered

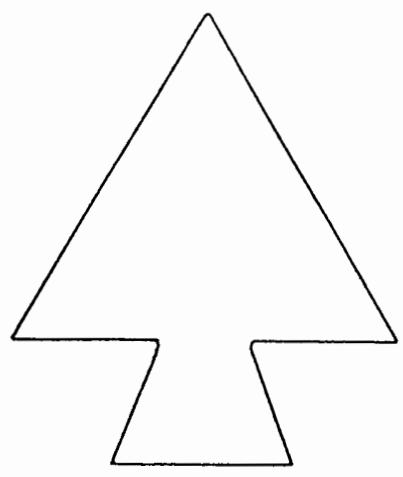

Diverging Stem

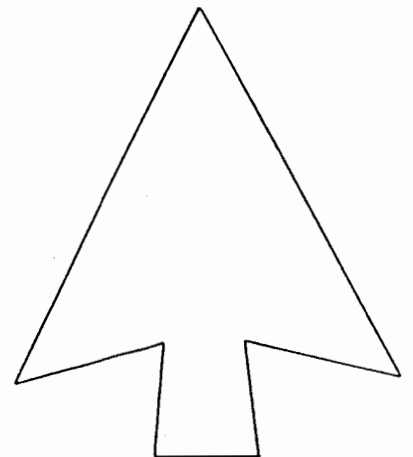

Barbed
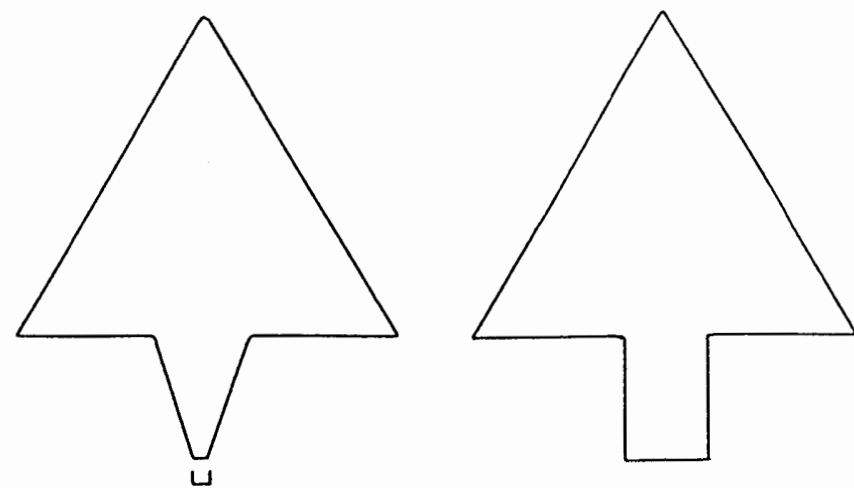

Non-diverging Stem

Figure 3. Pettigrew's projectile point attributes. 


\section{Projectile Point Types}

The resultant types fall into three groups. These groups are stemmed points, sidenotched points, and stemless (or unstemmed) points (and are described in greater detail in Chapter IV). Pettigrew divides the group of stemmed points into narrow-necked and broadnecked categories. The former have necks less than $7.5 \mathrm{~mm}$ wide and the latter with necks $7.5 \mathrm{~mm}$ or wider. ${ }^{6}$ This division represents the distance halfway between the two modes of neck widths (i.e. $5 \mathrm{~mm}$ and $10 \mathrm{~mm}$ ) he found at the Merrybell site, the earliest of the excavated sites in this study (p. 38). Types 1-5 are broad-necked; types 7-10 are narrow-necked.

The second group are the side-notched points. Type 11 is ovate in plan view; Type 12 has a triangular blade; and Type 15 is "side-notched and stemmed" (p. 4). No neck width is specified.

The last set of types are unstemmed points. Type 6, as mentioned before, has 4 subtypes which are distinguished by overall plan view -- ovate, diamond-shaped, bipointed, teardrop -- and other non-uniformly applied descriptives, such as retention of striking platform, size (small, medium to large), and base shape. Types 13,14 and 16 are triangular in shape with basal differences: Type 13 has an incurvate base, Type 14 does not, and Type 16 has an unmodified base.

In summary, the Pettigrew's Portland Basin types sort out into stemmed, side-notched and unstemmed categories, although he did not organize his typology thusly. Apart from the measured neck width attribute, the other attributes are qualitative. Importance is given implicitly to overall shape, blade shape, and basal shape as well as explicitly to neck width,

\footnotetext{
${ }^{6}$ Pettigrew's initial neck width division called for narrow-necked points to have neck widths $7 \mathrm{~mm}$ and below, while broad-necked points were defined as those with neck widths $8 \mathrm{~mm}$ and above. This measurement was later refined (Pettigrew 1980:86) and is used here.
} 
presence or absence of barbs, and whether a stem is diverging or non-diverging. In other words, Pettigrew's typology has no clear formal basis.

\section{THE FLANAGAN SITE TYPOLOGY}

\section{Projectile Point Attributes}

For the Flanagan site projectile point typology, Toepel (1985:81-82) chose quantitative attributes that reflected the reduction over time not only in neck width but also in general projectile point size. She drew on work by Corliss (1972) and Thomas (1981) to select four attributes ${ }^{7}$, all of them quantitative: neck width, basal width, maximum specimen width, and thickness (Figure 4). Following Thomas, she concentrates on basal attributes. She accepts Thomas' assertion (1981:14-15) that basal attributes are more stable and resistant to use-life alterations than attributes such as weight, maximum length, or other blade attributes. Toepel includes in this list of unstable variables the presence or absence of barbs, one of Pettigrew's attributes.

In addition to size, the other dimension Toepel strives to define is hafting configuration. Her reasoning here is that the shape of the hafted portion of a point is configured to fit a particular type of hafting technique and may be temporally sensitive. Using the four attributes mentioned above, Toepel derives three measurements to describe the hafting dimension. They are explained in Table I.

\footnotetext{
${ }^{7}$ Included here are only those measurements that Toepel subsequently used in constructing her typology. Other attribute measurements she initially adopted from Thomas did not provide usedful discriminating results for Willamette Valley types.
} 
TABLE I

PROJECTILE POINT ATTRIBUTE DEFINITIONS IN TOEPEL TYPOLOGY

Significant attributes:

1. neck width

2. basal width

3. maximum specimen width

4. maximum thickness

$\mathbf{W}_{\mathbf{n}}$
$\mathbf{W}_{\mathbf{b}}$
$\mathbf{W}_{\mathbf{m}}$
$\mathbf{T}$

Derived measurements:

$\begin{array}{ll}\mathbf{W}_{b}-\mathbf{W}_{n}: & \begin{array}{l}\text { determines expanding versus contracting stem for stemmed } \\ \text { points; when } W_{b}-W_{n}=W_{b}, \text { point is stemless } \\ \text { defines notching category for stemmed points; defines point } \\ \mathbf{W}_{b} / \mathbf{W}_{m}\end{array} \\ \mathbf{T} / \mathbf{W}_{\mathbf{m}} & \begin{array}{l}\text { shape for stemless points } \\ \text { defines degree of rotundity for stemless points }\end{array}\end{array}$

\section{Projectile Point Types}

Using metrically based type definitions, Toepel devised a keyed projectile point typology. Figure 5 is an adapted version of her original key. ${ }^{8}$ She classifies points as either stemless or stemmed. There are 5 series of points: Small Stemless, Heavy Stemless, Narrow-necked Stemmed, Moderate Broad-necked Stemmed, and Heavy Broad-necked Stemmed. A thickness of $5 \mathrm{~mm}$ divides the Small Stemless from the Heavy Stemless. The basal width/ maximum width measurement $\left(\mathrm{W}_{\mathrm{b}} / \mathrm{W}_{\mathrm{m}}\right)$ divides these into types based on overall shape.

Stemmed points are defined primarily by neck width, with $7 \mathrm{~mm}$ dividing narrownecked from moderate broad-necked and $9 \mathrm{~mm}$ dividing moderate broad-necked from heavy broad-necked points. Within each of these major series are three types defined by the basal width/ maximum width ratio $\left(\mathrm{W}_{\mathrm{b}} / \mathrm{W}_{\mathrm{m}}\right)$, stem shape $\left(\mathrm{W}_{\mathrm{b}}-\mathrm{W}_{\mathrm{n}}\right)$, or thickness $(\mathrm{T})$.

\footnotetext{
${ }^{8} \mathrm{I}$ have left out the $\mathrm{T} / \mathrm{W}_{\mathrm{m}}$ figures for the stemless points as they are not used to actively key any of the points.
} 

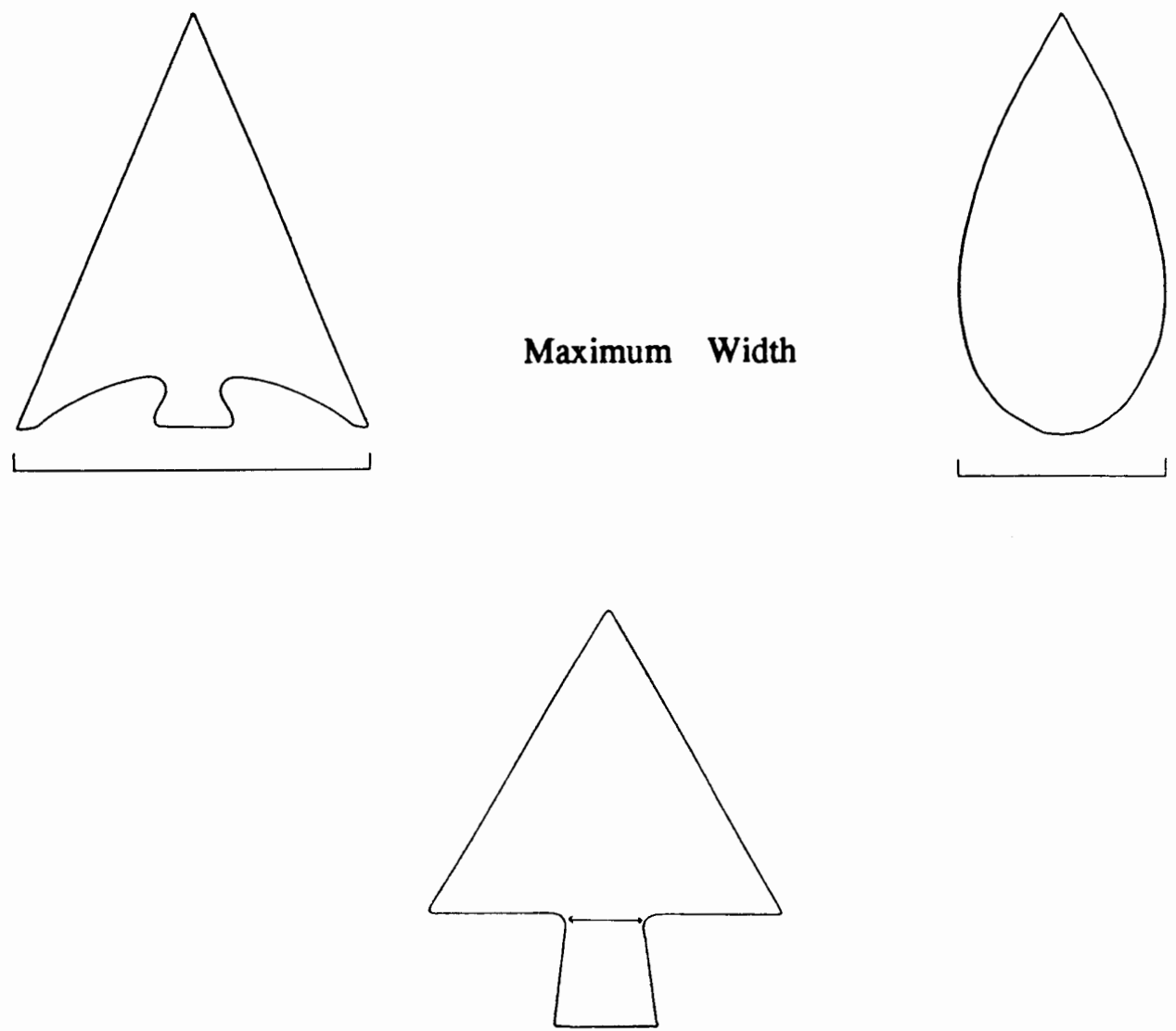

Neck Width
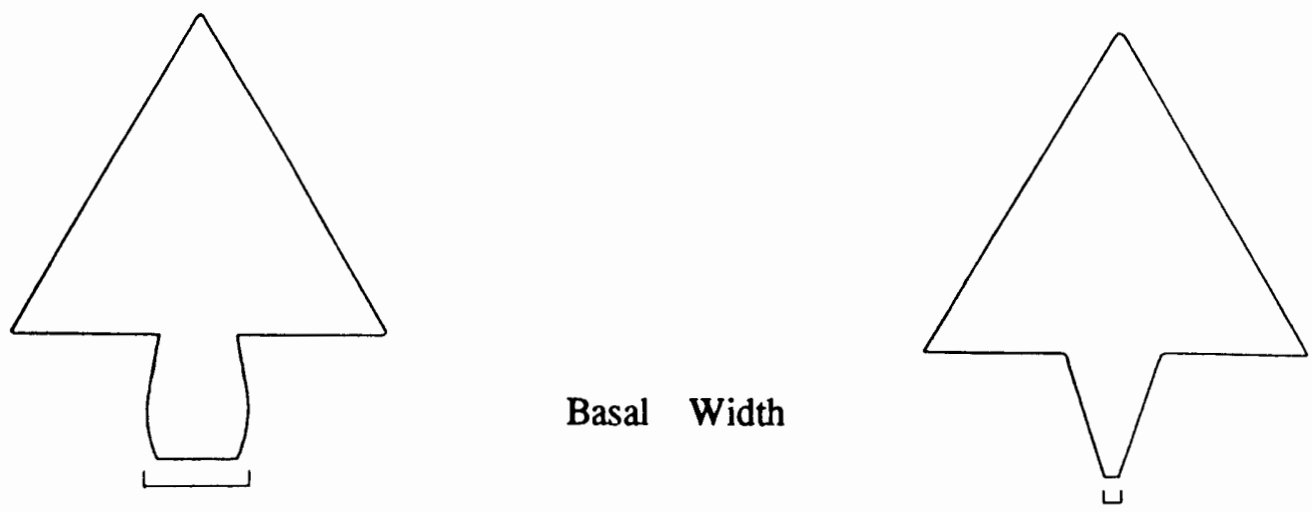

Figure 4. Toepel's projectile point attributes. 


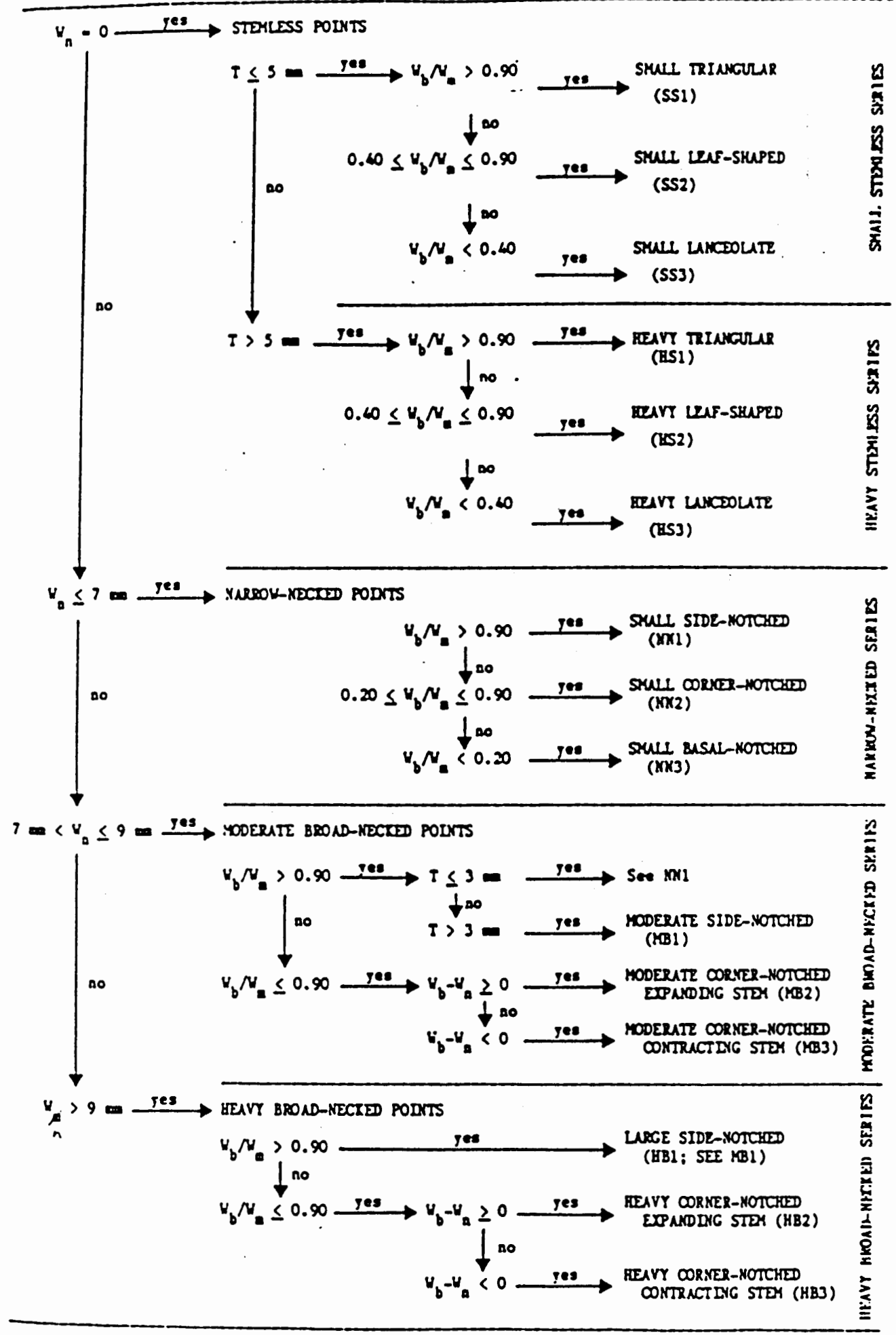

Figure 5. Flanagan site projectile point key. 
The specific projectile point types at the Flanagan site total 15 . These are described in detail in the following chapter.

\section{SYNTHESIS: DESCRIBING THE HEYNDERICKX AND IBACH PROJECTILE POINTS}

In setting up a worksheet to describe the projectile points from the Heynderickx and Ibach farms, I devised descriptions that would incorporate all the attributes used by both Pettigrew and Toepel in defining their types. For the Toepel types these attributes were only four metric measurements: neck width, maximum width, basal width, and thickness. The derived measurements (see Table I) were calculated from these.

Some of the attributes for Pettigrew's types could be derived from the Flanagan metric attributes. Neck width was measured the same way, and stem shape (diverging versus non-diverging) could be derived from basal width minus neck width, although I described it visually as Pettigrew did. I described the blade-stem juncture for stemmed points as shouldered or notched; and if notched whether it was side, corner or basally notched. This separated Pettigrew's shouldered stemmed points from barbed points (which could be corner or basal notched) and also marked the side-notched points. Point outline for stemless points was a visual determination.

It should be noted that the effect of Toepel's typology is to essentially lump shouldered points with corner-notched points. The change in terminology may be disconcerting to the reader.

I added several other attributes commonly used to provide general descriptive and comparative information. These attributes include raw material, presence of serration, blade cross-section, evidence of edge grinding, total length and weight. Appendix A contains 
detailed definitions of all described attributes, and Appendix B lists descriptions for each projectile point. 


\section{CHAPTER IV}

\section{RESULTS}

This chapter presents the results of classifying the Heynderickx and Ibach projectile points using the descriptive techniques specified in Chapter III. Both projectile point collections are typed in two ways: first, using Pettigrew's Portland Basin typology; and, second, using Toepel's Flanagan site typology. This chapter begins with summary descriptions of the projectile points and projectile point fragments in the Heynderickx and Ibach collections. Following that, I describe how these projectile points sort into types using the typology established by Pettigrew. Table V displays the resultant spectrum of point types using Pettigrew's typology. Lastly, using Toepel's type definitions, I re-sort the Heynderickx and Ibach points into Toepel's projectile point typlogy. Table XIV provides this information. Appendix B contains descriptive and metric data for each projectile point, as well as the specific Toepel type and Pettigrew type for each point.

\section{SUMMARY DESCRIPTION OF THE STUDY COLLECTIONS}

There are 119 artifacts classified as projectile points in the Heynderickx collection and 107 in the Ibach collection. Although these totals are comparable, noticeable differences characterize both the broad point categories and the raw material used (Tables II and III). For instance, whereas the Heynderickx points are predominately stemmed $(\mathbf{7 7 \%})$, the Ibach points separate out more evenly into stemmed, stemless and point fragment categories, with the majority $(40 \%)$ in the stemless group. The use of raw material differs also. While $78 \%$ 
of the Heynderickx points are cryptocrystalline silicates (ccs) and only $2 \%$ are basalt, $60 \%$ of the Ibach collection are ccs and 14\% are basalt. Obsidian proportions in each collection are similar.

TABLE II

HEYNDERICKX PROJECTILE POINTS

\begin{tabular}{|c|c|c|c|c|c|c|c|c|}
\hline \multirow[b]{2}{*}{ Category } & \multicolumn{2}{|c|}{$\mathrm{CCS}$} & \multicolumn{2}{|c|}{ Obsidian } & \multicolumn{2}{|c|}{ Basalt } & \multicolumn{2}{|c|}{ TOTAL } \\
\hline & & $(\%)$ & & (\%) & \# & $(\%)$ & $\#$ & (\%) \\
\hline Stemmed & 70 & & 20 & & 2 & & 92 & (77) \\
\hline Stemless & 18 & & 4 & & -- & & 22 & (18) \\
\hline Fragment & 5 & & -- & & -- & & 5 & ( 5$)$ \\
\hline TOTAL & 93 & (78) & 24 & (20) & 2 & (2) & 119 & $(100)$ \\
\hline
\end{tabular}

TABLE III

IBACH PROJECTILE POINTS

\begin{tabular}{|c|c|c|c|c|c|}
\hline \multirow[b]{2}{*}{ Category } & $\mathrm{CCS}$ & Obsidian & Basalt & \multicolumn{2}{|c|}{ TOTAL } \\
\hline & $\# \quad(\%)$ & (\%) & $\# \quad(\%)$ & $\#$ & $(\%)$ \\
\hline Stemmed & 21 & 14 & 1 & 36 & (34) \\
\hline Stemless & 22 & 9 & 12 & 43 & (40) \\
\hline Fragment & 21 & 5 & 2 & 28 & (26) \\
\hline TOTAL & $64 \quad(60)$ & $28 \quad(26)$ & $15 \quad(14)$ & 107 & (100) \\
\hline
\end{tabular}

In several cases where projectile points are too fragmentary to assign to a definite type but are identifiable as belonging to a general group (such as broad-necked points), I have categorized them that way. Projectile points even too fragmentary to assign to a general group are classified together as fragments. Although specific metric data is found in Appendix B, general comments regarding the fragments in both collections follow.

Projectile point fragments account for $4 \%$ of the Heynderickx group. All 5 specimens are ccs blade fragments (Figure 6). Three are triangular blades: one with slight serration and 
one with the deep serrations that give it a Christmas tree or fern effect. Although the other two fragments are more substantial, they are missing enough hafted area to prevent my classifying them as either stemmed or stemless. However, Specimen 85-18.66.2, I suspect, may be a slightly shouldered stemmed point. Specimen $85-18.67 .36$ looks like a smaller version of 85-18.68.7, a stemless point.

In the Ibach collection, twenty-eight fragments (Figure 7) constitute $26 \%$ of the Ibach points. Twenty of these point fragments are blades, and $25 \%$ of these are serrated. Seven projectile point fragments are mid-sections: that is, they are missing substantial sections of both ends. Although size of complete points cannot be decisively inferred merely from their mid-sections, again the size of these fragments suggest large points. The single haft fragment has a convex base and part of a heavily damaged blade.

Two main differences between the Heynderickx and Ibach fragments stand out. One is fragment size; the other is the percentage fragments constitute in each collection. Table IV illustrates size differences in the fragments. The Ibach fragments are longer, thicker and heavier than the Heynderickx ones; sample size may be a factor.

\section{TABLE IV}

\section{COMPARATIVE DATA ON POINT FRAGMENTS}

\begin{tabular}{llc} 
& Heynderickx & Ibach \\
\hline Number of fragments & 5 & 28 \\
Range of Lengths (mm) & $18.2-38.9$ & $6.9-68.2$ \\
Mean Length (mm) & 27.5 & 35.7 \\
Range of Thicknesses (mm) & $2.2-6.4$ & $4.1-12.2$ \\
Mean Thickness (mm) & 4.3 & 7.1 \\
Range of Weights (gm) & $0.3-4.9$ & $1.2-22.7$ \\
Mean Weight (gm) & 2.1 & 5.9
\end{tabular}


(9E'L9 'SI'69

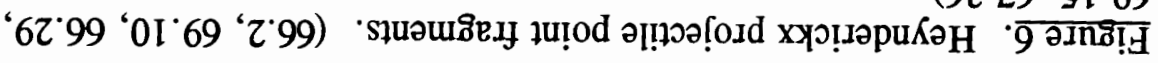

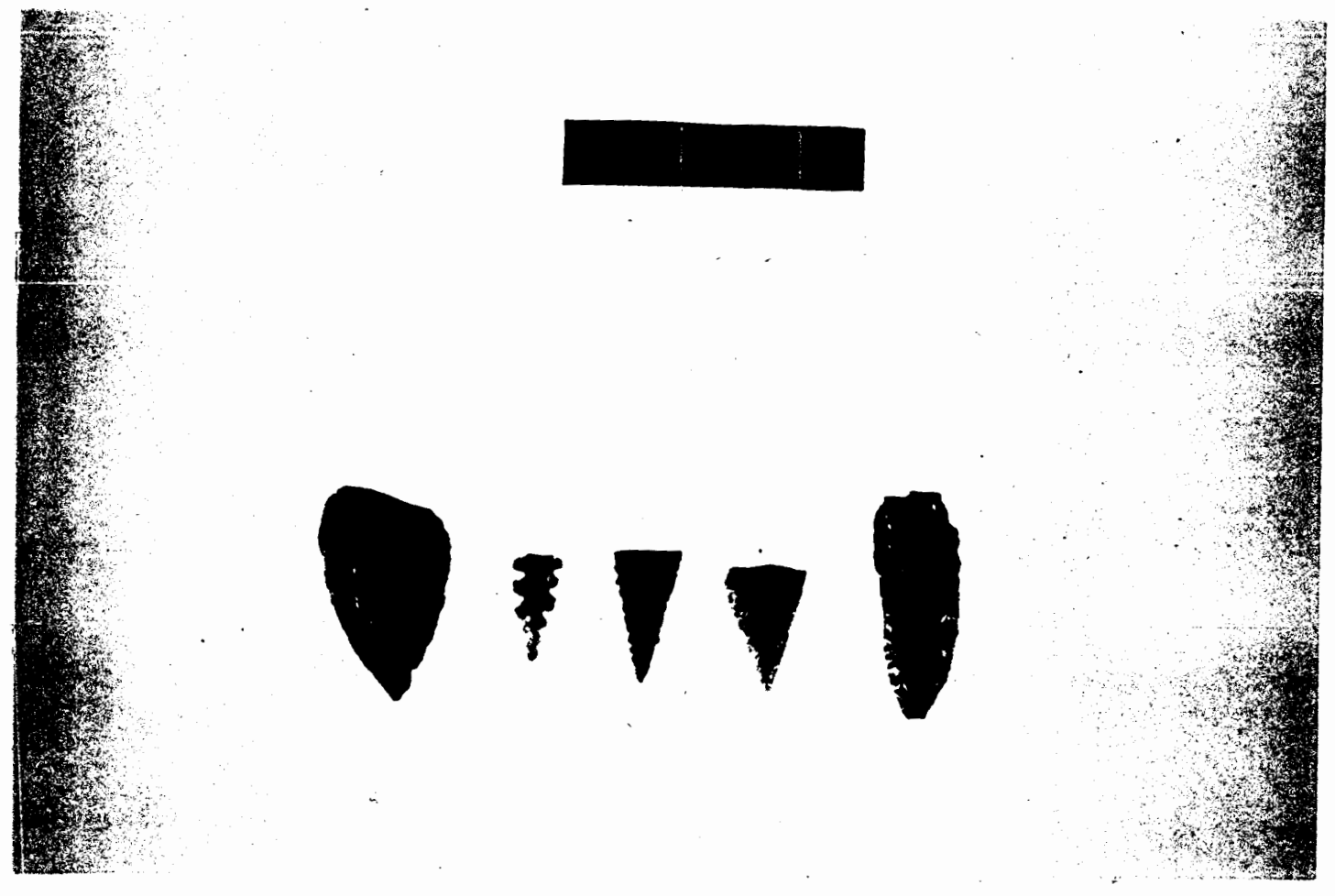




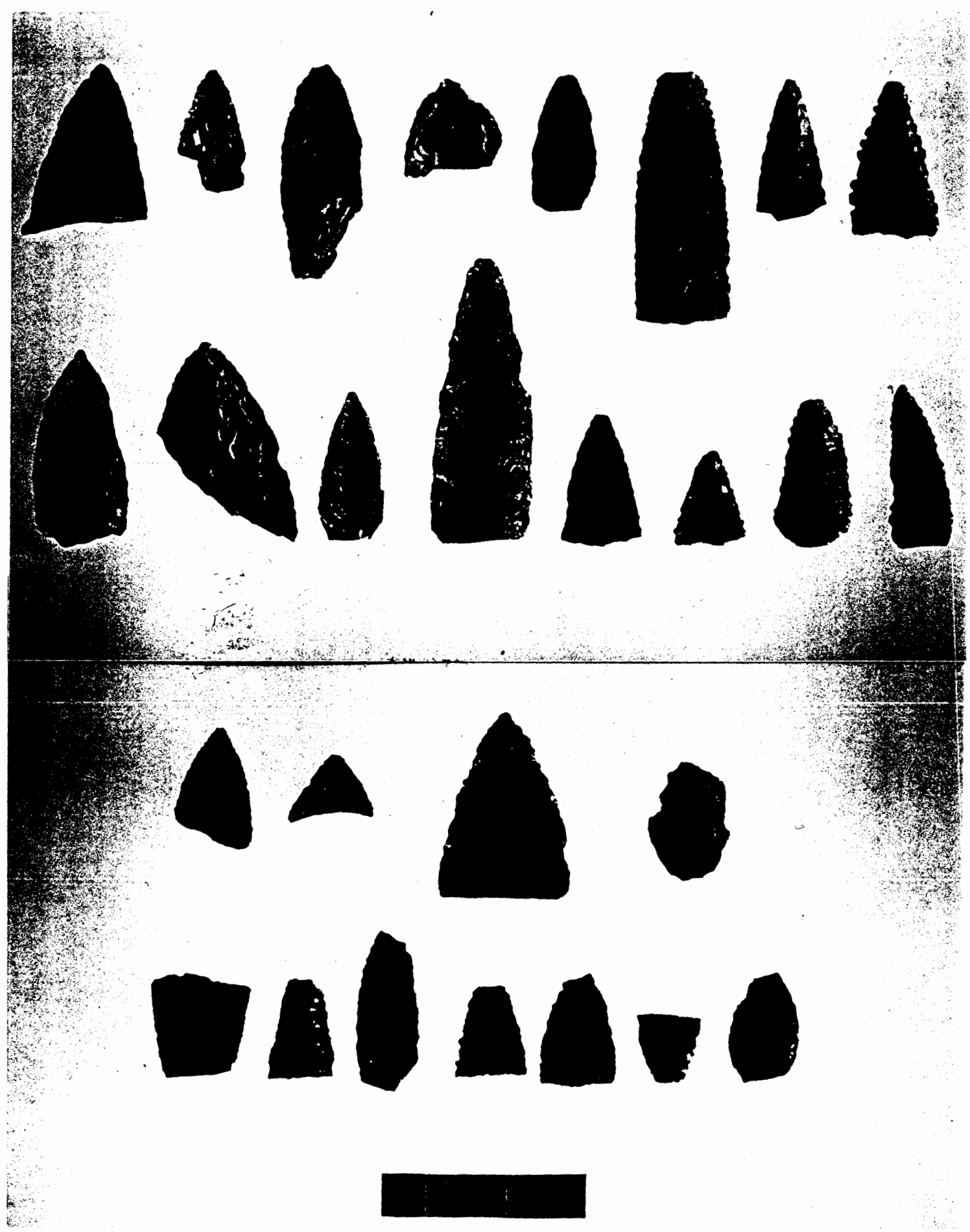

Figure 7. Ibach projectile point fragments. (Row 1: 1.6, 1.9, 1.21, 1.39, $1.40,1.49,1.57,1.61$. Row 2: $1.77,1.80,1.123,1.106,1.93,1.89$, 1.132, 1.115. Row 3: $1.63,1.134,1.110,1.87$. Row 4: $1.27,1.64,1.38$, $1.98,1.72,1.96,1.78)$ 
The difference in projectile point fragments as a percentage of each collection is dramatic and not easily explained. From accounts of the collecting process -- i.e., each farmer collecting artifacts found during the course of working his land -- there is no selection difference. Both farmers picked up large and small, complete and broken points as well as non-artifactual material, yet the Ibach point fragments constitute $26 \%$ of the total, while Heynderickx fragments make up a mere $4 \%$. One possible explanation is that sites functions differed; activities at the Ibach place may have produced more fragments.

\section{TUALATIN VALLEY POINTS IN PETTIGREW'S TYPOLOGY}

This section presents the results of typing the 114 Heynderickx points and 79 Ibach points using Pettigrew's projectile point typology. Pettigrew (1977) initially set up his typology to describe points just in the Portland Basin. In 1980 he modified the typology slightly 1) to refine the metric demarcation between narrow and broad-necked projectile points and 2) to accommodate the somewhat different constellation of points found in the Willamette Valley at Hager's Grove in Salem. In the following classification of Heynderickx and Ibach points, I use Pettigrew's 1980 neck width definitions (see Chapter III, Footnote 6) but follow the original projectile point type definitions while noting subsequent changes made at Hager's Grove. Discussion of attributes and definitions of other terms used here may be found in Chapter III and Appendix A.

For ease of presentation, I have grouped Pettigrew's point types in a manner similar to the way Toepel groups hers. That is, a point is either stemmed or stemless. Within the stemmed group are the broad-necked, narrow-necked and side-notched points. For each type within a group, I provide Pettigrew's definition. The complete definition of a specific point type, then, includes the hierarchical definitions included in the overall grouping (stemmed or 
stemless), the next level down (e.g., broad-necked), and then the specific type attributes. All these definitions are Pettigrew's definitions. Listed after each type is information about that point type as illustrated by the Heynderickx and Ibach samples. Table V presents the results of typing the Heynderickx and Ibach points in Pettigrew's typology.

\section{Stemmed Points}

Points with a measurable neck width and, therefore, a stem. The major groups in Pettigrew's typology (1977) are broad-necked, narrow-necked and side-notched projectile points.

Broad-necked points. These are stemmed points with a neck width greater than or equal to $7.5 \mathrm{~mm}$. There are five types based mostly on stem shape and barb/shoulder configuration (Tables VI, VII and Appendix B).

Type 1: "broad-necked, barbed, with a diverging stem" (p. 40). (Figures 8 and 9) Heynderickx: $\mathrm{n}=14$. Type 1 is the second-most frequent broad-necked projectile point type in the Heynderickx collection and makes up $33 \%$ of all broad-necked points. All specimens are made of ccs. Four are complete points; two are serrated. All 13 describable blade-stem junctures are cornernotched. Specimen 85-18.68.4 stands out as remarkably larger than the others of this type. At $44.7 \mathrm{gm}$ and with a $17.1 \mathrm{~mm}$ neck width, it is four times heavier than the next largest point (Specimen 85-18.68.1), which has a neck width of $14.6 \mathrm{~mm}$.

Ibach: $\mathrm{n}=5$. Type 1 accounts for $19 \%$ of Ibach broad-necked types and is also the second most common type in this collection. Four points are ccs; one is obsidian. None are complete. None are serrated. All are corner-notched. 


\section{TABLE V}

PROJECTILE POINTS: PETTIGREW TYPOLOGY

\begin{tabular}{ccccc} 
& \multicolumn{2}{c}{ IBACH } & \multicolumn{2}{c}{ HEYNDERICKX } \\
TYPE & No. & Percent & \multicolumn{2}{c}{ No. Percent } \\
\hline Broad-necked: & 5 & 6 & 14 & 12 \\
Type 1 & 2 & 3 & 3 & 3 \\
Type 2 & - & - & - & - \\
Type 3 & 3 & 4 & 3 & 3 \\
Type 4 & 11 & 14 & 19 & 17 \\
Type 5 & 6 & -3 & 4 & 3 \\
Unidentified & -- & -5 & 38
\end{tabular}

Narrow-necked:

Type 7

Type 8

Type 9

Type 10

Unidentified

$\begin{array}{cccc}- & - & 11 & 10 \\ - & - & 1 & 1 \\ - & - & 14 & 12 \\ 1 & 1 & 12 & 10 \\ 4 & 5 & 9 & 8 \\ -- & -- & -- & -- \\ 5 & 6 & 47 & 41\end{array}$

Side-notched:

Type 11

Type 12

Type 15

\begin{tabular}{cccc}
- & - & - & - \\
4 & 5 & 2 & 2 \\
- & - & - & - \\
-- & -- & -- & - \\
\hline 4 & 5 & 2 & 2
\end{tabular}

Stemless:

Type 6a

Type 6b

Type 6c

Type 6d

Type 6 unclass.

Type 13

Type 14

Type 16

TOTAL

$\begin{array}{lccl}6 & 8 & 3 & 3 \\ 8 & 10 & 6 & 5 \\ - & - & - & - \\ - & - & 1 & 1 \\ 29 & 37 & 10 & 9 \\ - & - & - & - \\ - & - & 2 & 2 \\ - & - & - & - \\ -- & -- & -- & -- \\ 43 & 55 & 22 & 20 \\ == & === & === & =101^{*}\end{array}$

*Percentage does not equal 100 due to rounding. 


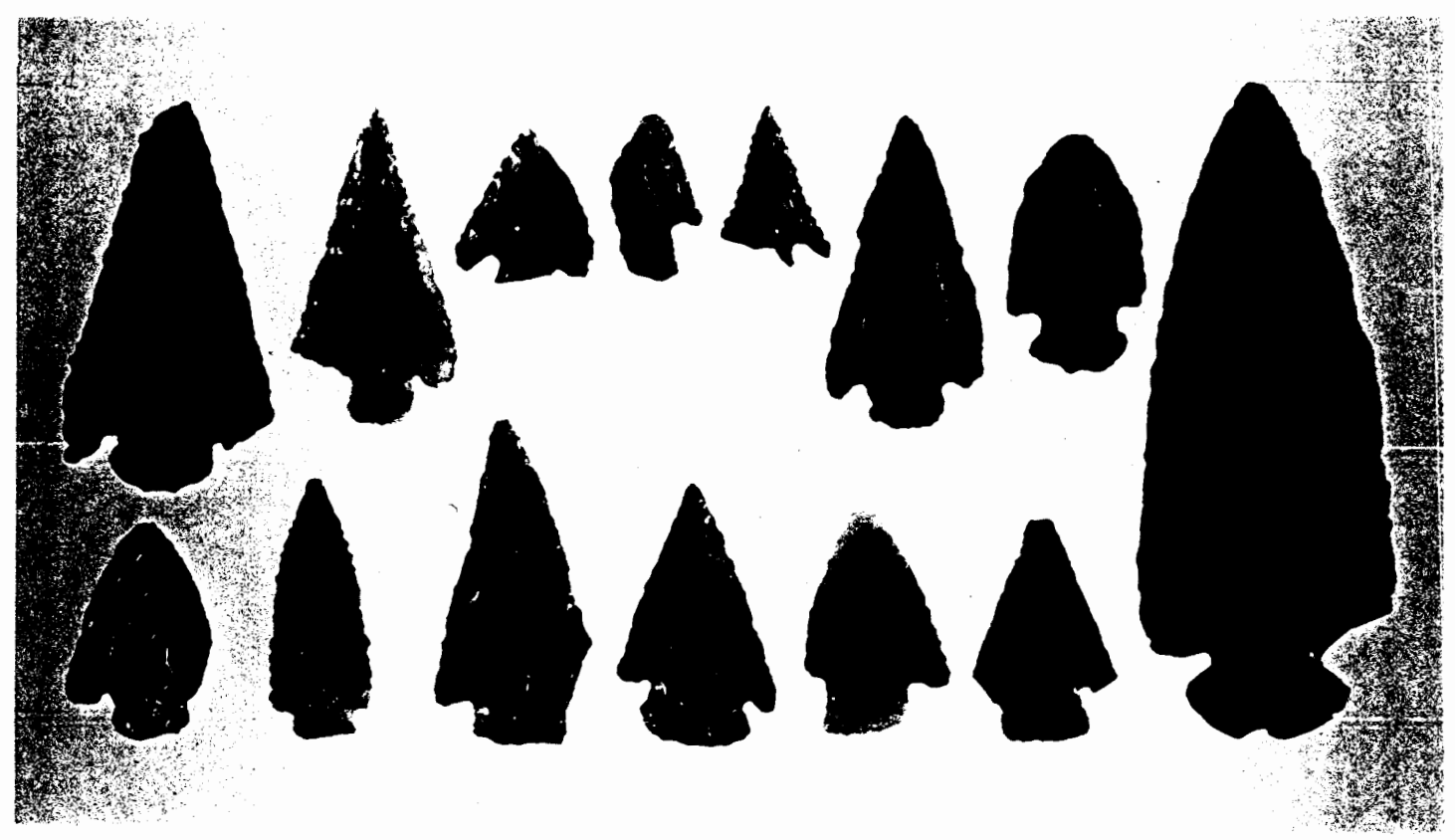

Figure 8. Heynderickx projectile points typed as Pettigrew Type 1. (Row 1: $68.1,67.23,69.22,66.21,69.24,66.15,66.18$. Row 2: 67.14, 67.6, $67.30,67.15,67.9,67.13,68.4)$ 

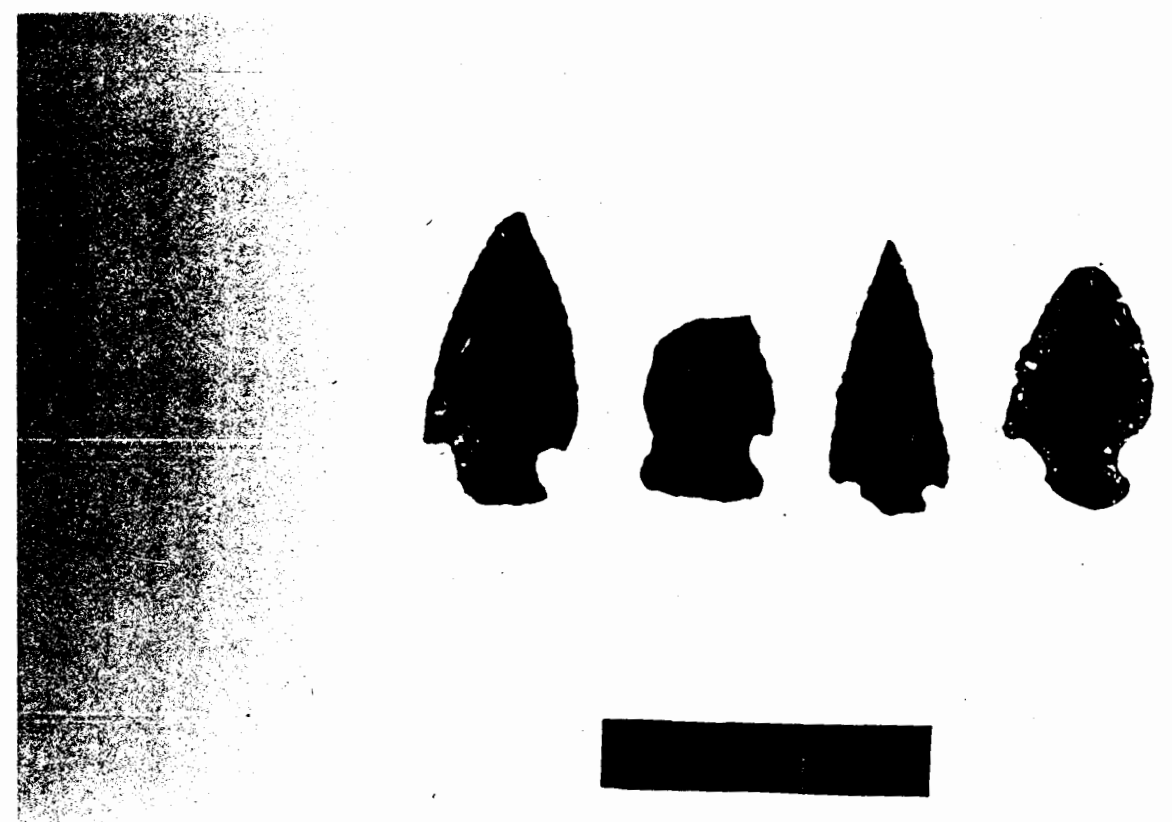

Figure 9. Ibach projectile points typed as Pettigrew Type 1. (1.2, 1.29, $1.47,1.117 .1 .58$ not photographed.) 
Type 2: "broad-necked, shouldered, with a diverging stem" (p. 40). (Figure 10) Heynderickx: $\mathrm{n}=3$. The basalt and ccs points are complete; the obsidian one is not. The basalt point, unlike the other two triangular bladed points, has an ovate blade and is almost side-notched in appearance; I debated classifying this a Type 11 (ovate and side-notched), but after consulting representative photographs of Pettigrew's types, decided it fit Type 2 better. Ibach: $\mathbf{n}=2$. Both points are ccs. One is complete; neither point is serrated. Here too, one point might be called a shallow side-notched point. In the absence of rigorous metric type definitions, I placed it in this category and not Type 12 (side-notched with a triangular blade).

Type 3: "broad-necked, with an incurvate stem base" (p. 40). Heynderickx: $\mathrm{n}=0$.

Ibach: $\mathrm{n}=0$.

(Although Pettigrew also found no Type 3 at Hager's Grove, he notes in that report (1980) that Type 3 includes only corner-notched points.)

Type 4: "broad-necked, barbed with a non-diverging stem" (p. 41). (Figure 11) Heynderickx: $\mathrm{n}=3$. All three are ccs. None are serrated, and none are complete. All are corner-notched.

Ibach: $\mathrm{n}=3$. These also are all ccs. None are serrated, and all show some damage. All three are corner-notched.

Type 5: "broad-necked, shouldered with a non-diverging stem" (p. 41). (Figures 12 and 13)

Heynderickx: $\mathrm{n}=19$. The predominant broad-necked type is Type 5. It represents $44 \%$ of all the Heynderickx broad-necked points. None are 

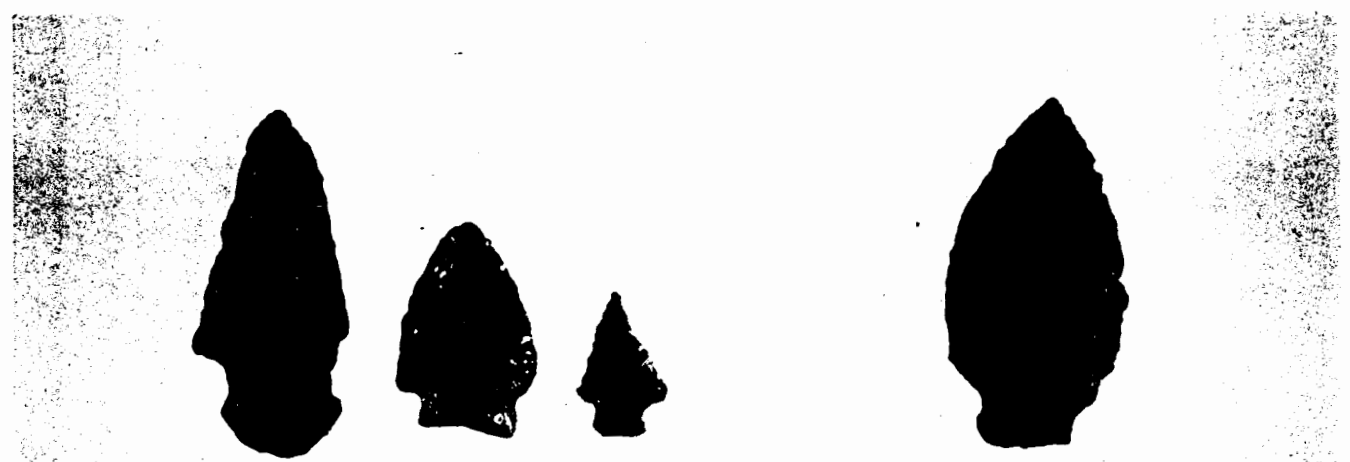

Figure 10. Heynderickx and Ibach projectile points typed as Pettigrew Type 2. Heynderickx (Left: $66.35,67.32,69.29$ ). Ibach (Right: 1.30. 1.62 not photographed.)
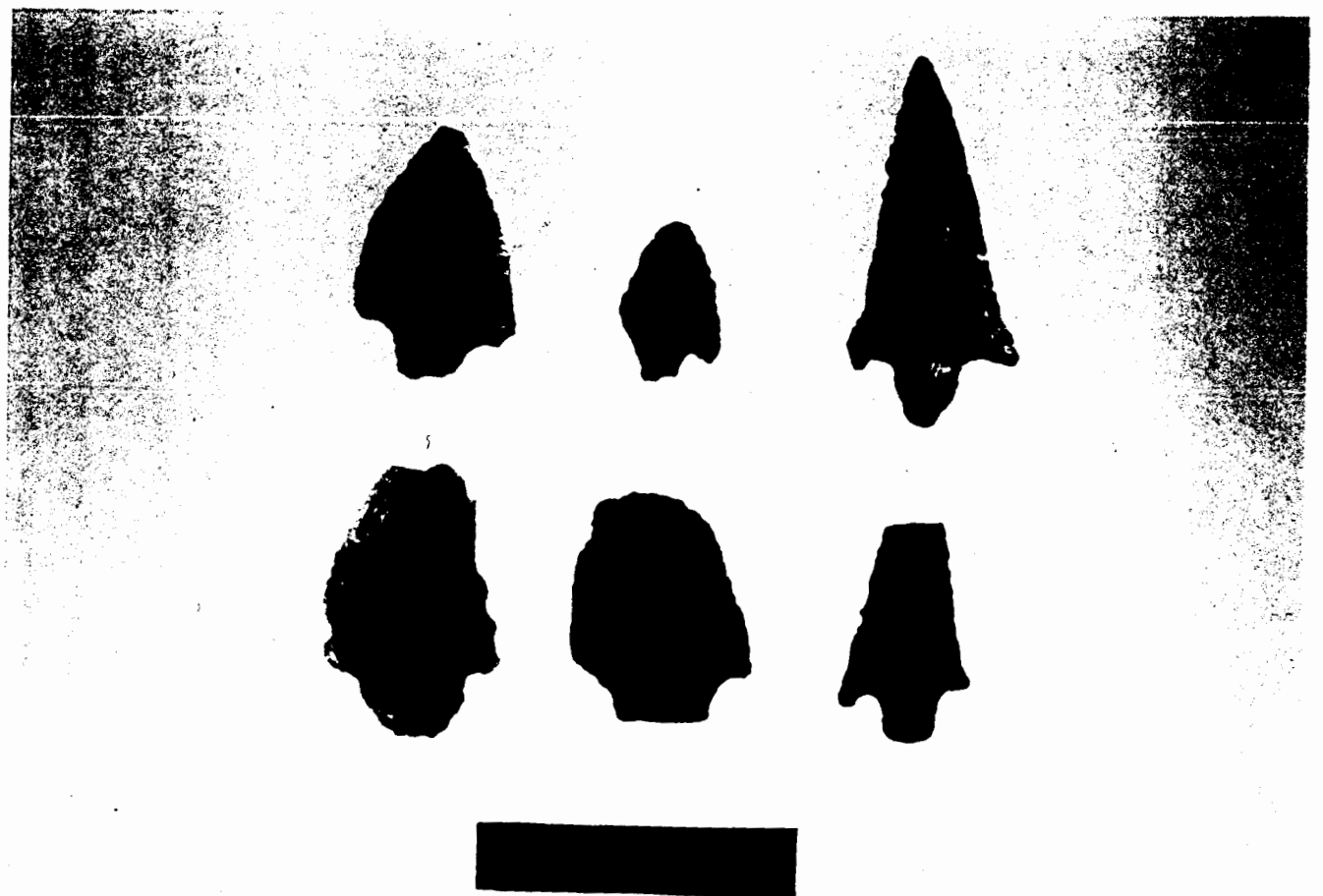

Figure 11. Heynderickx and Ibach projectile points typed as Pettigrew Type 4. Heynderickx $n=3$ (Row 1: 67.2, 66.10, 68.2). Ibach $n=3$ (Row 2: $1.65,1.113,1.66)$. 


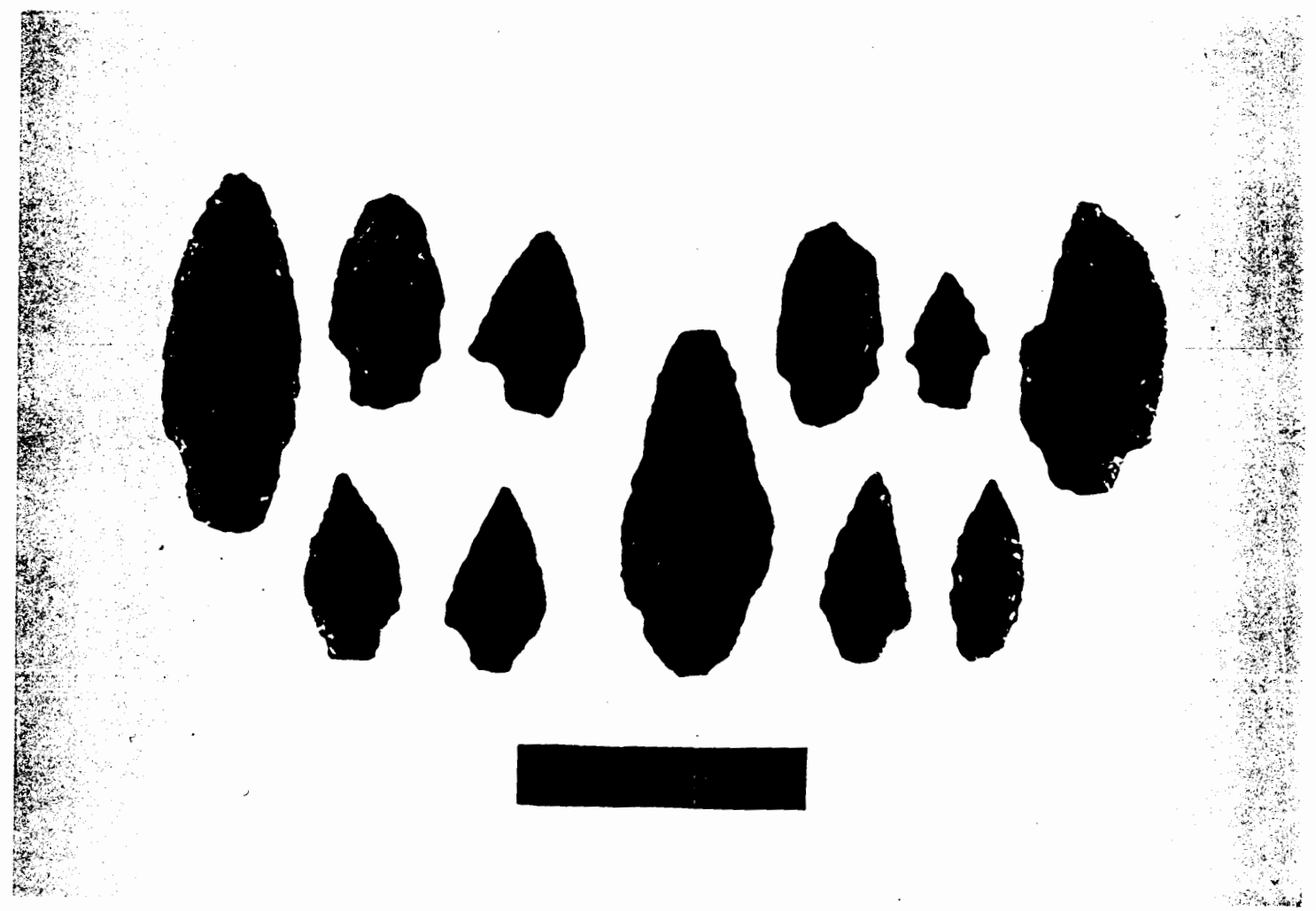

Figure 12. Ibach projectile points typed as Pettigrew Type 5. (Row 1:

$1.124,1.4,1.45,1.50,1.83,1.112$. Row 2: $1.84,1.91,1.23,1.60,1.120$ ) 


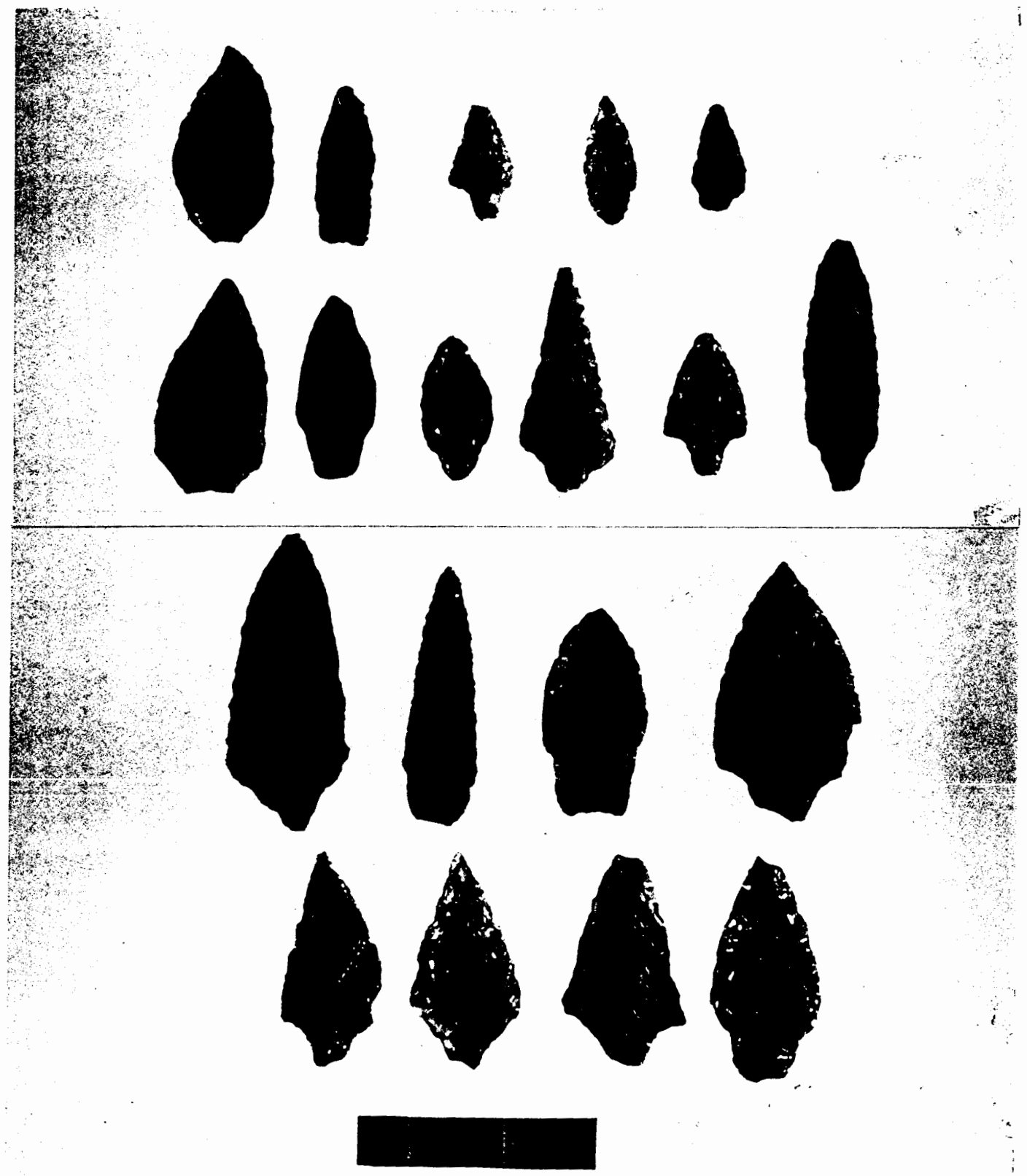

Figure 13. Heynderickx projectile points typed as Pettigrew Type 5. (Row 1: $66.22,66.24,66.11,66.7,69.23$. Row 2: $66.25,66.19,66.20,66.13$, $67.38,66.9$. Row 3: $67.7,67.4,67.33,67.10$. Row 4: 67.26, 67.19, $67.3,67.28)$ 
serrated. Six points are complete. Of the 19 , all are made of ces except four made of obsidian and one of basalt. Although most of these points exhibit sharply contracting stems, three (Specimens 85-18.66.19, 85-18.66.24, and 85-18.67.33) evidence slight shoulders and have wide bases relative to their widths. The largest one (85-18.67.33), additionally, has a pronounced, nicely thinned concave base with ground edges and resembles a Windust point, a very early point type (Rice 1972).

Ibach: $\mathrm{n}=11$. Type 5 is also the most dominant broad-necked type, accounting for $41 \%$ of these points. Six (55\%) are obsidian, one is basalt, and the rest are ccs. None are serrated. Three are complete.

Broad-necked, unidentified: not typable due primarily to stem damage (Figure 14).

Heynderickx: $\mathrm{n}=4$. Three points are either Type 1 or Type 4. Of these, one is obsidian and two are ccs. The fourth, made of obsidian, is either Type 2 or Type 5 . All four are serrated.

Ibach: $\mathrm{n}=6$. Two points with expanding stems are either Type 1 or Type 12. Another two points are either Type 1 or 4 , and the last two are Type 2 or 5. 


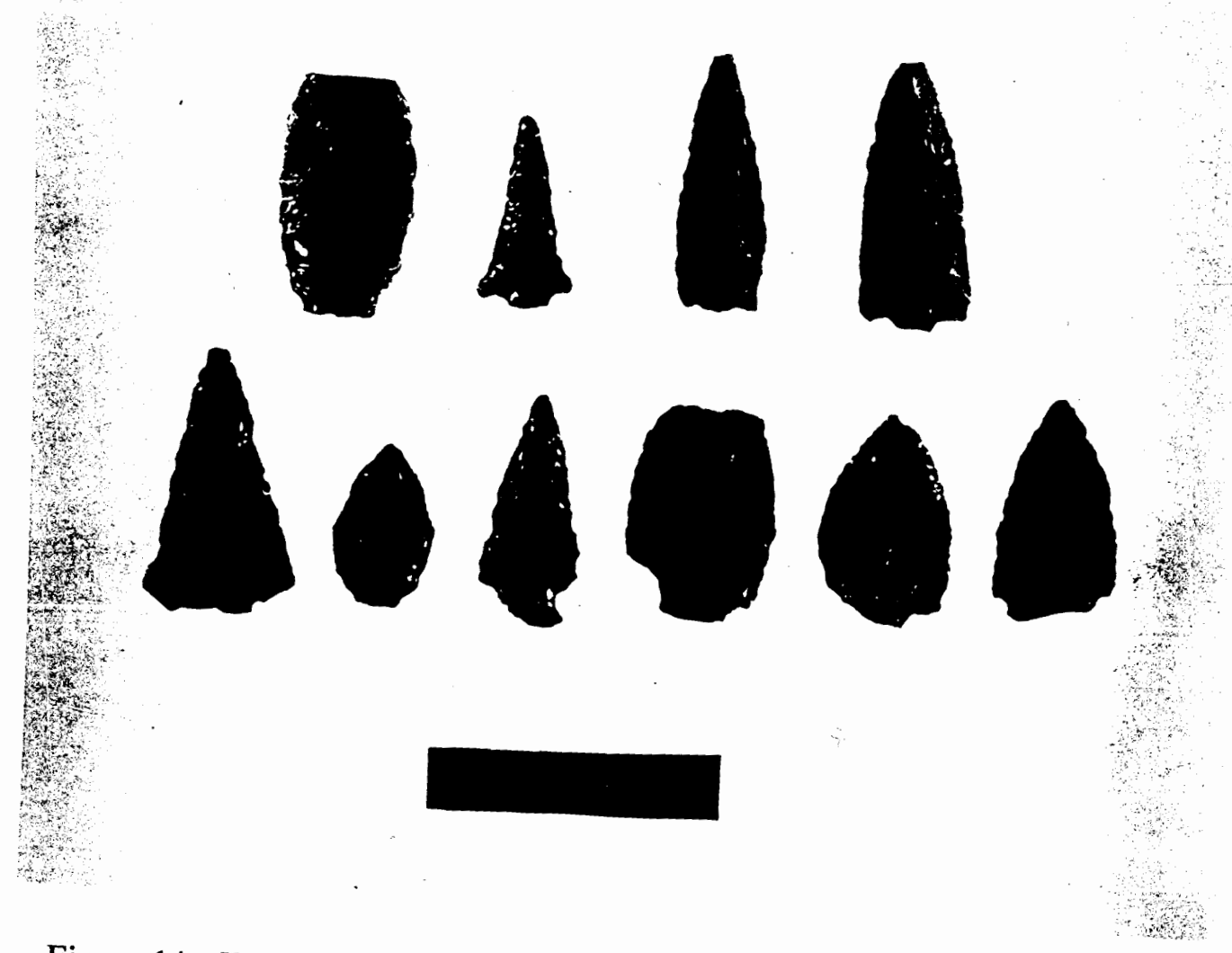

Figure 14. Heynderickx and Ibach projectile points typed as Pettigrew type 66.8). Ibach (Row 2: 1.114, 1.37, 1.18, 1.28 1: 67.27, 67.40, 67.17, 
TABLE VI

HEYNDERICKX BROAD-NECKED POINTS

\begin{tabular}{lcccccc} 
Type & $\begin{array}{l}\text { Neck Width } \\
\text { Range (mm) }\end{array}$ & $\begin{array}{c}\text { Neck Width } \\
\text { Mean }(\mathrm{mm})\end{array}$ & Frequency & \multicolumn{3}{c}{ Raw material } \\
\hline 1 & $8.1-17.1$ & 11.7 & 14 & 14 & & \\
\hline 2 & $7.9-16.0$ & 12.9 & 3 & 1 & 1 & 1 \\
3 & & & - & & & \\
4 & $8.1-11.2$ & 10.2 & 3 & 3 & & \\
5 & $7.5-17.6$ & 11.1 & 19 & 14 & 4 & 1 \\
Unident. & $7.6-13.3$ & 9.1 & 4 & 2 & 2 & \\
\hline-
\end{tabular}

TABLE VII

\section{IBACH BROAD-NECKED POINTS}

\begin{tabular}{lcccccc} 
Type & Neck Width & \multicolumn{2}{c}{ Neck Width } & Frequency & \multicolumn{3}{c}{ Raw material } \\
& Range $(\mathrm{mm})$ & Mean $(\mathrm{mm})$ & & ccs & obs & bas \\
\hline 1 & $10.2-16.2$ & 13.2 & 5 & 4 & 1 & \\
2 & $14.2-14.6$ & 14.4 & 2 & 2 & & \\
3 & & & - & & & \\
4 & $9.8-17.2$ & 14.4 & 3 & 3 & & 1 \\
5 & $8.8-18.1$ & 12.4 & 11 & 4 & 6 & 1 \\
Unident. & $8.1-16.2$ & 12.4 & 6 & 3 & 3 & \\
\hline
\end{tabular}

Narrow-necked Points. These are stemmed points with a neck width less than 7.5

$\mathrm{mm}$. There are four types based on stem shape and barb/shoulder configuration (Tables VIII, IX and Appendix B).

Type 7: "narrow-necked, barbed, with a diverging stem) (p. 41). (Figure 15)

Heynderickx: $\mathrm{n}=11$. Only two specimens are complete, with the others showing barb and stem damage. Eight are ccs, and three are obsidian. All are corner-notched. Three show slight serration; one is deeply serrated.

Ibach: $\mathrm{n}=0$. 
Type 8: "narrow-necked, shouldered, with a diverging stem" (p. 41). (Figure 15) Heynderickx: $\mathrm{n}=1$. This obsidian point is not serrated and shows some breakage.

Ibach: $\mathbf{n}=\mathbf{0}$.

Type 9: "narrow-necked, barbed, with a non-diverging stem" (p. 41). (Figure 16) Heynderickx: $\mathrm{n}=14$. This type accounts for $30 \%$ of the narrow-necked points in this collection. Eleven are ccs; 3 are obsidian. Only three are complete; as with Type 7, over half show barb damage. Three are slightly serrated. One point is basally notched, while all the rest are corner-notched. Ibach: $\mathbf{n}=\mathbf{0}$.

Type 10: "narrow-necked, shouldered with a non-diverging stem" (p. 44). (Figure 17) Heynderickx: $\mathrm{n}=12$. Four points are complete. One is obsidian, the rest ccs. None are serrated.

Ibach: $\mathbf{n}=1$. This specimen is complete and made of ccs. It has no serrations.

(At Hager's Grove, Pettigrew created subtypes of Type 10 on the basis of serration. Type 10a has no or slight serration; Type $10 \mathrm{~b}$ is deeply serrated. He found no Type 10a there, and only one Type 10b. Under this subdivision, all Heynderickx and Ibach points would be Type 10a.)

Narrow-necked, unidentified: not typable due primarily to stem damage (Figure 18). Heynderickx: $\mathrm{n}=9$. All 9 points have sustained stem damage. Eight are either Type 7 or $9 ; 3$ are obsidian and 5 are ccs. The other point is Type 8 or 10 and is obsidian. 

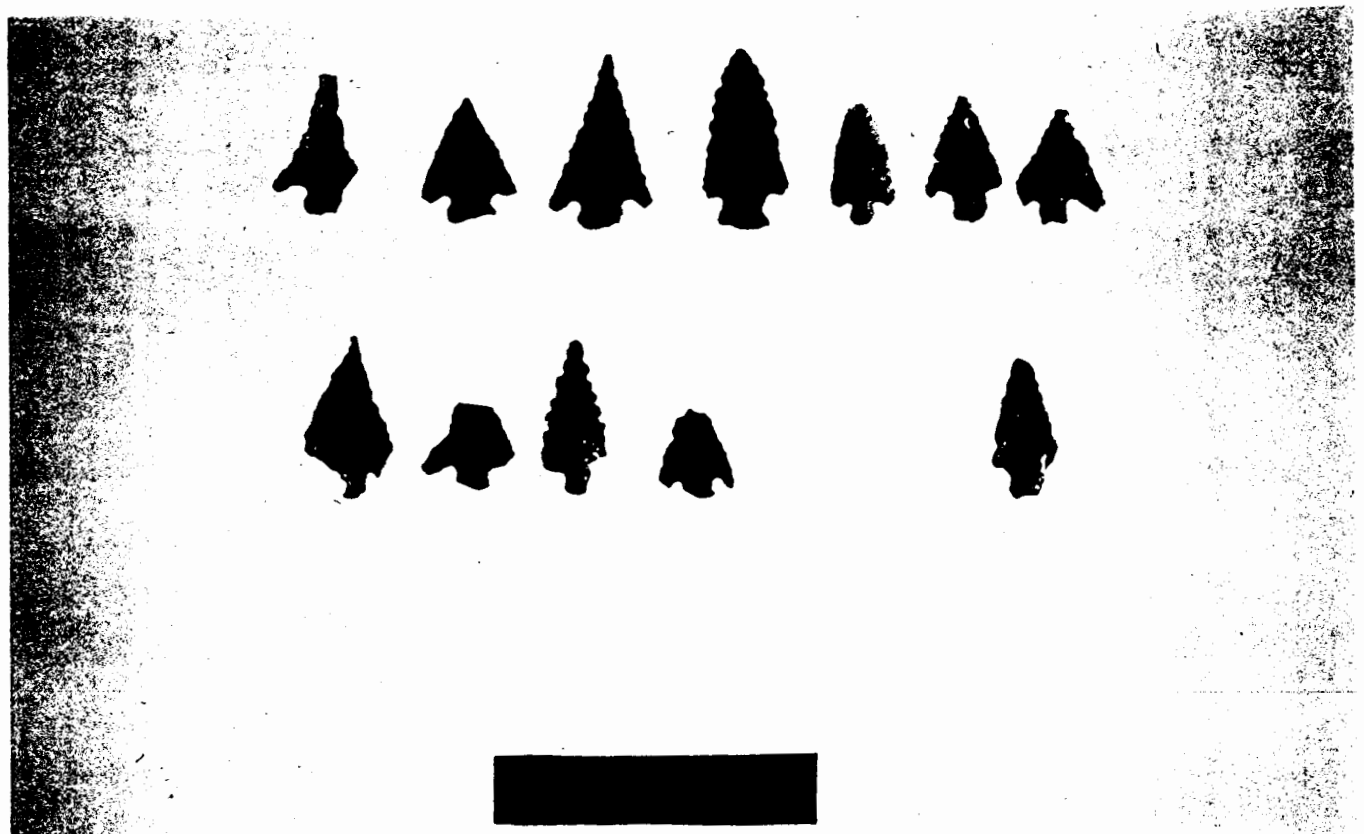

Figure 15. Heynderickx projectile points typed as Pettigrew Type 7 and Type 8. Type 7 (Row 1: 66.30, 66.34, 67.21, 67.41, 69.5, 69.8, 69.17. Row 2: $69.18,69.33,69.44,69.46$ ). Type 8 (Bottom right: 69.42).

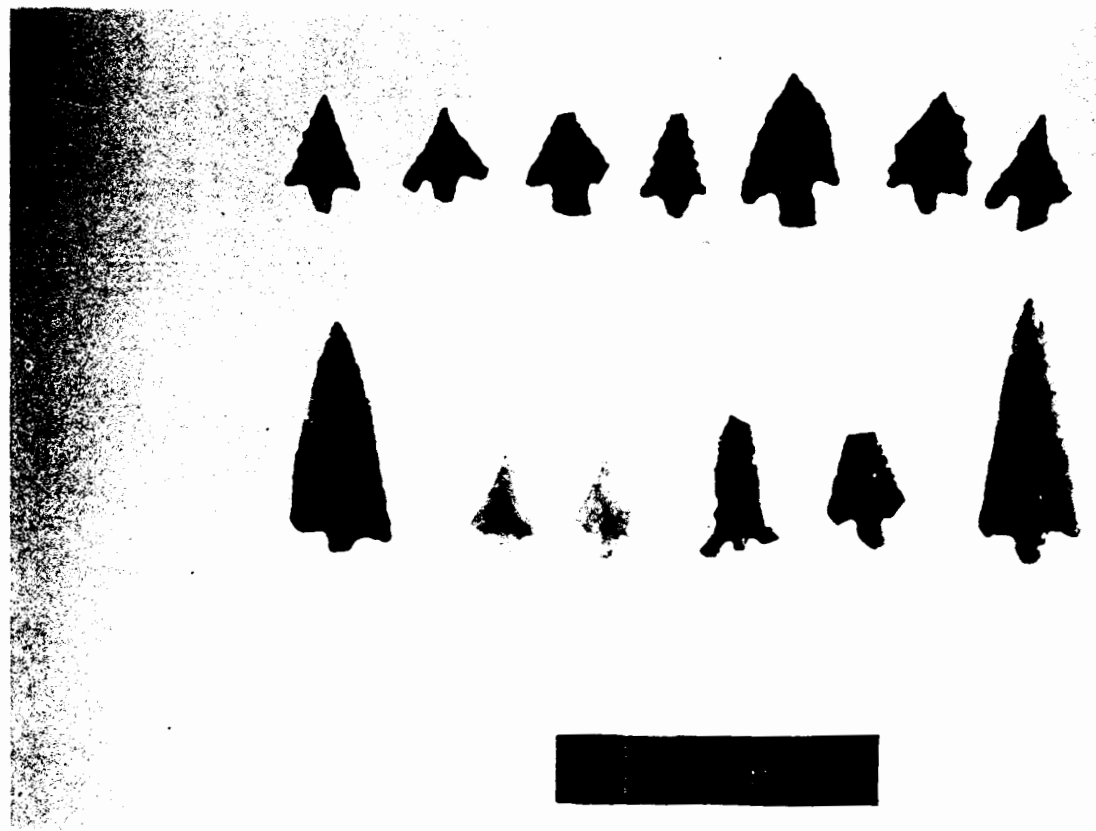

Figure 16. Heynderickx projectile points typed as Pettigrew Type 9. (Row 1: $69.30,69.31,69.32,69.35,69.36,69.39,69.45$. Row 2: 67.5, 69.6, $69.16,69.19,69.20,69.28$. 66.31 not photographed.) 


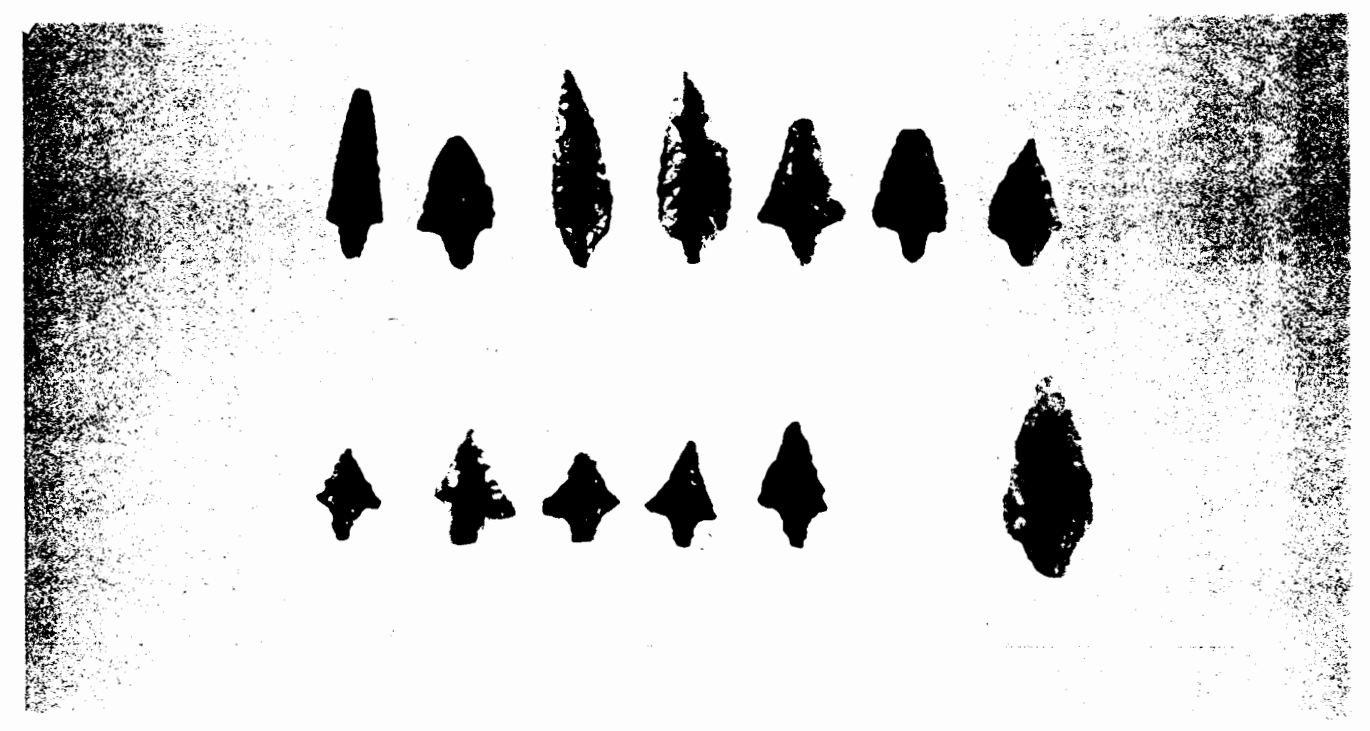

Figure 17. Heynderickx and Ibach projectile points typed as Pettigrew Type 10. Heynderickx (Row 1: 66.28, 66.33, 67.20, 67.22, 69.1, 69.2, 69.3. Row 2: 69.40, 69.4, 69.7, 69.21, 69.26). Ibach (Bottom right: 1.82).
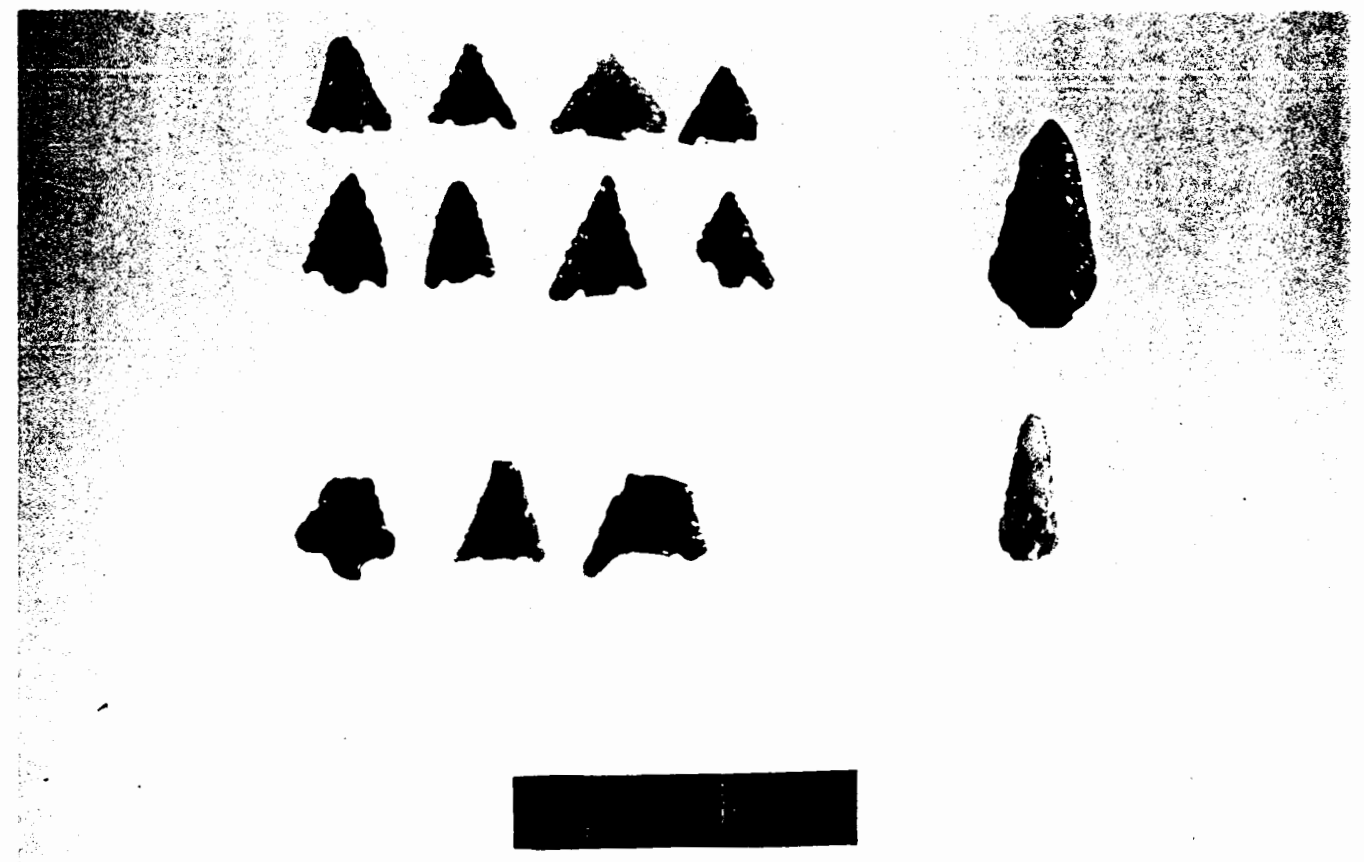

Figure 18. Heynderickx and Ibach projectile points typed as Pettigrew Type Narrow-necked, unidentified. Heynderickx (Row 1: 69.9, 69.11, 69.12, 69.27. Row 2: 66.32, 69.34, 69.37, 69.41, 67.39). Ibach (Row 3: 1.99, $1.125,1.133,1.97)$. 
Ibach: $\mathrm{n}=4$. This group accounts for $80 \%$ of the narrow-necked points.

Three are Type 7 or 9 . Two are non-serrated obsidian; the third is ccs but is too badly damaged to discern serration. The fourth is Type 8 or 10 , a slightly serrated ccs point.

TABLE VIII

HEYNDERICKX NARROW-NECKED POINTS

\begin{tabular}{|c|c|c|c|c|c|}
\hline \multirow[t]{2}{*}{ Type } & \multirow{2}{*}{$\begin{array}{l}\text { Neck Width } \\
\text { Range (mm) }\end{array}$} & \multirow{2}{*}{$\begin{array}{l}\text { Neck Width } \\
\text { Mean }(\mathrm{mm})\end{array}$} & \multirow[t]{2}{*}{ Frequency } & \multicolumn{2}{|c|}{ Raw material } \\
\hline & & & & $\operatorname{ccs}$ & obs \\
\hline 7 & $3.5-6.6$ & 4.6 & 11 & 7 & 3 \\
\hline 8 & 5.4 & 5.4 & 1 & & 1 \\
\hline 9 & $2.4-6.1$ & 4.5 & 14 & 7 & 3 \\
\hline 10 & $3.9-6.5$ & 5.2 & 12 & 11 & 1 \\
\hline Unident. & $3.9-7.0$ & 5.0 & 9 & 5 & 4 \\
\hline
\end{tabular}

TABLE IX

\section{IBACH NARROW-NECKED POINTS}

\begin{tabular}{|c|c|c|c|c|c|c|}
\hline Type & $\begin{array}{l}\text { Neck Width } \\
\text { Mean (mm) }\end{array}$ & $\begin{array}{l}\text { Neck Width } \\
\text { Mean (mm) }\end{array}$ & Frequency & & $\begin{array}{l}\text { material } \\
\text { obs }\end{array}$ & bas \\
\hline 7 & & & - & & & \\
\hline 8 & & & - & & & \\
\hline 9 & & & - & & & \\
\hline 10 & 7.3 & 7.3 & 1 & 1 & & \\
\hline Unident. & $4.9-7.0$ & 5.6 & 4 & 2 & 2 & \\
\hline
\end{tabular}

Side-Notched Points. Stems on these points are demarcated by notches on the sides of the point blade. There are 3 types (Tables X, XI and Appendix B) based on attributes noted with each point type. As mentioned earlier, I have included Pettigrew's side-notched points under the stemmed category partly because Toepel treats them as a variant of stemmed points 
and partly because it makes sense since they have measurable neck widths like other stemmed points. Therefore, when he defines the following points as "unstemmed" this should be read as "not corner- or basal- notched."

Type 11: "ovate in outline, and side-notched" (p. 44).

Heynderickx: $\mathrm{n}=0$.

Ibach: $\mathrm{n}=0$.

(None of Type 11 was found in Hager's Grove, either, although as noted earlier, some Type 1 points may grade into Type 11.)

Type 12: "has a triangular blade and is side-notched and unstemmed" (p. 44).

(Figure 19)

Heynderickx: $\mathrm{n}=2$.

Ibach: $\mathrm{n}=4$. Two are obsidian; two are ccs. All show some damage, primarily to tips. None show serration.

(For the Hager's Grove sites, Pettigrew created Types 12a and 12b: 12a is narrow-necked and $12 \mathrm{~b}$ is broad-necked. All six points here have neck widths not less than $9.9 \mathrm{~mm}$ and, therefore, would be Type 12b. All points at Hager's Grove were also Type 12b. Although I use Type 12 to designate these points in the Ibach and Heynderickx groups, I presume that the Type 12 points Pettigrew encountered in the Portland Basin had much narrower neck widths. (See discussion in Chapter V.)

Type 15: "both side-notched and stemmed" (p. 44).

Heynderickx: $\mathrm{n}=0$.

Ibach: $\mathrm{n}=0$. 


$$
\text { I.18 }
$$


(Type 15 is dropped without comment from the typology in the Hager's Grove report.)

\section{TABLE X}

HEYNDERICKX SIDE-NOTCHED POINTS

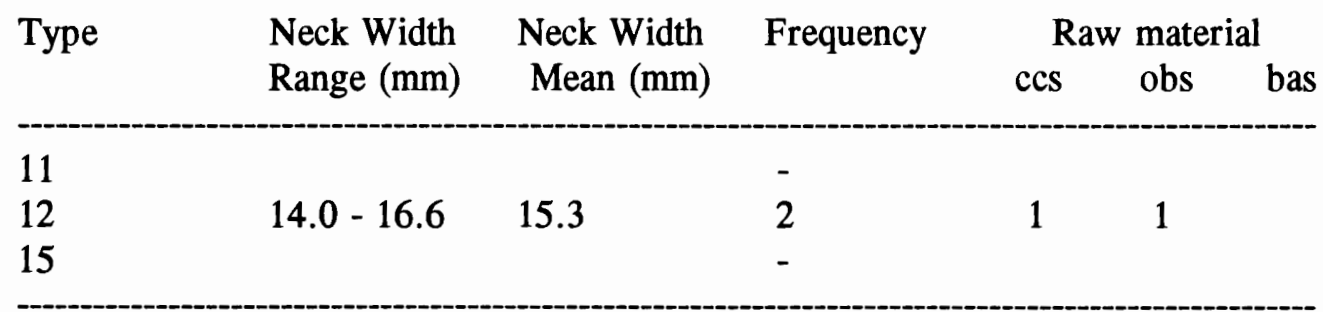

TABLE XI

IBACH SIDE-NOTCHED POINTS

\begin{tabular}{lcccc} 
Type & $\begin{array}{c}\text { Neck Width } \\
\text { Mean (mm) }\end{array}$ & $\begin{array}{c}\text { Neck Width } \\
\text { Mean (mm) }\end{array}$ & Frequency & \multicolumn{2}{c}{ Raw material } \\
ccs & obs bas \\
11 & & & - & 2 \\
12 & $9.9-20.7$ & 13.7 & 4 & 2 \\
15 & & & - &
\end{tabular}

\section{Stemless Points}

Although Pettigrew doesn't call these points "stemless", he recognizes them as "unnotched and unstemmed" and as having no measurable neck width. There are four main types (Tables XII, XIII and Appendix B). Discriminating attributes among types follow no pattern.

Type 6: "ovate or bipointed in outline, unnotched and unstemmed" (p. 41).

Pettigrew established four subtypes (6a-6d) to cover the variety he saw. 
Type 6a: length $17-63 \mathrm{~mm}$; ovate to diamond-shaped outline; striking platform evident on base (p. 41). (Figure 20)

Heynderickx: $\mathrm{n}=3$. All three specimens are made of ccs, and all have slight tip damage. Striking platforms are prominent.

Ibach: $\mathrm{n}=6$. Five points are ccs, and one is basalt. All have striking platform remnants, but some are not prominent. Three are complete, but none show any serration.

Type 6b: narrow and bipointed (p. 41). (Figure 21)

Heynderickx: $\mathrm{n}=6$. All have pointed bases and are made of ccs. Five are complete and without breakage. None are serrated.

Ibach: $\mathbf{n}=8$. Five specimens are ces, one is obsidian, and two are basalt. Two points are complete. While two are slightly serrated, one shows deep serrations. I am not certain that I have typed these the way Pettigrew sorted the Portland Basin Type $6 \mathrm{~b}$ points, as the range in size seems great. Also, how narrow is "narrow"? However, in the absence of more precise guidelines, I have grouped these together.

Type 6c: length $11-18 \mathrm{~mm}$; "bipointed and diamond-shaped" (p. 41).

Heynderickx: $\mathrm{n}=0$.

Ibach: $\mathrm{n}=0$.

Type 6d: small; tear-drop shape with widest part in proximal $1 / 3$ of point ( $p$. 41). (Figure 22).

Heynderickx: $\mathrm{n}=1$. This Type $6 \mathrm{~d}$ point has a slightly damaged tip. It is made of ces and is also slightly serrated.

Ibach: $\mathrm{n}=0$. 


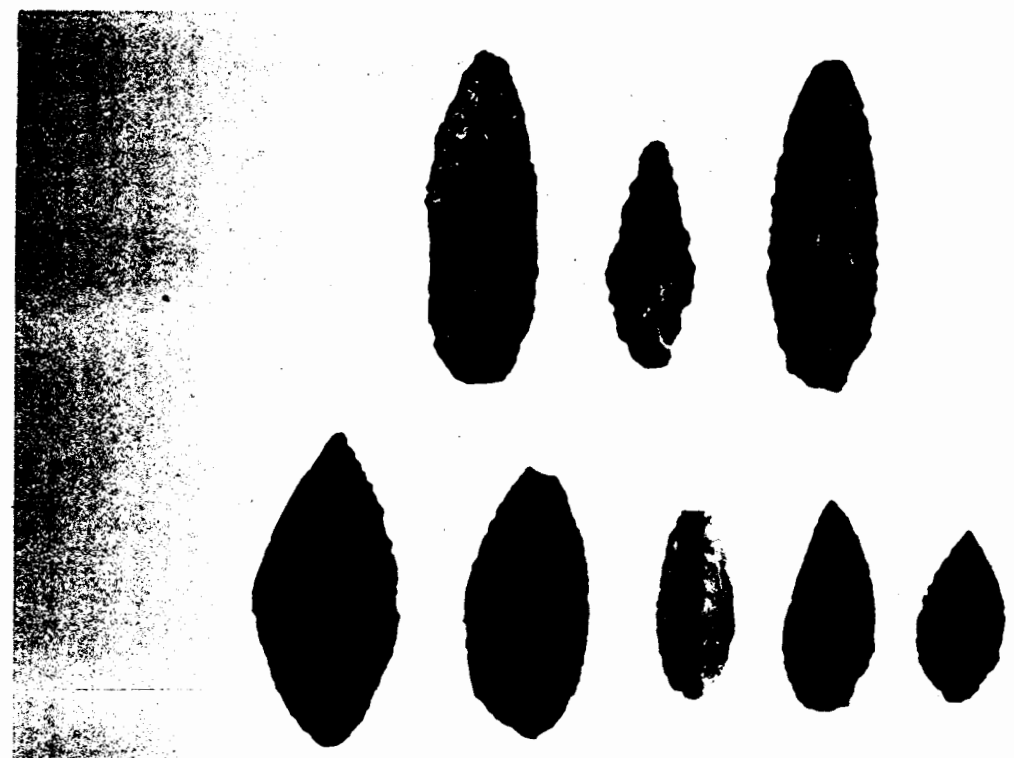

Figure 20. Heynderickx and Ibach projectile points typed as Pettigrew Type 6a. Heynderickx (Row 1: 67.34, 66.12, 66.26). Ibach (Row 2: 1.7, 1.31, $1.33,1.43,1.85)$.

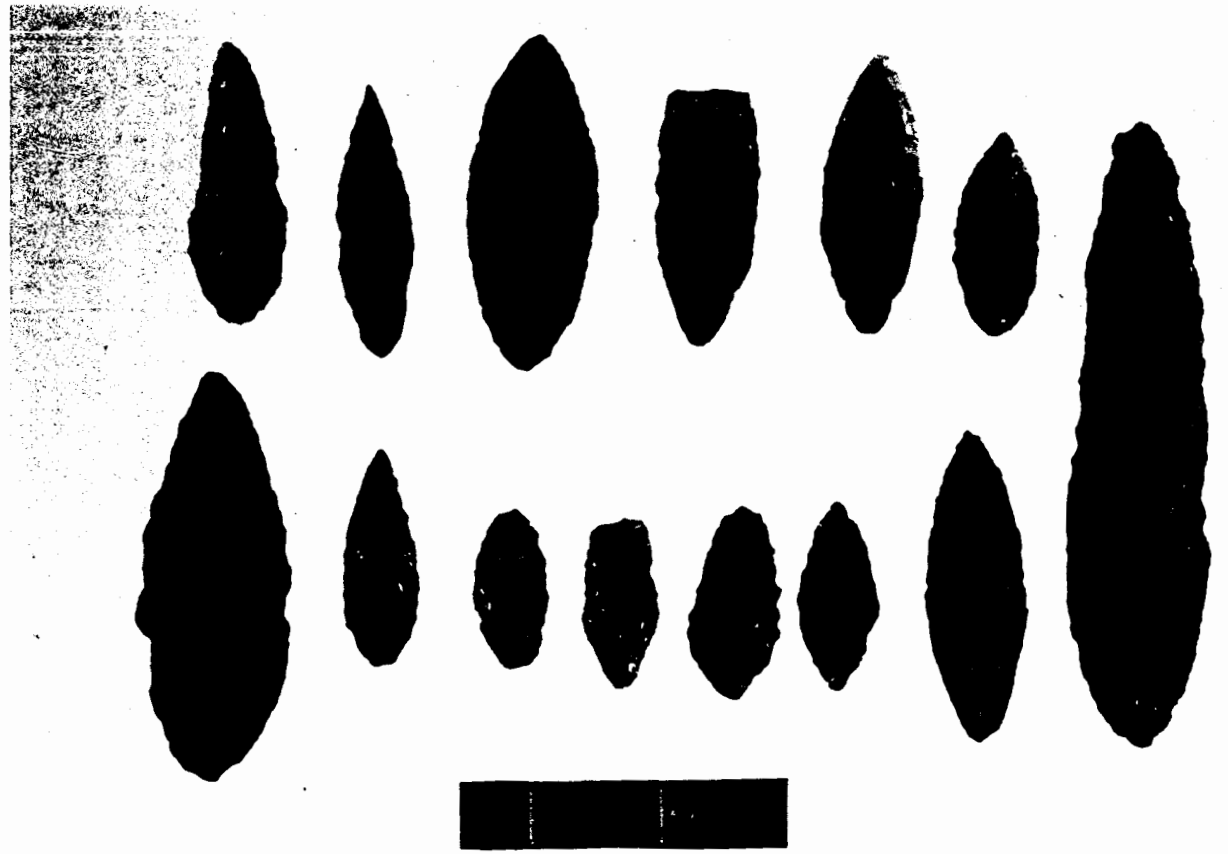

Figure 21. Heynderickx and Ibach projectile points typed as Pettigrew Type 6b. Heynderickx (Row 1: 66.4, 66.17, 66.37, 67.1, 67.8, 67.18). Ibach (Row 2: 1.81, 1.44, 1.86, 1.103, 1.119, 1.128, 1.19, 1.48). 
Type 6 (no subtype): all Type 6 points that did not meet subtype descriptions.

(Figures 23 and 24).

Heynderickx: $\mathrm{n}=10$. Most of these are large, tear-drop shaped points.

Eight are ccs; two are obsidian. Four are complete.

Ibach: $\mathrm{n}=29$. Less than half of these are ccs. Eight (28\%) are obsidian, while $31 \%$ are basalt. Only $3(10 \%)$ are without breakage. Five are slightly serrated; one is deeply serrated. In contrast to the Heynderickx Type 6 points, only about half of these are tear-drop shaped and the other half are lanceolate in outline.

I found it difficult to type these not because of breakage, as in the case of the stemmed points, but because most of the points did not fit the Portland Basin subtype descriptions and, consequently, fell out into an undifferentiated Type 6 category. For example, several points had a Type $6 d$ shape but were much larger than "small" could reasonably describe. (At Hager's Grove, Pettigrew (1980:87) keeps all Type 6 points together without differentiating among subtypes.)

Type 13: " unnotched and unstemmed, with an incurvate base" (p. 44).

Heynderickx: $\mathrm{n}=0$.

Ibach: $\mathrm{n}=0$.

No specimens were found at Hager's Grove.

Type 14: "triangular blade with a base that is not incurvate, and is unnotched and unstemmed" (p. 44). (Figure 22) Heynderickx: $\mathrm{n}=2$. Both are small, complete obsidian points. One is slightly serrated; the other's serration is more pronounced. 
Ibach: $\mathrm{n}=\mathbf{0}$.

Type 16: "unstemmed, with an unmodified or only slightly retouched base" (p. 44).

Heynderickx: $\mathrm{n}=0$.

Ibach: $\mathrm{n}=0$.

This is the "Trojan point" reported from 35 CO 1 (Warner and Warner 1975).

Pettigrew does not even mention this type in the Hager's Grove report.

TABLE XII

HEYNDERICKX STEMLESS POINTS

\begin{tabular}{llclll} 
Type & Length & Thick. & Frequency & \multicolumn{2}{c}{ Raw material } \\
& Range (mm) & Range (mm) & & ccs & obs bas \\
\hline 6a & $37.1-53.5$ & $7.2-8.9$ & 3 & 3 & \\
6b & $31.9-52.2$ & $5.2-8.9$ & 6 & 6 & \\
6c & & & - & & \\
6d & 21.4 & 3.2 & 1 & 1 & \\
6 (unclass) & $36.4-90.4$ & $5.1-9.1$ & 10 & 8 & 2 \\
13 & & & - & & 2 \\
14 & $14.1-16.0$ & $1.9-2.1$ & 2 & & \\
16 & & & - & & \\
\hline
\end{tabular}

TABLE XIII

IBACH STEMLESS POINTS

\begin{tabular}{lllllll} 
Type & Length & Thick. & Frequency & \multicolumn{2}{l}{ Raw material } \\
& Range $(\mathrm{mm})$ & Range $(\mathrm{mm})$ & & ccs & obs & bas \\
\hline 6a & $26.8-60.2$ & $2.8-9.0$ & 6 & 5 & & 1 \\
6b & $26.1-97.6$ & $4.1-8.2$ & 8 & 5 & 1 & 2 \\
6c & & & - & & & \\
6d & & & - & & & \\
6 (unclass) & $22.1-76.4$ & $5.2-10.0$ & 29 & 12 & 8 & 9 \\
13 & & & - & & & \\
14 & & & - & & & \\
16 & & & - & &
\end{tabular}

*Includes minimum lengths of points shortened by breakage. 

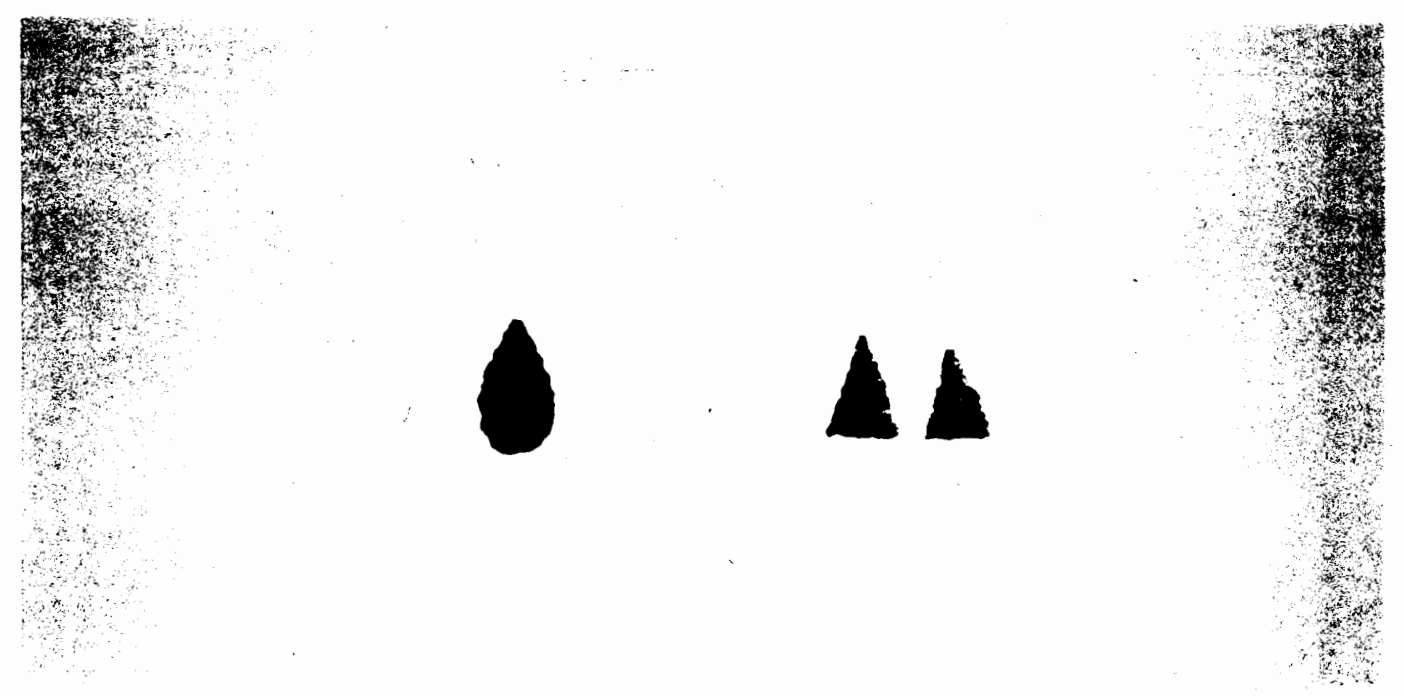

Figure 22. Heynderickx projectile points typed as Pettigrew Type 6d and Type 14. Type 6d (Left: 69.25). Type 14 (Right: 69.38, 69.43).
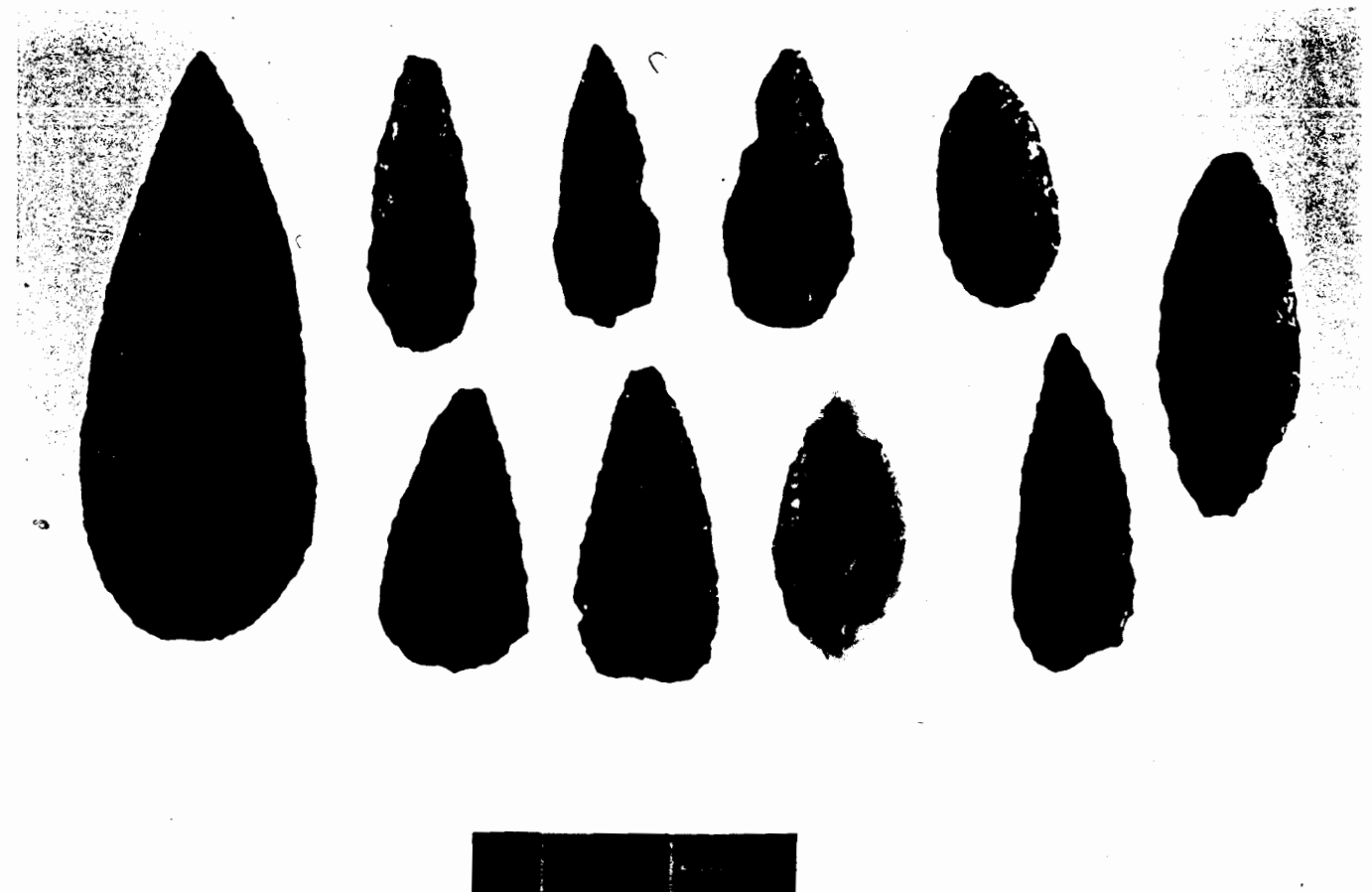

Figure 23. Heynderickx projectile points typed as Pettigrew Type 6, unclassified. (Row 1: 67.29, 66.16, 67.31. Row 2: 68.7, 67.35, 68.3, $67.11,67.25,66.36$.) 


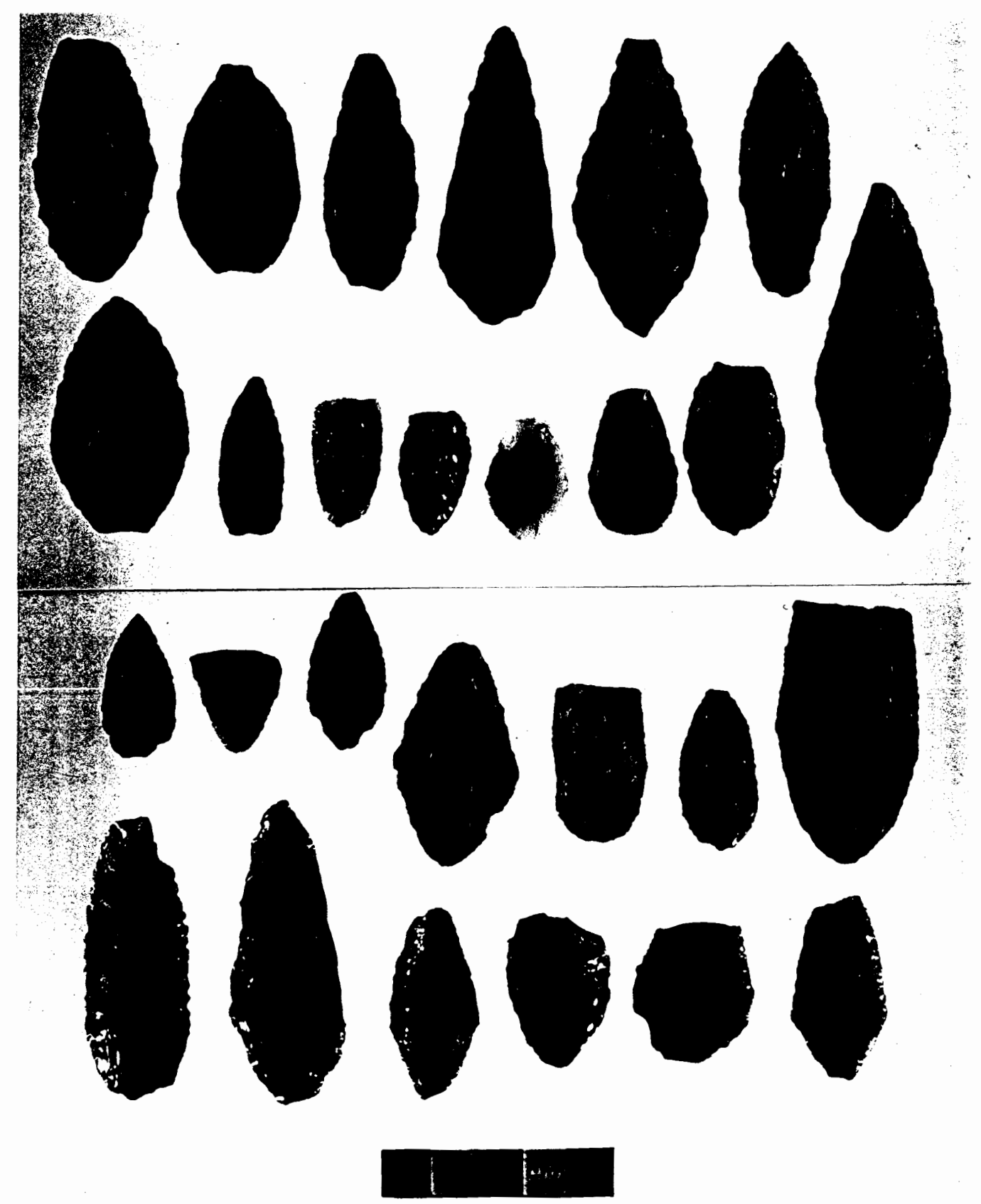

Figure 24. Ibach projectile points typed as Pettigrew Type 6, unclassified. (Row 1: 1.3 1.8, 1.67, 1.17, 1.54, 1.14. Row 2: 1.34, 1.41, 1.56, 1.24, 1.26, 1.13, 1.74, 1.35. Row 3: 1.100, 1.95, 1.102, 1.42, 1.75, 1.116, 1.76. Row 4: $1.107,1.109,1.126,1.118,1.122,1.127$. 


\section{TUALATIN VALLEY POINTS IN TOEPEL'S TYPOLOGY}

For the projectile points excavated at the Flanagan site, Toepel (1985) devised a keyed, metrically based typology to render measured rigor or objectivity to the typing of projectile points. This last section of the chapter reports the results of using her type definitions to categorize the Heynderickx and Ibach projectile points. In the following section, I list her type definitions only briefly in the text (using Toepel's own descriptive terms from pages 90 - 109). These should be used in conjunction with the more precise and more importantly defining metric parameters in her projectile point key (reproduced in Figure 5). Table XIV presents the results of typing the collection points according to this typology.

\section{Stemless Points}

Points with "no apparent neck", i.e. a neck width which equals 0 (Toepel 1985:87). The major stemless groups in the Toepel typology are the small stemless and heavy stemless series. Thickness differentiates the small from the heavy stemless points. Basal shape (i.e., triangular, leaf-shaped or lanceolate, as determined through the basal width/maximum width ratio) distinguishes types within the series. Degree of rotundity, as measured by thickness/maximum width ratio, is added as a secondary, less consistent type characteristic.

Small Stemless. Stemless points with a thickness less than or equal to $5 \mathrm{~mm}$ (Figure 25).

Type 1 (SS1), (Triangular): "thin, unnotched", triangular" (p. 91);

$$
\mathrm{W}_{\mathrm{b}} / \mathrm{W}_{\mathrm{m}}>0.90 \text {. }
$$

'While Pettigrew used unnotched to mean not side-notched but possibly corner- or basalnotched, Toepel uses the word to mean not side-, corner- or basal-notched. 
Heynderickx: $\mathrm{n}=2$. Both are complete obsidian points, and both are serrated, although one more deeply than the other.

Ibach: $\mathbf{n}=\mathbf{0}$.

Thirteen of the fourteen Type SS1 points at the Flanagan site were made of obsidian. Twelve were serrated.

Type 2 (SS2), (Leaf-shaped): "thin, unnotched and leaf-shaped in outline" (p. 92); $0.40<\mathrm{W}_{\mathrm{b}} / \mathrm{W}_{\mathrm{m}}<0.90$.

Heynderickx: $\mathrm{n}=1$. The single specimen is made of ccs, is slightly serrated and is unbroken except for a tiny nick off the tip.

Ibach: $\mathrm{n}=0$.

In the Flanagan site, of the nineteen recovered all but one was obsidian, and ten showed heavy serration.

Type 3 (SS3), (Lanceolate): "small, unnotched and lanceolate in form" (p.

93); $\mathrm{W}_{\mathrm{b}} / \mathrm{W}_{\mathrm{m}}<0.40$.

Heynderickx: $\mathrm{n}=0$.

Ibach $: \mathbf{n}=3$. All three are complete. Two are ccs; one is obsidian. None are serrated. This is the only type of small stemless point in the Ibach collection.

A lone unserrated ccs specimen was found at the Flanagan site.

Heavy Stemless. Stemless points with a thickness greater than $5 \mathrm{~mm}$.

Type 1 (HS1), (Triangular): "thick, unnotched and triangular" (p.94);

$\mathrm{W}_{\mathrm{b}} / \mathrm{W}_{\mathrm{m}}>0.90$.

Heynderickx: $\mathrm{n}=0$.

Ibach: $\mathrm{n}=0$. 


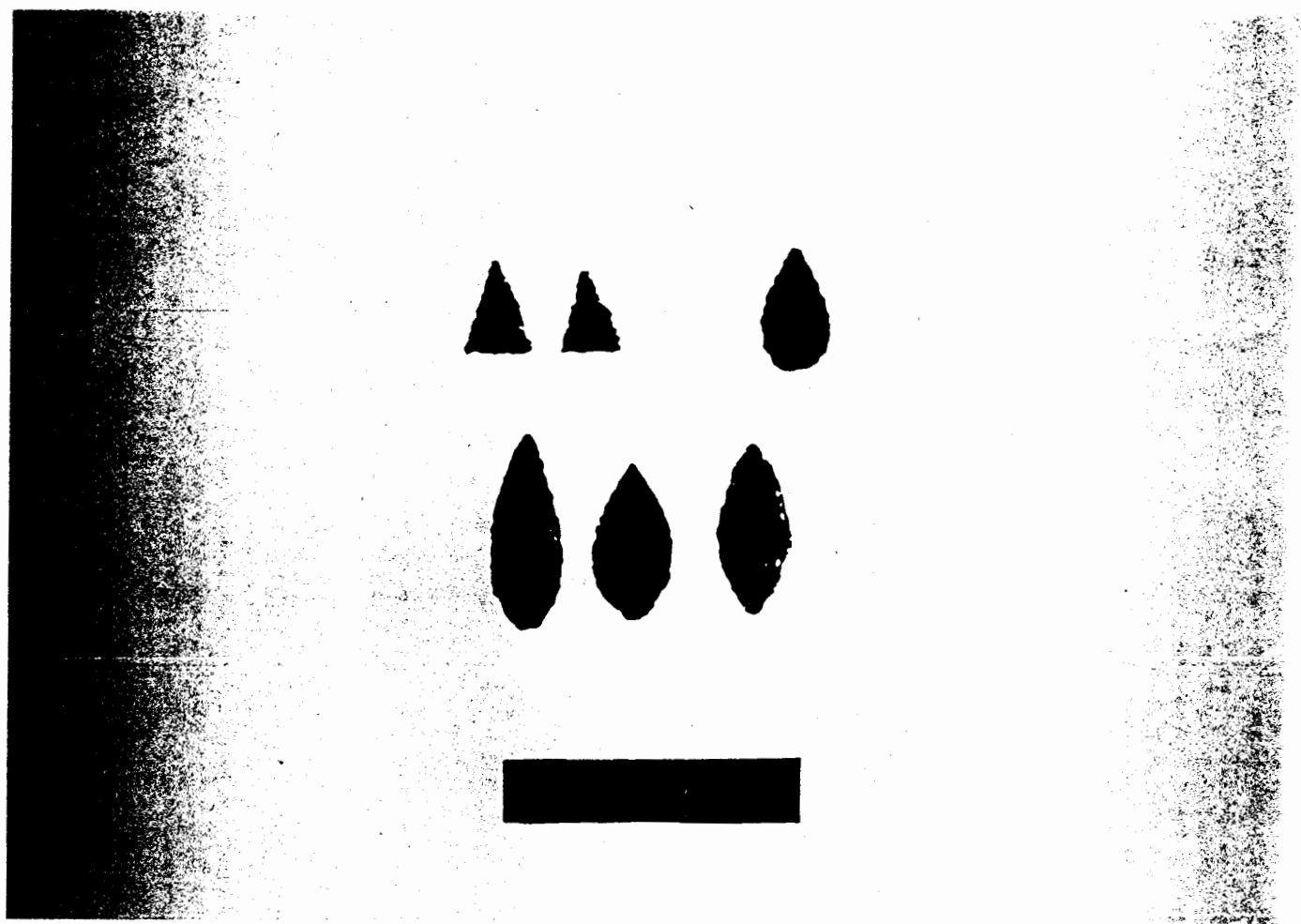

Figure 25. Heynderickx and Ibach projectile points typed as Toepel Types SS1, SS2 and SS3. Heynderickx (Row 1, Type SS1: 69.38, 69.43; Type SS2: 69.25). Ibach (Row 2, Type SS3: $1.44,1.85,1.128$ ). 
TABLE XIV

PROJECTILE POINTS: TOEPEL TYPOLOGY

IBACH

TYPE

Small Stemless:

SS1

SS2

SS3

Heavy Stemless:

HS1

HS2

HS3

Narrow-necked:

NN1

NN2

NN3

NN(unident.)

Moderate Broad-necked:

MB1

MB2

MB3

MB(unident.)

Relative

No. Frequency

-
-
3
--

-

31

11

39

40

50

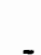

2$$
3
$$

$-$

2

$-$

3

4

6

4

6
HEYNDERICKX

Relative

No. Frequency

-
-
4
--
4

2

1

11

33

10

9

10
9

8

19

17

3

28

25

10

9

9

47

8

42

$\begin{array}{cc}1 & 1 \\ - & - \\ 3 & 4 \\ 1 & 1 \\ -5 & 6\end{array}$

Heavy Broad-necked:

HB1

HB2

HB3

HB(unident.)

\section{2}

11

10

4

$--$

27

3
14

14

13

5

---

35

$\begin{array}{cc}- & - \\ 4 & 3 \\ 7 & 6 \\ 3 & 3 \\ -- & -- \\ 14 & 12\end{array}$

6

$==$

79

$==$
$101 *$

2

13

15

1

31

27

TOTAL

$==$

114

$==$

$101^{*}$ 
This type is tentatively proposed by Toepel. None was found at the Flanagan site, either. Although a conceptual complement to the smaller SS1, it may not describe any actual points of this size and shape in the Willamette Valley.

Type 2 (HS2), (Leaf-shaped): "thick, unnotched and leaf-shaped" (p. 94); $0.40<\mathrm{W}_{\mathrm{b}} / \mathrm{W}_{\mathrm{m}}<0.90$. (Figures 26 and 27) Heynderickx: $\mathrm{n}=10$. All points are made of ccs. Only three are without any breakage. One (Specimen $85-18.68 .7$ ) is much larger than the others. Its maximum width is $36.7 \mathrm{~mm}$, while the next widest point (which in shape looks exactly like a smaller version of the large point) is $23.2 \mathrm{~mm}$. None of these HS2 points is serrated. Ibach: $\mathrm{n}=9$. Three points are obsidian; the rest are ccs. Only three of the nine are complete, and two of the obsidian points are slightly serrated. One point (83-1.14) looks lanceloate, but the Wbase/Wmax ratio falls into the leaf-shaped type. While Type HS2 accounted for over half the Heynderickx heavy stemless points, it makes up less than a fourth of the heavy stemless Ibach points. The only Type HS2 specimen found at the Flanagan site was a serrated obsidian point.

Type 3 (HS3), (Lanceolate): "thick, unnotched and lanceolate" (p. 95); $\mathrm{W}_{\mathrm{b}} / \mathrm{W}_{\mathrm{m}}<0.40$. (Figures 28 and 29) Heynderickx: $\mathrm{n}=9$. All points are ces, except for one obsidian. Two-thirds are complete. Only one shows slight serration. 

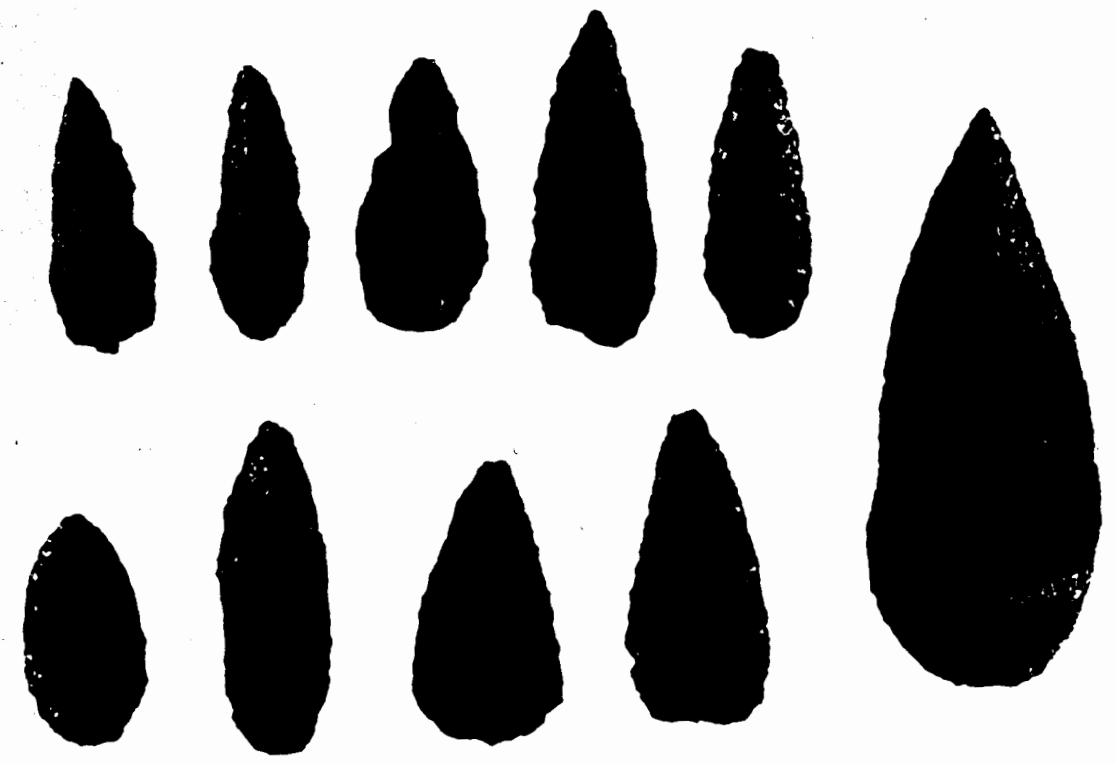

Figure 26. Heynderickx projectile points typed as Toepel Type HS2. (Row 1: 66.1, 66.4, 66.16, 67.25, 67.29. Row 2: 67.31, 67.34, 67.35, 68.3, 68.7.)
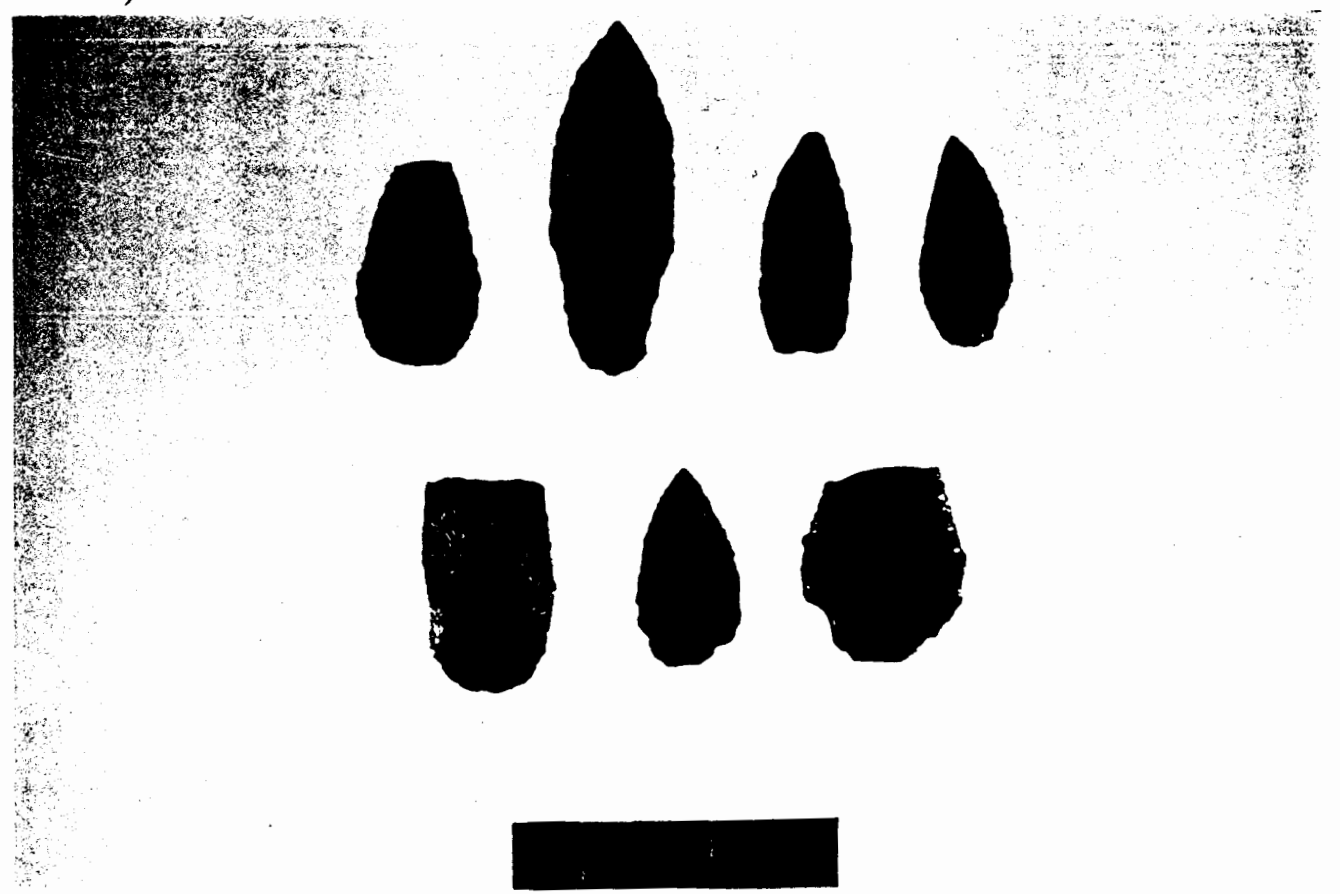

Figure 27. Ibach projectile points typed as Toepel Type HS2. (Row 1: $1.13,1.14,1.41,1.43$. Row 2: $1.75,1.100,1.122$. 1.1 and 1.72 not photographed.) Scale same as Figure 26. 


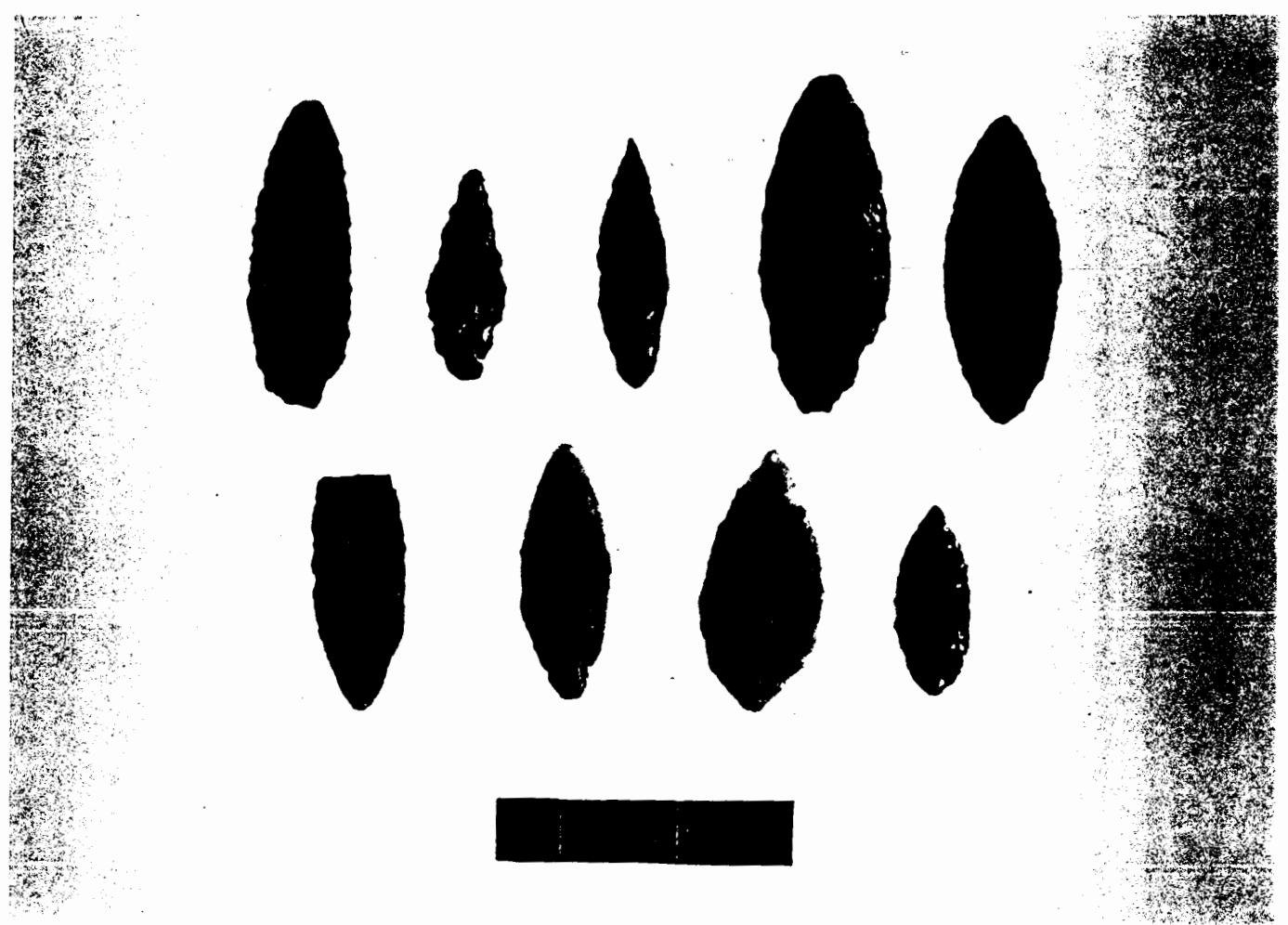

Figure 28. Heynderickx projectile points typed as Toepel Type HS3. (Row 1: $66.26,66.12,66.17,66.36,66.37$. Row 2: $67.1,67.8,67.11,67.18$. 


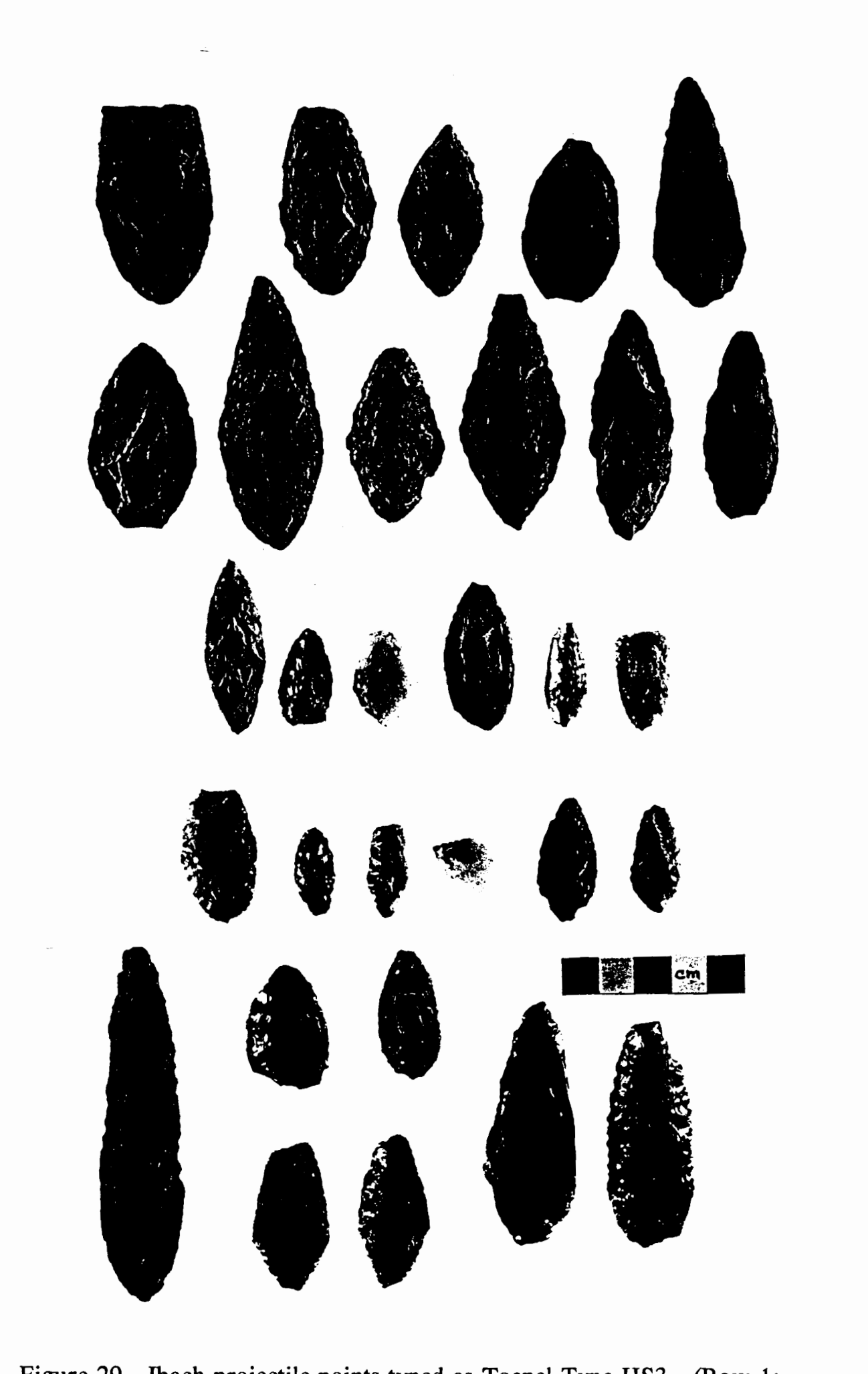


Ibach: $\mathrm{n}=31$. This type is the predominant type in the Ibach collection, making up about $40 \%$ of all types, both stemless and stemmed. Twelve (39\%) are basalt and are unserrated, and two of these basalt points are the only complete points in the set. Five Type HS3 points are obsidian, and 14 are ccs. Specimen 83-1.17 measures as a HS3 but looks widest in the lowest $1 / 3$, like a HS2.

Toepel (1985:95) points out that Type HS3 resembles the "Cascade" point. All 7 of the Flanagan Type HS3 points were found in the early layers of the site, and 4 were basalt.

\section{Stemmed Points}

These are points with a measurable neck width. The main subdivisions (based on neck width) are narrow-necked, moderate broad-necked and heavy broad-necked. (As noted earlier, Toepel considers side-notched points stemmed points.)

Narrow-necked Points. Neck width less than or equal to $7 \mathrm{~mm}$. The manner of notching (side, corner or basal) as determined by basal width/maximum width ratio separates the types.

Type 1 (NN1), (Side-notched): "small, thin, triangular points with notches high on the sides" (p. 97); $\mathrm{W}_{\mathrm{b}} / \mathrm{W}_{\mathrm{m}}>0.90$

Heynderickx: $\mathrm{n}=0$.

lbach: $\mathrm{n}=0$.

Type NN1 is known as the Desert side-notch point in other places. Although no Type NN1 was found at the Flanagan site, either, Toepel proposes a conceptual type which is essentially Type SS1 with the addition of side notches. 
Type 2 (NN2), (Corner-notched): "narrow-necked corner-notched" (p. 101); $0.20<\mathrm{W}_{\mathrm{b}} / \mathrm{W}_{\mathrm{m}}<0.90$. (Figure 30)

Heynderickx: $\mathrm{n}=28$. Over $40 \%$ of the entire Heynderickx collection is narrow-necked points, and of these $60 \%$ are Type NN2. Twenty-one points are ccs; the other eight are obsidian. Of these, six are complete. Sixty-nine percent exhibit stem and/or barb breakage. Ibach: $\mathrm{n}=2$. Narrow-necked points comprise only $6 \%$ of the Ibach collection, so the fact that $\mathrm{NN} 2$ accounts for half of these is not significant. Both Type NN2 points are ccs. One is slightly serrated. Neither point is complete.

In order to evaluate the significance of expanding stems versus contracting stems as a type attribute, which many archaeologists (including Pettigrew) use, Toepel (1985:99) plotted stem configuration (derived from maximum basal width $\left(\mathrm{W}_{\mathrm{b}}\right)$ minus neck width $\left(\mathrm{W}_{\mathrm{n}}\right)$ ) against frequency. The resulting graph (p. 99) is a bell-shaped curve clustered tightly "on either side of the straight stem configuration $\left(\right.$ where $\mathrm{W}_{\mathrm{b}}-\mathrm{W}_{\mathrm{n}}=0$ )" (p. 98). Therefore, she concludes that stem configuration is not significant for these narrow-necked, cornernotched points. Further, Toepel (1985:101) also reports extensive damage to barbs and stems, precluding finer differentiation based on barb or stem configuration.

Type 3 (NN3), (Basal-notched): "basal-notched, narrow-necked" (p. 102); $\mathrm{W}_{\mathrm{b}} / \mathrm{W}_{\mathrm{m}}<0.20$. (Figure 31) 
Heynderickx: $\mathrm{n}=10$. Nine points are ccs, and one is obsidian.

Three are complete. Only one shows slight serration.

Ibach: $\mathrm{n}=0$.

This point type definition posed sorting problems for my collections. Toepel (1985:102) notes that the type definition for Type NN3 in fact merely defines a contracting stem. As indicated in the discussion of Type NN2, basal width/maximum width ratios between 0.20 and 0.90 include both contracting and expanding stems for these points. Ratios less than 0.20 , she found, pertain to only contracting stems. Although Type NN3 is supposed to define basal-notched points, in my Heynderickx sample, for example, only one (Specimen 85-18.69.19) stands out visually as basally notched. The other nine include a range of corner-notched or shouldered points with contracting stems.

Narrow-necked, unidentifiable: not typable due to damage. (Figure 32). Heynderickx: $\mathrm{n}=9$. Five are ccs; four are obsidian. Four (44\%) are slightly serrated. All have sustained stem damage, and five also have barb breakage.

Ibach: $\mathrm{n}=2$. Both points are obsidian. Neither is serrated.

Broad-necked Points. Points with neck width greater than $7 \mathrm{~mm}$. They are further divided into moderate broad-necked and heavy broad-necked series based on neck width.

Moderate Broad-necked Points. Neck width greater than $7 \mathrm{~mm}$ but equal to or less than $9 \mathrm{~mm}$. Types are based on style of notching and stem configuration: side-notched, corner-notched with expanding stem, and corner-notched with contracting stem. 


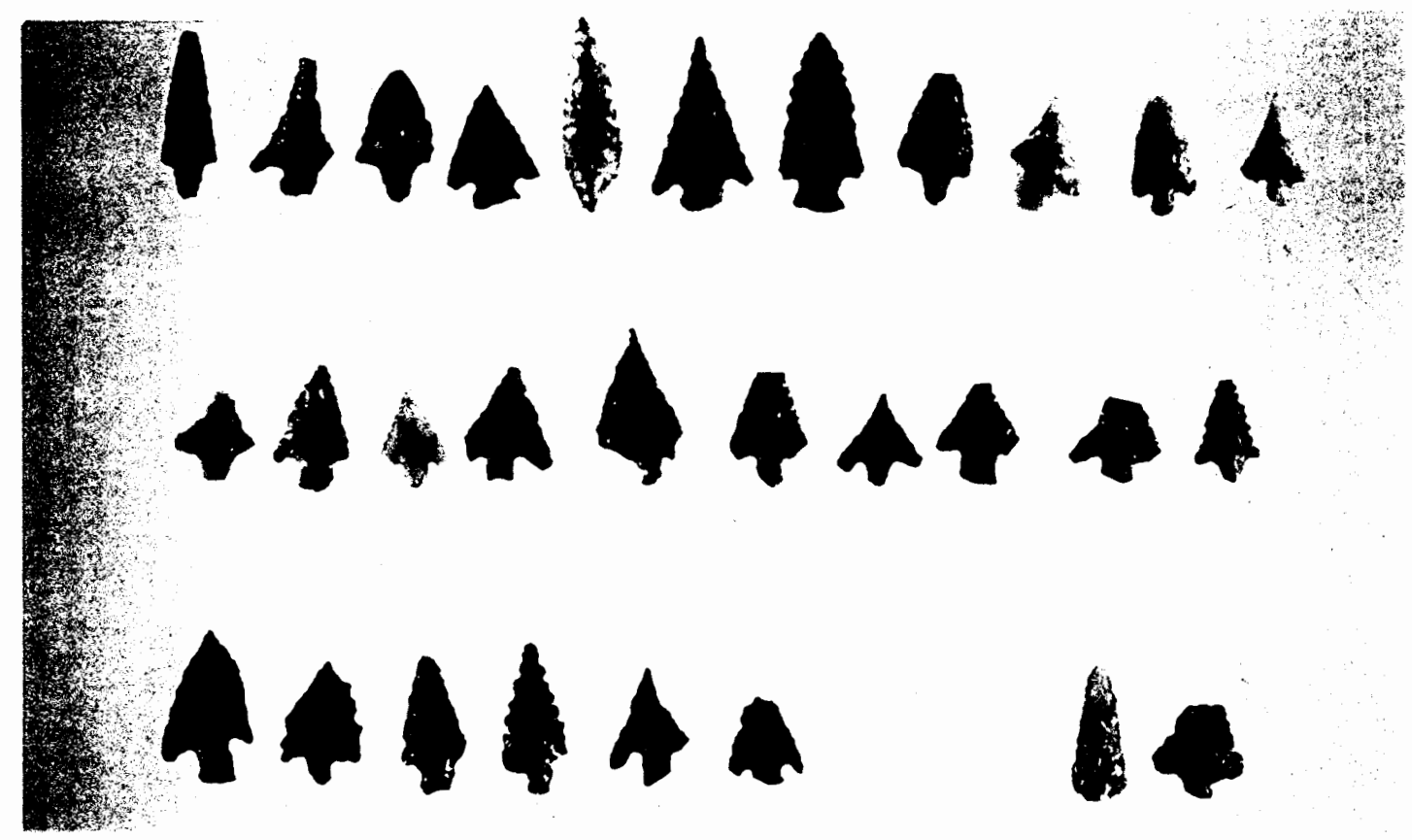

Figure 30. Heynderickx and Ibach projectile points typed as Toepel Type NN2. Heynderickx (Row 1: 66.28, 66.30, 66.33, 66.34, 67.20, 66.21, $66.41,69.2,69.4,69.5,69.6$. Row 2: 69.7, 69.8, 69.16, 69.17, 69.18, $69.20,69.31,69.32,69.33,69.35$. Row 3: $69.36,69.39,69.42,69.44$, 69.45, 69.46. 66.31 not photographed.) Ibach (Row 3, right: 1.97, 1.99).

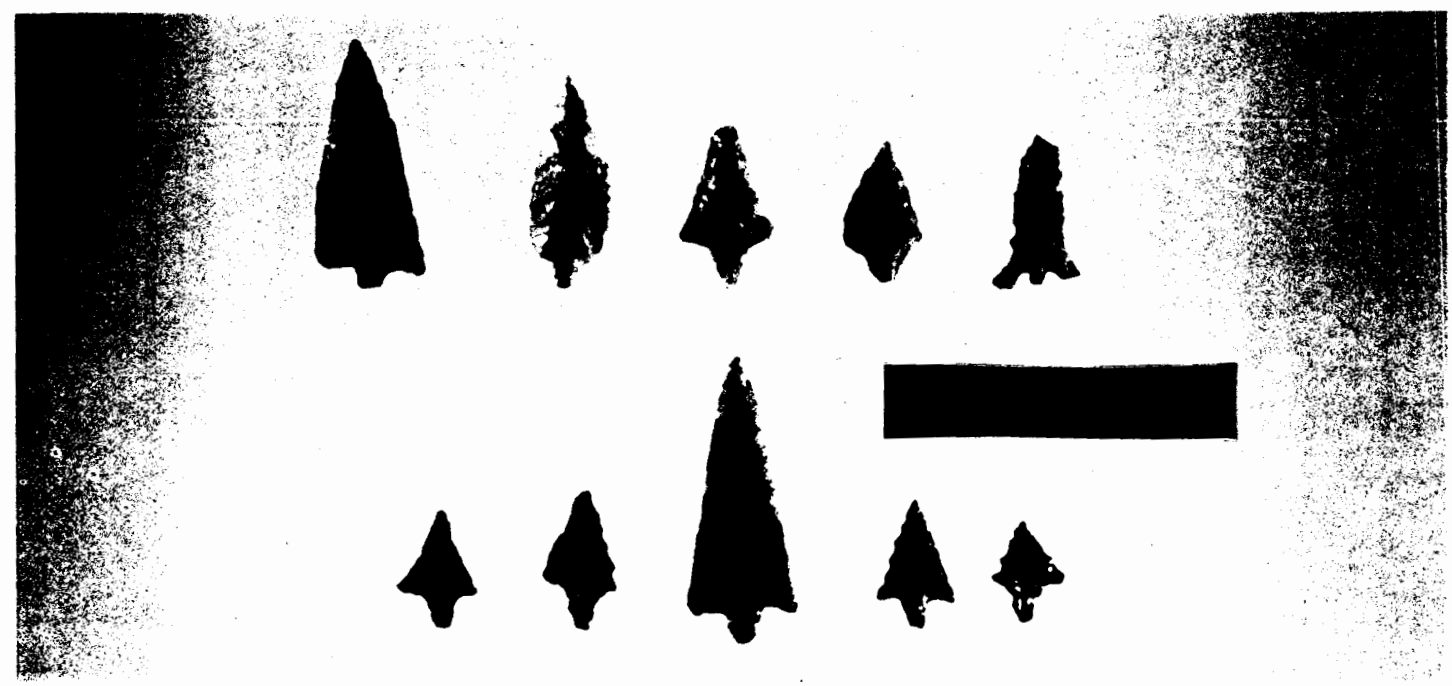

Figure 31. Heynderickx projectile points typed as Toepel Type NN3. (Row 1: $67.5,67.22,69.1,69.3,69.19$. Row 2: 69.21, 69.26, 69.28, 69.30, 69.40.) Scale same as Figure 30. 
Type 1 (MB1), (Side-notched): "thick, triangular side-notched" (p. 106); $\mathrm{W}_{\mathrm{b}} / \mathrm{W}_{\mathrm{m}}>0.90, \mathrm{~T}>3 \mathrm{~mm}$. (Figure 33)

Heynderickx: $\mathrm{n}=0$.

Ibach: $\mathrm{n}=1$. The only specimen is obsidian, unserrated and not complete.

Toepel (1985:216) found only 2 large side-notched points with neck widths of 8.7 and $10.2 \mathrm{~mm}$ and thicknesses of 5 and $4.3 \mathrm{~mm}$, respectively. Due to the small sample size and the rarity of large side-notched points in the Willamette Valley, she places both points in the Type MB1 category, with further adjustments or divisions to be made later with a larger sample population. Because side-notched points have wider necks than other broad-necked points relative to their size, the neck width used to classify these points is wider, too, as Toepel provides for in her key. Toepel uses thickness to differentiate between NN1 and MB1 types. I have taken the liberty of splitting the MB1 and HB1 types based on the obvious size difference in points in the Heynderickx and Ibach collections. The Ibach specimen has a neck width of $10.8 \mathrm{~mm}$ and is $3.9 \mathrm{~mm}$ thick. It fits in with Toepel's sample. The four points I have classified as HBI (next section) have appreciably wider neck widths and greater thicknesses.

Type 2 (MB2), (Corner-notched, Expanding Stem): "corner-notched with expanding stem" (p. 107); $\mathrm{W}_{\mathrm{b}} / \mathrm{W}_{\mathrm{m}}<0.90, \mathrm{~W}_{\mathrm{b}}-\mathrm{W}_{\mathrm{m}}<0 \quad$ (Figure 33) Heynderickx: $\mathrm{n}=4$. All four points are ccs. One is serrated. Only one is complete. 


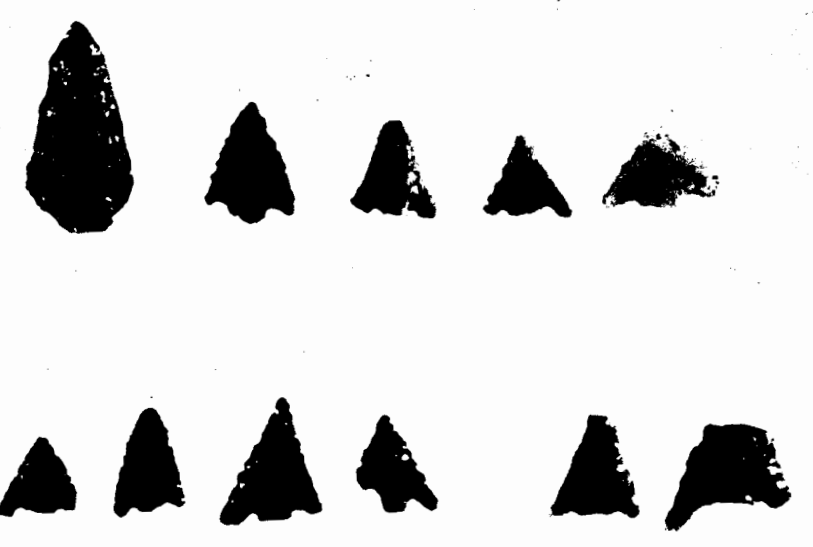

Figure 32. Heynderickx and Ibach projectile points typed as Toepel Type NN, unidentified. Heynderickx (Row 1: 67.39, 66.32, 69.9, 69.11, 69.12. Row 2: 69.27, 69.34, 69.37, 69.41). Ibach (Row 2, right: $1.125,1.133$ ).
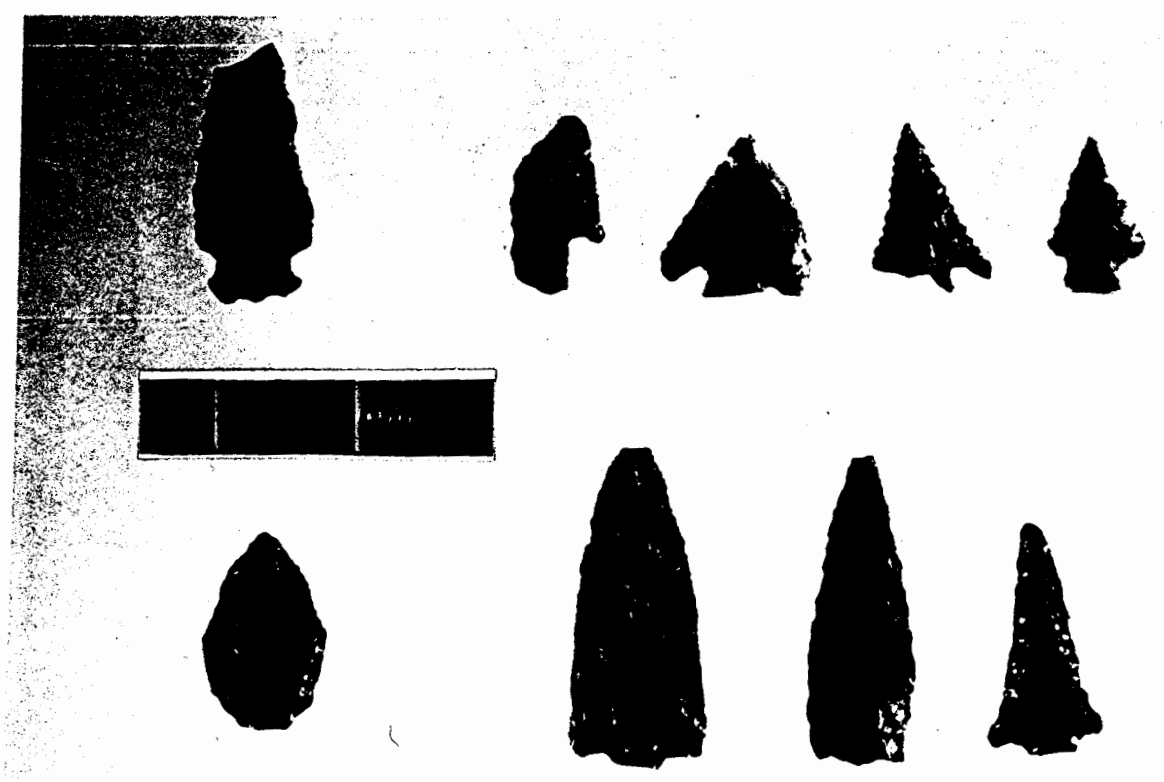

Figure 33. Heynderickx and Ibach projectile points typed as Toepel Types MB1, MB2 and MB, unidentified. Heynderickx (Row 1 right, MB2: 66.21, 69.22, 69.24, 69.29. Row 2 right, MB: 66.8, 67.17, 67.40). Ibach (Row 1 left, MB1: 1.73. Row 2 left, MB: 1.37). Scale same as Figure 32. 
Ibach: $\mathrm{n}=0$.

Five Type MB2 points were found at the Flanagan site.

Type 3 (MB3), (Corner-notched, Contracting Stem): "corner-notched with constracting stem" (p. 108); $\mathrm{W}_{\mathrm{b}} / \mathrm{W}_{\mathrm{m}}<0.90, \mathrm{~Wb}-\mathrm{Wn}<0$. (Figure 34)

Heynderickx: $\mathrm{n}=7$. Six points are ccs; the seventh is obsidian.

None are serrated. Three are complete. Type MB3 accounts for 50\% of the Heynderickx moderate broad-necked points.

Ibach: $\mathrm{n}=3$. This type is also the dominant moderate broad-necked point type in the Ibach collection. Two-thirds are complete. None are serrated. Two are obsidian, and one is ccs.

Moderate Broad-necked, unidentifiable: not able to be typed due primaily to stem damage. (Figure 33).

Heynderickx: $\mathrm{n}=3$. Two are ccs; one is obsidian. None is serrated.

Ibach: $\mathrm{n}=1$. This ccs point has an impact fracture where the stem joined the blade. The distal one-half is slightly serrated.

Toepel found four points of this type.

Heavy Broad-necked Points. Neck width greater than $9 \mathrm{~mm}$. Types are based on style of notching and stem configuration: side-notched, corner-notched with expanding stem, and corner-notched with contracting stem.

Type 1 (HB1), (Side-notched): "thick, triangular side-notched" (p.106).

(Figure 35)

Heynderickx: $\mathrm{n}=2$. One is obsidian with the very tip broken off, and the other is a complete ces point. Neither one is serrated. 


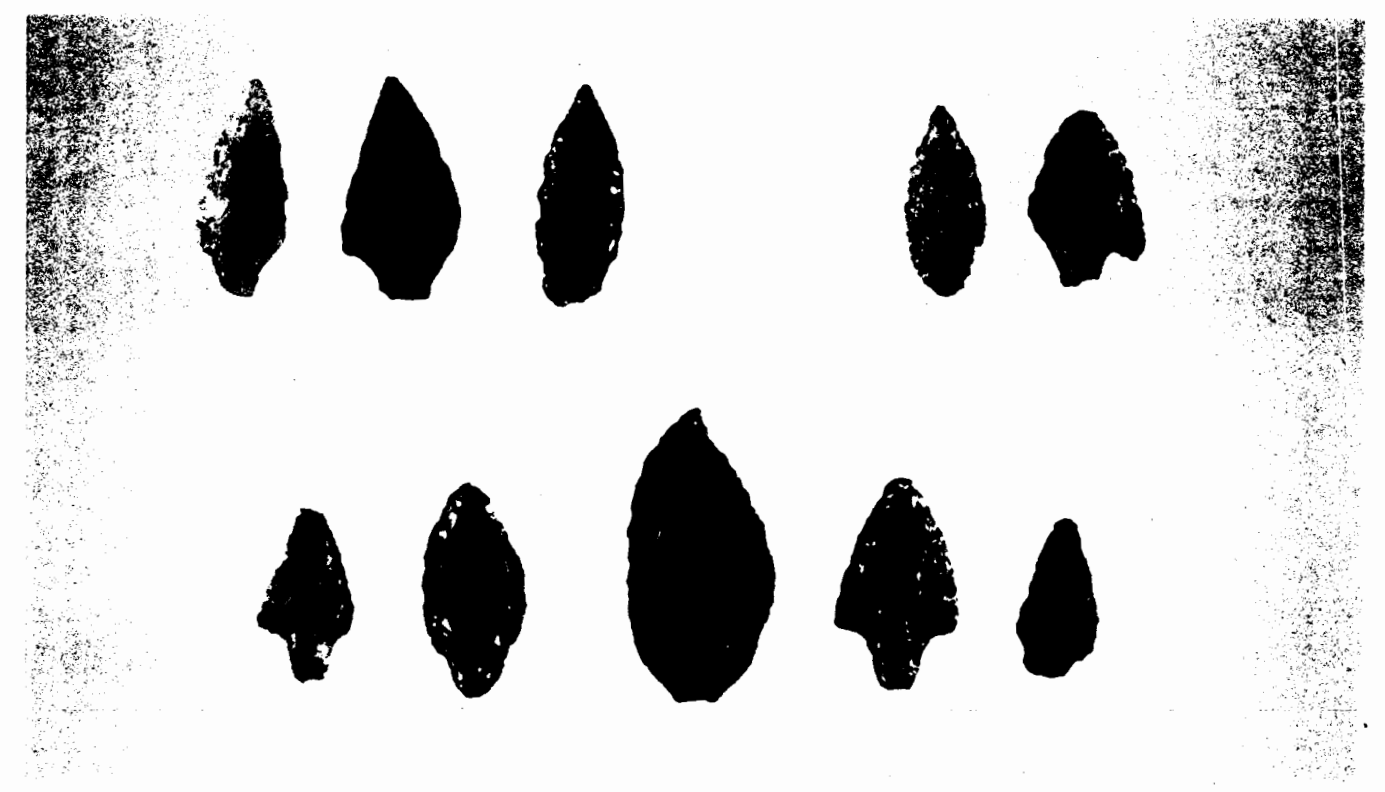

Figure 34. Ibach and Heynderickx projectile points typed as Toepel Type MB3. Ibach (Row 1, left: 1.82, 1.91, 1.120). Heynderickx (Row 1, right: $66.7,66.10$. Row 2: $66.11,66.20,66.22,67.38,69.23$ ).
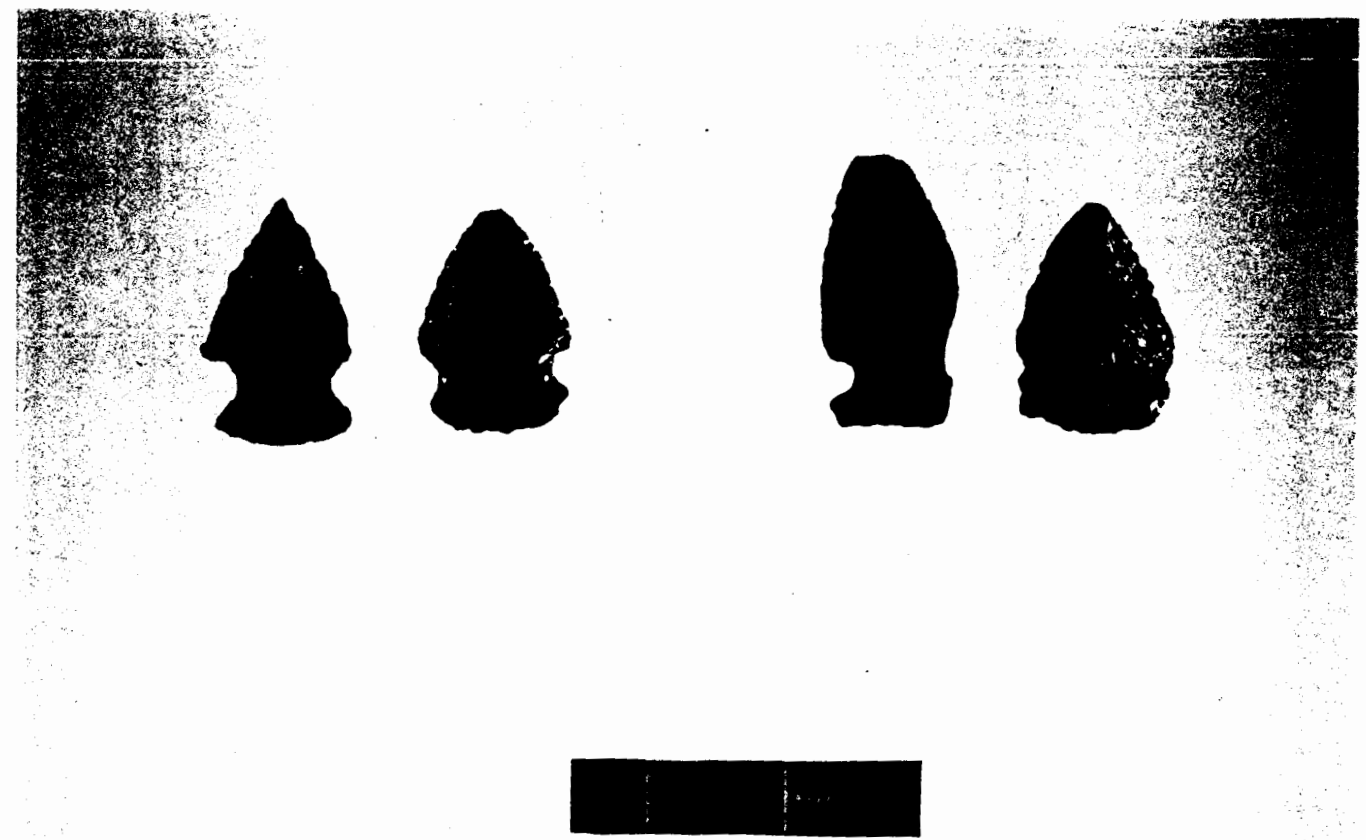

Figure 35. Heynderickx and Ibach projectile points typed as Toepel Type HB1. Heynderickx (Left: 66.3, 67.37). Ibach (Right: 1.5, 1.59). 
Ibach: $\mathbf{n}=2$. Both are ccs. One has deep, pronounced side notches, while the other has very shallow ones. Both have sustained damage.

Toepel puts the Flanagan site sample of two large side-notched points into the MB1 type category. Whereas one Ibach specimen fits in with her sample, the four I have typed as HB1 are much larger, with the neck width range $13.4-20.7 \mathrm{~mm}$ and the thickness range $5.4-8.2$ mm.

Type 2 (HB2), (Corner-notched, Expanding Stem): "corner-notched with expanding stem" (p. 108); $\mathrm{W}_{\mathrm{b}} / \mathrm{W}_{\mathrm{m}}<0.90, \mathrm{~W}_{\mathrm{b}}-\mathrm{W}_{\mathrm{n}}>0$. (Figures 36 and 37)

Heynderickx: $\mathrm{n}=13$. Eleven of these are ccs, another is obsidian, and one is basalt. A sizable proportion (5 or $38 \%$ ) are complete. Only one is slightly serrated. Specimen $85-18.68 .4$ stands out in this group due to its size. It is the same point discussed under Pettigrew's Type 1. Types HB2 and HB3 together make up almost one-fourth of all the Heynderickx points.

Ibach: $\mathrm{n}=11$. Nine are ccs; two are obsidian. Three are complete. None are serrated. Type HB2 is the most numerous heavy broadnecked type in this collection and is second only to the heavy stemless Type HS3.

Although Toepel describes this type as corner-notched, she also notes (1985:107) that some points visually classified as side-notched points slip into the HB2 basal width/maximum width definition. Specimen 


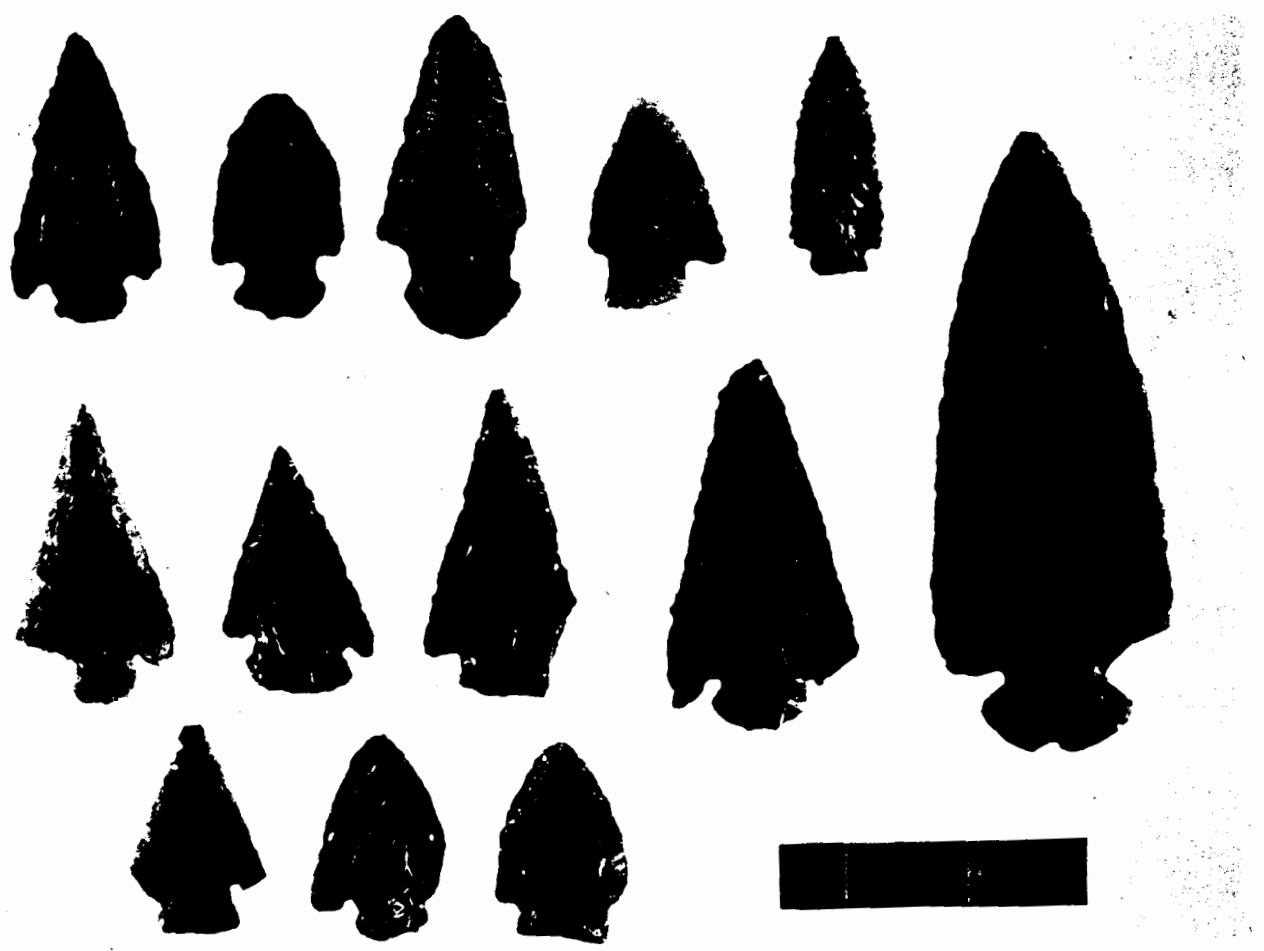

Figure 36. Heynderickx projectile points typed as Toepel Type HB2. (Row 1: $66.15,66.18,66.35,67.9,67.14$. Row 2: 67.23, 67.15, 67.30, 68.1, 68.4. Row 3: $67.13,67.6,67.32$.)

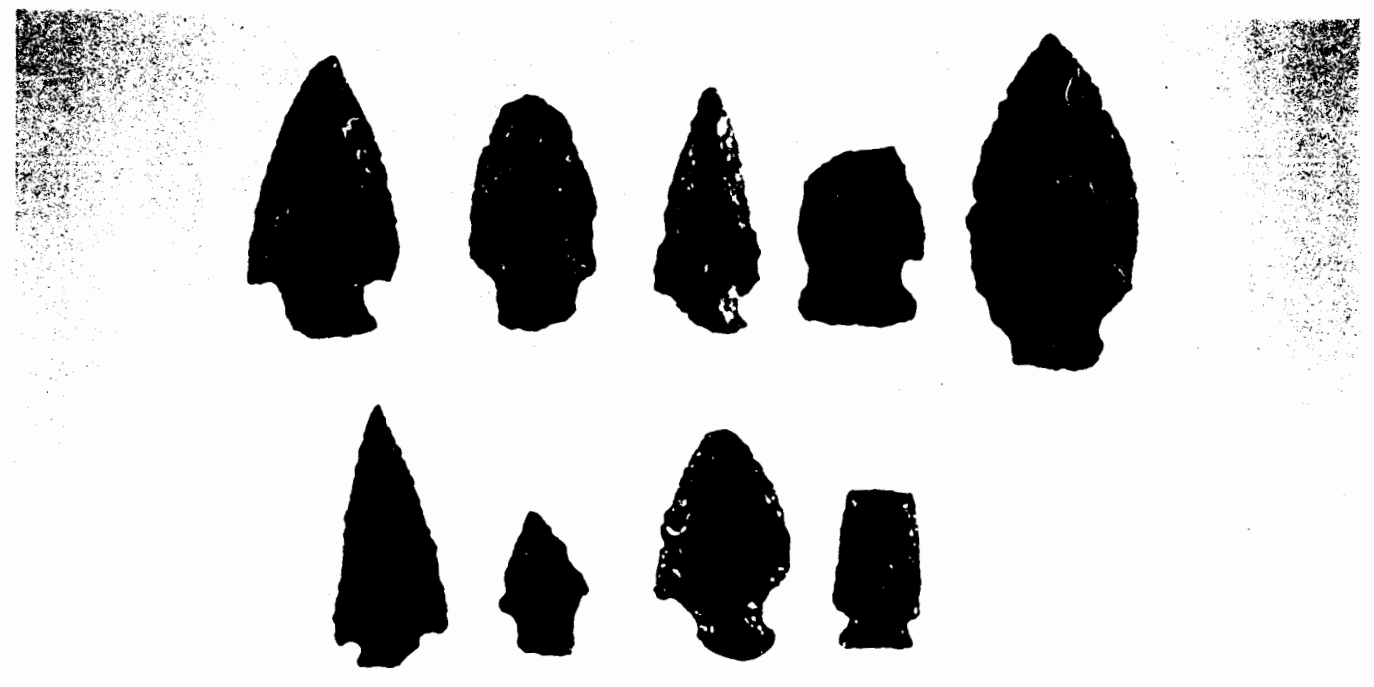

Figure 37. Ibach projectile points typed as Toepel Type HB2. (Row 1: 1.2, $1.4,1.18,1.29,1.30$. Row 2: $1.47,1.83,1.117,1.121$. $1.58,1.62$ not photographed.) Scale same as Figure 36. 
85-18.66.35, a basalt point, from the Heynderickx collection and three points (Specimens 83-1.29, 83-1.62, 83-1.121) from the Ibach collection are examples. Toepel notes HB2 is the commonest broadnecked point type at the Flanagan site (p. 108).

Type 3 (HB3), (Corner-notched, Contracting Stem): "corner-notched with contracting stem" (p. 108-109); $\mathrm{W}_{\mathrm{b}} / \mathrm{W}_{\mathrm{m}}<0.90 ; \mathrm{W}_{\mathrm{b}}-\mathrm{W}_{\mathrm{n}}<0$. (Figures 38 and 39)

Heynderickx: $\mathrm{n}=15$. Eleven are ccs, 3 are obsidian, and one is basalt. None show serrations. Only three are complete. As noted earlier under Pettigrew's Type 5, Specimen 85-18.67.33 resembles a classic Windust point, which is not usually described as cornernotched.

Ibach: $\mathrm{n}=10$. Five points are ccs, four are obsidian, and one is basalt. None is serrated and all have sufered some breakage. This type was one of the least common of all the Flanagan types, yet for the Heynderickx points it is the second largest group and for the Ibach points it is almost tied for second with Type HB2.

Heavy Broad-necked, unidentifiable: not typable due to stem breakage.

(Figure 40).

Heynderickx: $\mathrm{n}=1$. This single specimen is made of obsidian and is not serrated. The tip and most of the stem are missing.

Ibach: $\mathrm{n}=4$. Three points are obsidian; the fourth is ccs. None is serrated. 


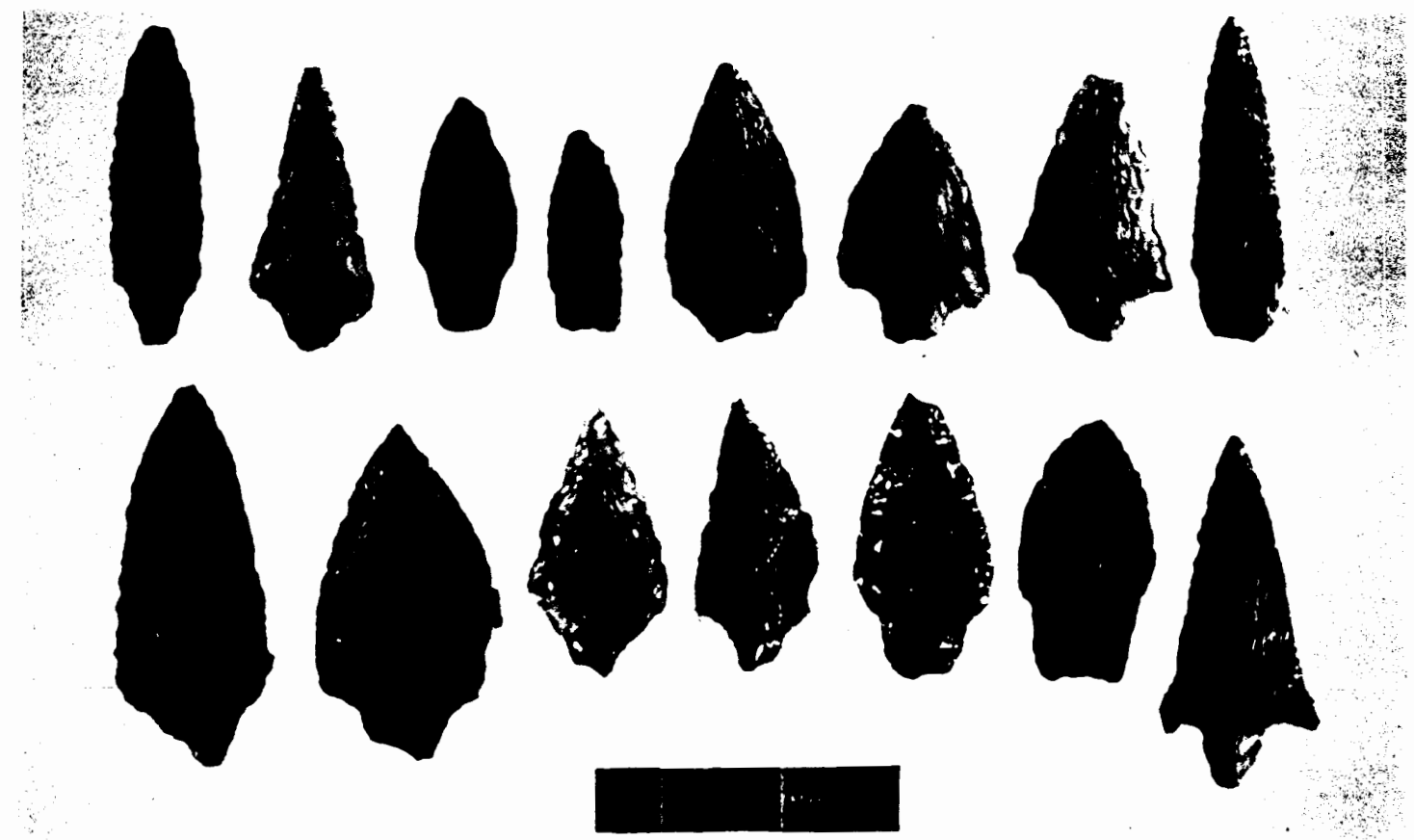

Figure 38. Heynderickx projectile points typed as Toepel Type HB3. (Row 1: $66.9,66.13,66.19,66.24,66.25,67.2,67.3,67.4$. Row 2: 67.7, $67.10,67.19,67.26,67.28,67.33,68.2$.)
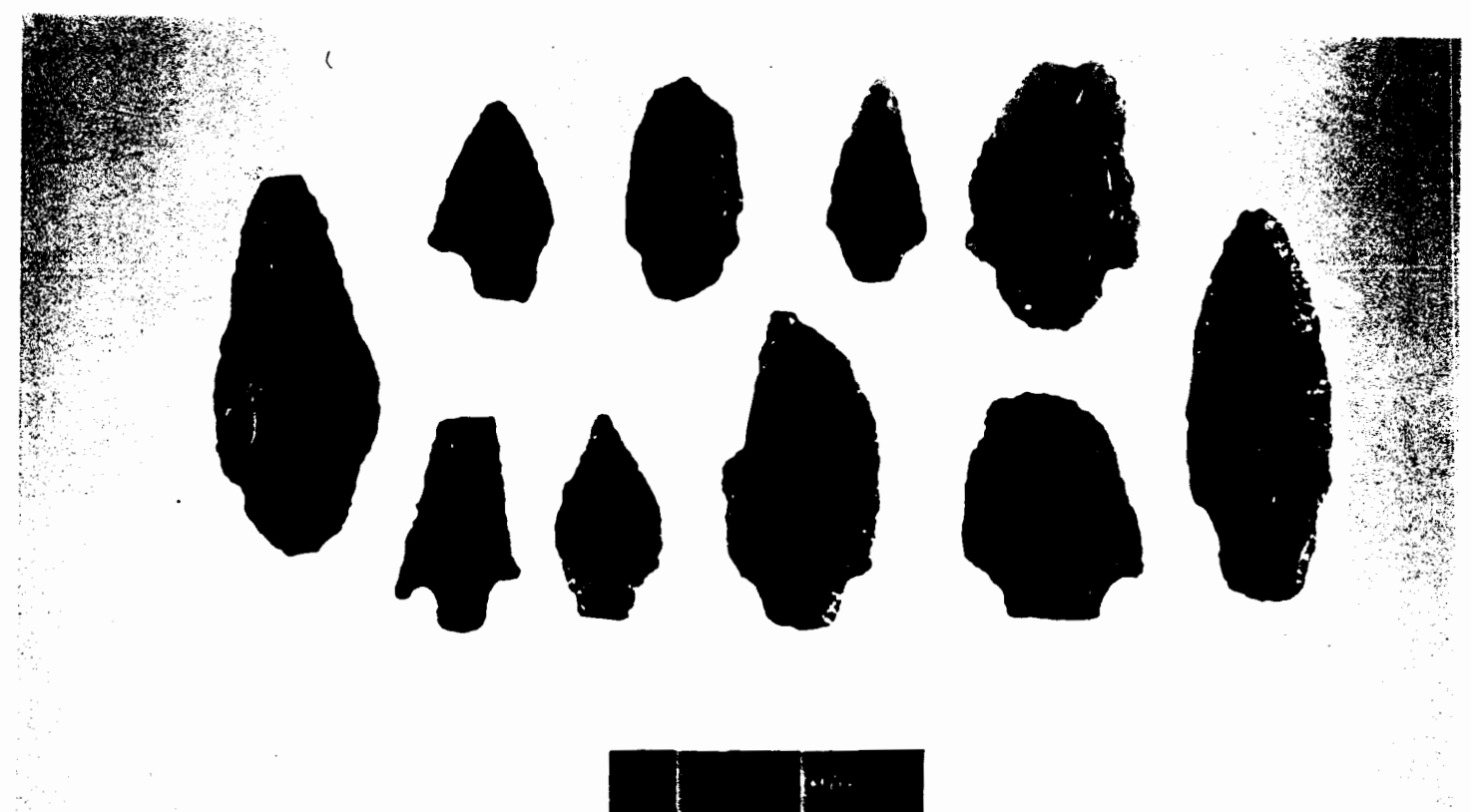

Figure 39. Ibach projectile points typed as Toepel Type HB3. (Row 1:

$1.45,1.50,1.60,1.65$. Row $2: 1.23,1.66,1.84,1.112,1.113,1.124$. 

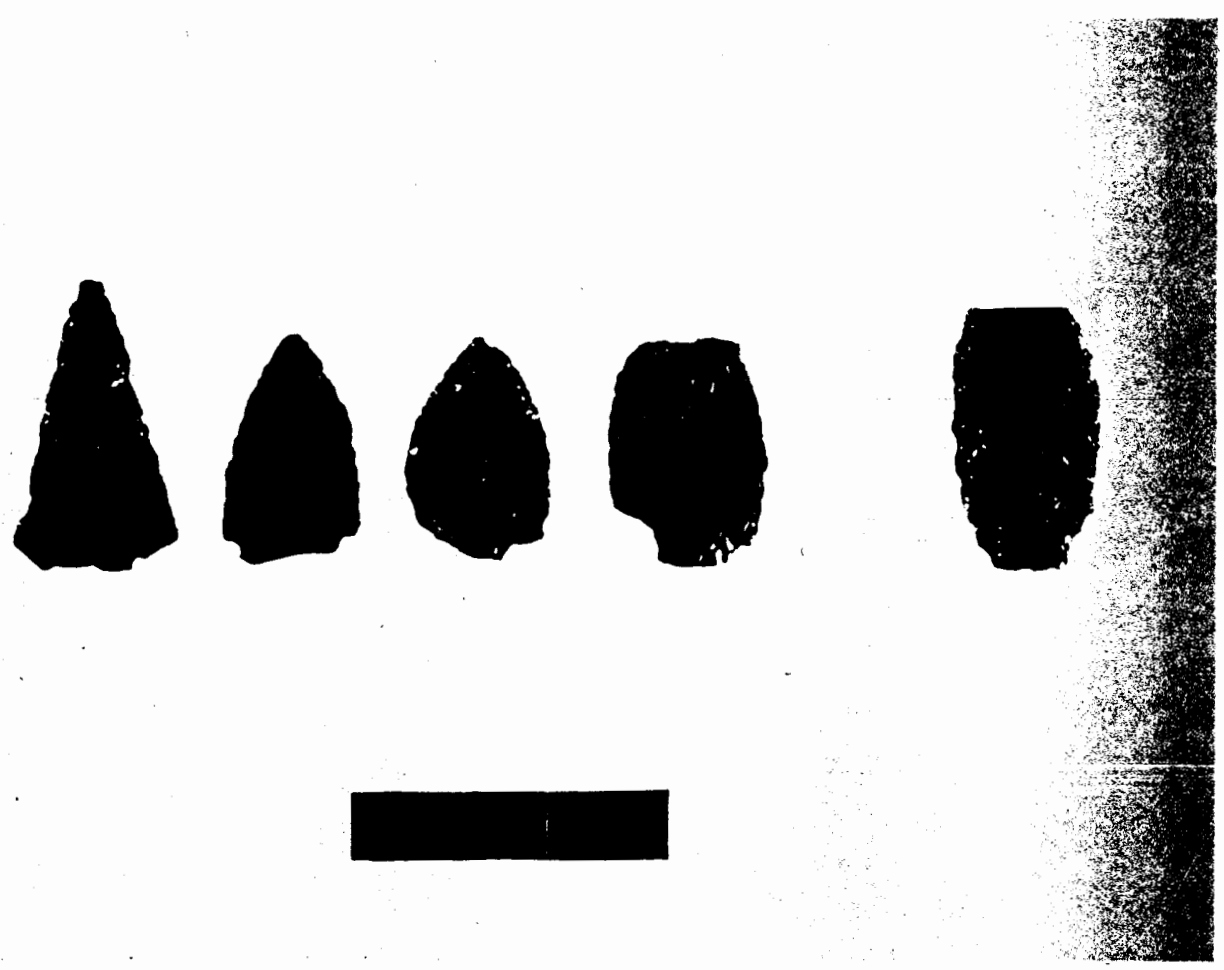

Figure 40. Ibach and Heynderickx projectile points typed as Toepel Type HB, unidentified. Ibach (Left: $1.114,1.71,1.104,1.28)$. Heynderickx (Right: 67.27). 
COMMENTS REGARDING USING TOEPEL'S AND PETTIGREW'S TYPOLOGIES

This chapter presented the results of applying the different type definitions created by Pettigrew and Toepel to the Heynderickx and Ibach projectile point collections. The process of typing the points revealed strengths and weakness and idiosyncrasies in each typology and what follows is a recapitulation of some of these observations I found most significant.

A major factor preventing successful type classification -- besides operationalization of type attributes -- is breakage affecting point parts incorporated in attributes. For example, description of stem shape may be prevented by stem breakage, and the description of bladestem juncture may not be possible due to barb breakage. In fact, stem and barb damage accounted for many unidentifiable narrow-necked points. I noted with interest during the classification process that the most stable part of the point was not the stem or haft as a whole but specifically the neck area for stemmed points and the blade-haft juncture on stemless points. This stability of the neck area on stemmed points and the fact that both Toepel and Pettigrew used a quantitative value for the neck width attribute made the initial sorting of these points easy.

The process of assigning each projectile point to a specific type is fairly easy using the metrically based, clearly formulated criteria set out in the Flanagan site typology. The keyed typology is logical and convenient to use. However, there is lack of "internal cohesion" in defining Narrow-necked Basal-notched types (NN3) as basally-notched and not merely with contracting stems. The other unclear factor is where exactly to measure the basal width on a lanceolate or leaf-shaped point. Nevertheless, typing stemless points in this typology is uncomplicated, especially comnpared with the confusing discriminating characteristics of the Portland Basin stemless point type definitions. I often depended on photographs of Portland 
Basin point types to help make typing decisions. On the other hand, the Portland Basin sites did not provide the variety in sizes of stemless points represented in the Willamette Valley. Although Toepel's method was easier to apply, the results were not as clear, perhaps, as Pettigrew's. His seriational analysis nicely winnows out temporally-inert point types and leaves the temporally diagnostic types. This may be due to his large sample sizes, the attributes he selected, or the shorter, more distinct occupation periods of many of his sites. At this point, the Tualatin Valley projectile point collections have been typed under two typologies. The next chapter compares how the spectrum of Ibach and Heynderickx point types compares with that found in the Portland Basin sites, Hager's Grove, and the Flanagan site. 


\section{CHAPTER V}

\section{DISCUSSION}

The preceding chapter detailed the process and results of typing projectile points in the Heynderickx and Ibach collections using two different typologies -- one established by Pettigrew for Portland Basin sites and used also at Hager's Grove, the other created by Toepel for the Willamette Valley Flanagan site. At this point, a comparative analysis can now be made between the Tualatin Valley projectile points and those analyzed by Pettigrew and Toepel.

I begin with a review of Pettigrew's seriation of the Portland Basin sites and suggest how the Ibach and Heynderickx sites might fit into that chronology. I then shift geographically from the Portland Basin to the Willamette Valley to compare -- still using Pettigrew's typology -- the projectile point types in the Tualatin Valley collections with those excavated by Pettigrew at Hager's Grove. Next I look at the Flanagan site chronological ordering of projectile point types devised by Toepel and compare the Ibach and Heynderickx point types to those data. Lastly, I summarize what can be said about dating the Tualatin Valley points and evaluate the success of using seriational analysis to determine how long ago the Tualatin Valley sites were occupied. 


\section{TUALATIN VALLEY SITES IN THE PORTLAND BASIN CHRONOLOGY}

\section{Pettigrew's Seriation Process}

Pettigrew (1977) excavated 7 sites on Sauvie Island and on the mainland across Multnomah Channel from Sauvie Island in his pioneer effort to establish a chronological sequence for the Portland Basin. He focused his attention on the patterning of time-sensitive artifacts, especially projectile point types. My analysis considers only his projectile point and radiocarbon data.

Pettigrew begins with the premise that each site is a single component, and lumps together all projectile points. ${ }^{10}$ To ensure adequate sample sizes, he initially analyzed both excavated and (privately) collected projectile points from each site and then later compared those results with an order based on the smaller excavated samples by themselves.

Pettigrew (1977:282-299) examines the point types from several viewpoints: 1) using Robinson's Index of Similarity to compute closeness and distance of sites based on projectile type frequencies, 2) direct seriation of the sites using all point types, and 3) grouping together projectile point types that shared similar chronological patterning and basing site seriation on only those temporally diagnostic type groups. Out of these permutations consistently came the same overall chronological grouping of the 7 sites into 3 general time periods.

To test the compatibility of the relative chronological ordering of sites through seriation against an absolute dating method, he ranks the sites in chronological order using the radiocarbon dates for each site. The same three groupings hold firm. The C-14 dates

\footnotetext{
${ }^{10}$ Although this assumption serves as a working hypothesis, he does note that if one or more sites might indeed represent either a long period of occupation or more than one component, that site will present a blurry constellation of types in comparison to the other sites. One site, in fact, whose order in the seriation varied slightly with different analyses, did have a thousand year time span according to the C-14 dates.
} 
anchored the top level of the earliest site (35 MU 9) at circa 120 B.C. and the latest site at circa A.D. 1850 , a 2000 -year span. ${ }^{11}$

Finally, Pettigrew examines changes over time in neck widths. He had plotted neck width relative frequencies for all stemmed points at each site. In his analysis, he suggests that neck width frequencies in general decrease concomittantly with a site's decrease in age. That is, the earliest sites have more points with wider necks than more recent sites. Pettigrew points out that the earliest Portland Basin site, Merrybell, seems to be bimodal with neck width modes at $5 \mathrm{~mm}$ and $10 \mathrm{~mm}$ (Pettigrew 1977:38), while the later sites show a unimodality of $5 \mathrm{~mm}$ for neck width frequencies.

\section{Portland Basin Projectile Point Type Patterns}

Based on the seriation of projectile point types buttressed by radiocarbon dates, Pettigrew (1977:295-297) reasons that :

1) Types $6 \mathrm{~b}, 6 \mathrm{c}, 6 \mathrm{~d}, 8,10,11$ and 14 do not show chronological significance.

2) Types 1 through 6a are typical of sites earlier than A.D. 200 and drop sharply in frequency after A.D. 1250.

3) Types 7 and 9 are equally popular early but by A.D. 1250 Type 9 overtakes Type 7 in frequency.

4) Types 12, 13, and 15 occur in significant number after A.D. 1250, although only Type 12 appears at all before that time.

5) Type 16 drops in and out of the sequence in a sharply delimited time span around A.D. 700 .

\footnotetext{
${ }^{11}$ Three C-14 samples from Stratum 4 at 35 MU 9 supplied dates circa 900 B.C., but as just a few points were excavated from this stratum, Pettigrew states that the small sample size precludes linking projectile point types with that early date.
} 
Tualatin Valley Sites in the Portland Basin Chronology

To see how the Ibach and Heynderickx projectile point types seriate with the Portland Basin sites, I evaluate three site comparisons based on 1) all projectile point type percentages, 2) diagnostic-only projectile point type groups and 3) neck width frequencies. Table XV, adapted from Pettigrew (1977:292), displays relative frequencies for projectile point types for each site. Only excavated points supply data for the Portland Basin sites. I computed relative frequencies for the Ibach and Heynderickx points after eliminating the unidentifiable points.

The Tualatin Valley sites consistently fill positions in the seriation earlier than the earliest Portland Basin site.

\section{TABLE XV}

PETTIGREW TYPES: PROJECTILE POINT PERCENTAGES FOR EXCAVATED PORTLAND BASIN POINTS AND COLLECTED TUALATIN VALLEY POINTS

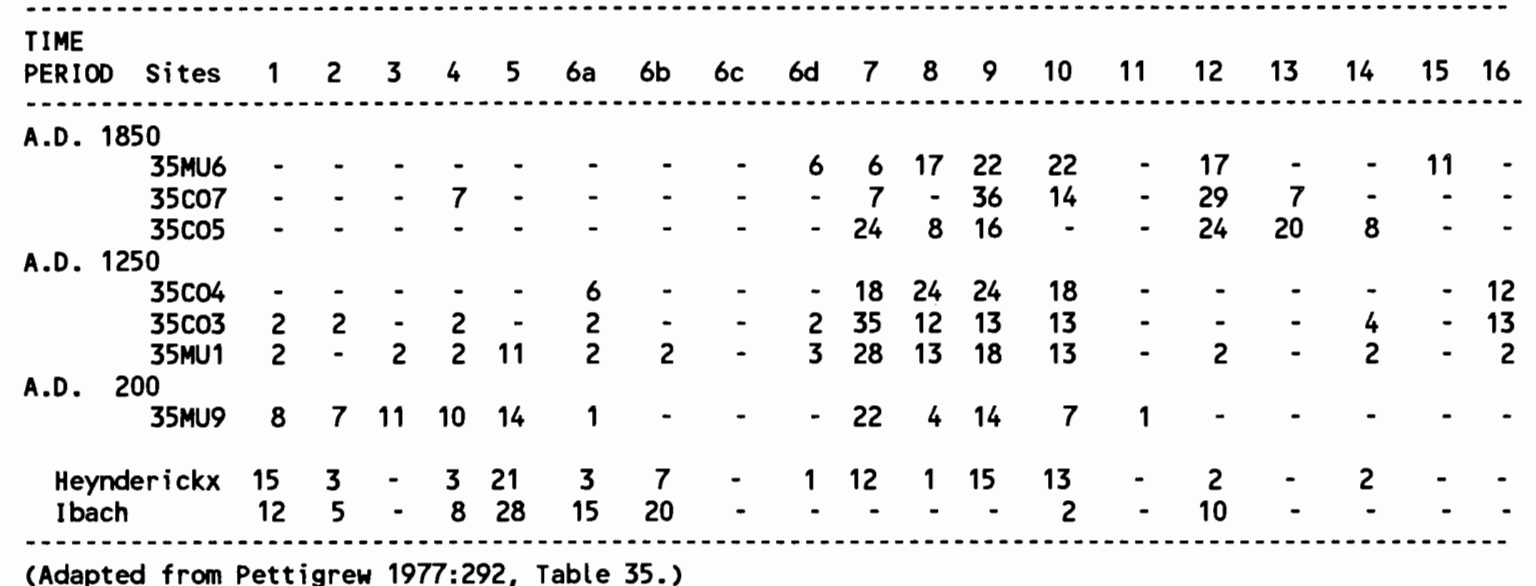

(Adapted from Pettigrew 1977:292, Table 35.)

The Ibach point types clearly stand out as early in this sequence. Whereas $53 \%$ are the broad-necked Types $1-5$, and an additional $15 \%$ are Type $6 a$, only $2 \%$ are narrow-necked. At first glance, Type 12 presents a slight anomaly. However, as discussed in the previous chapter and again in the next section, these Type 12 points appear to be a larger 
morphological counterpart of the smaller Portland Basin Type 12, and they may be earlier. For now, I am ignoring Type 12 in fitting the Ibach points into the Portland Basin seriation. The Heynderickx collection is not as easily placed as is the Ibach. Whether it should be positioned earlier, contemporary with, or later than 35 MU 9 is debatable. Again disregarding Type 12, I have placed it slightly earlier for these reasons: 1) Types 1 and 5 frequencies fit into a nicely decreasing order from early to late, and 2) the overall percentage of narrow-necked types is lower (41\%) than those for 35MU9 (47\%).

Of interest is the overall low frequency of Type $6 \mathrm{~b}$ in the Portland Basin sites and its stronger showing in the Tualatin Valley collections. Whether this has chronological or geographical significance is not known at this point.

Table XVI, adapted from Pettigrew (1977:288), presents another view of the sites in seriated order. Here I compare only temporally diagnostic type groups for both excavated and privately collected points in the Portland Basin with the same groupings from the Tualatin Valley sites. (For the two valley sites, Type 12 again does not figure into their chronological placement, for the reason discussed above.) Clearly the Ibach collection occupies the earliest position in the seriation. Eighty-nine percent of diagnostic types are the early Type 1 through 6a group; none are narrow-necked.

The Heynderickx diagnostic point types indicate a position between Ibach and 35MU9 based on the Type 1 through 6 a group relative frequency of $63 \%$, which is between $89 \%$ for Ibach and 59\% for 35MU9. The greater frequency of Type 9 relative to Type 7 , however, does not fit Pettigrew's analysis that Type 9 frequencies exceed those for Type 7 only after A.D. 1250. It is possible that that pattern does not hold for the Tualatin Valley. On the other hand, it should be noted that these narrow-necked points are susceptible to stem and barb breakage. If the eight damaged and untypable specimens in the Heynderickx collection 
(which I could narrow down in identity to either Type 7 or 9) were indeed Type 7 , then the ratio of diagnostic Types 7 and 9 would be consistent with the placement of the Heynderickx collection before 35MU9. For now, the aberration is noted.

\section{TABLE XVI}

PETTIGREW TYPES: PROJECTILE POINT PERCENTAGES, DIAGNOSTIC TYPE GROUPS ONLY, PORTLAND BASIN SITES AND TUALATIN VALLEY SITES

\begin{tabular}{|c|c|c|c|c|c|c|}
\hline \multirow[b]{2}{*}{ Sites } & \multirow[b]{2}{*}{$1-6 a$} & \multicolumn{4}{|c|}{ Types } & \multirow[t]{2}{*}{ Sample Size } \\
\hline & & 7 & 9 & $12,13,15$ & 16 & \\
\hline MU6 & - & 10 & 40 & 50 & - & $\mathrm{n}=10$ \\
\hline $\mathrm{CO5}$ & 3 & 23 & 31 & 44 & - & $\mathrm{n}=101$ \\
\hline $\mathrm{CO} 7$ & 4 & 18 & 40 & 37 & - & $\mathrm{n}=99$ \\
\hline MU1 & 11 & 43 & 43 & 3 & - & $\mathrm{n}=224$ \\
\hline $\mathrm{CO} 4$ & 19 & 41 & 30 & - & 11 & $\mathrm{n}=27$ \\
\hline $\mathrm{CO} 3$ & 14 & 50 & 20 & - & 16 & $\mathrm{n}=94$ \\
\hline MU9 & 59 & 24 & 17 & - & - & $\mathrm{n}=223$ \\
\hline Hend. & 63 & 15 & 19 & 3 & - & $\mathrm{n}=73$ \\
\hline Ibach & 89 & - & - & 11 & - & $\mathrm{n}=37$ \\
\hline
\end{tabular}

(Adapted from Pettigrew 1977:288, Table 34.)

The final comparison between the Portland Basin and Tualatin Valley sites is neck width frequencies. The relative frequencies of neck widths for the Ibach collection are shown in Figure 41. Those for the Heynderickx points are in Figure 42. For comparison, relative neck width frequencies for 35MU9 are in Figure 43.

The graphs show a marked difference in percentages of the wide neck widths in the three sites. The peak modes of $10 \mathrm{~mm}$ and $14 \mathrm{~mm}$ at the Ibach site shift to modes of $5 \mathrm{~mm}$, $8 \mathrm{~mm}$ and $13 \mathrm{~mm}$ at the Heynderickx location. At 35MU9, Pettigrew marks the modes at 5 $\mathrm{mm}$ and $10 \mathrm{~mm}$. The shift to smaller neck widths parallels the chronological sequence based on seriated projectile point types. 


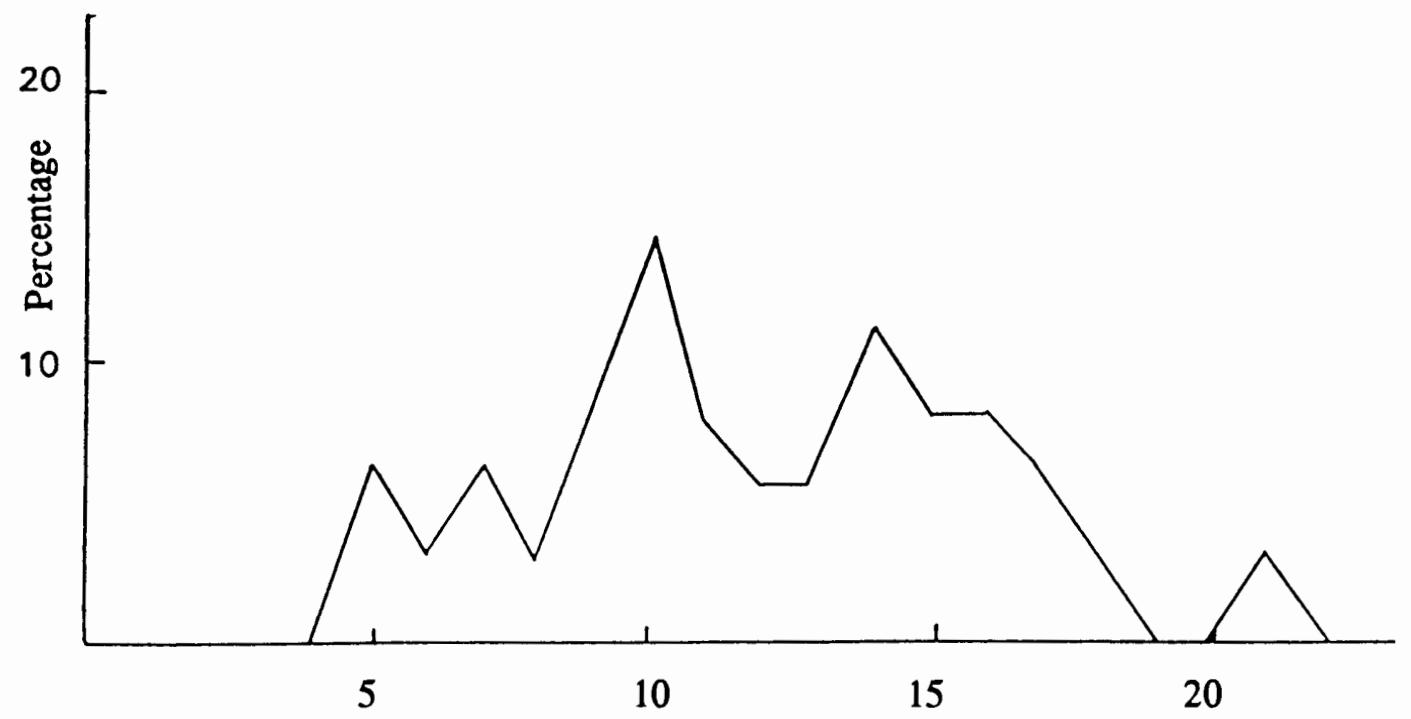

Neck width (mm)

Figure 41. Neck width relative frequencies (\%) for Ibach stemmed points. $\mathrm{n}=36$.

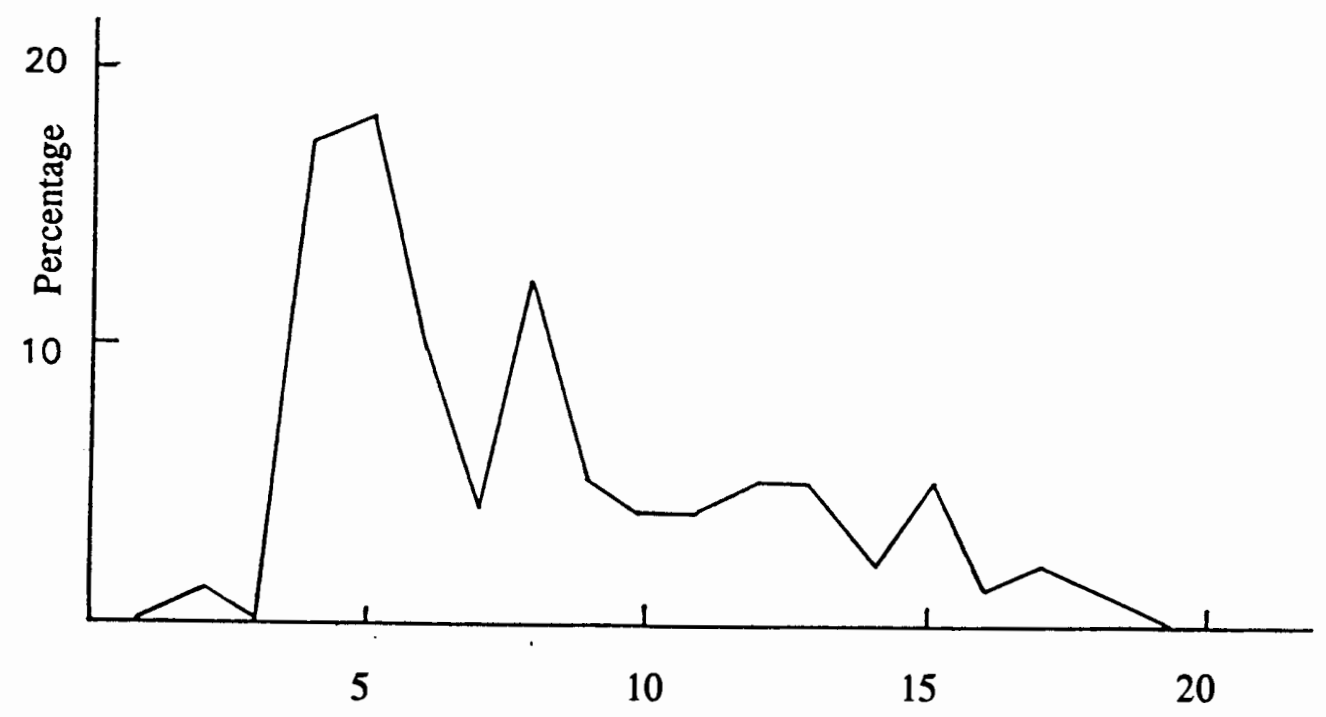

Neck width (mm)

Figure 42. Neck width relative frequencies (\%) for Heynderickx stemmed points. $\mathrm{n}=92$. 


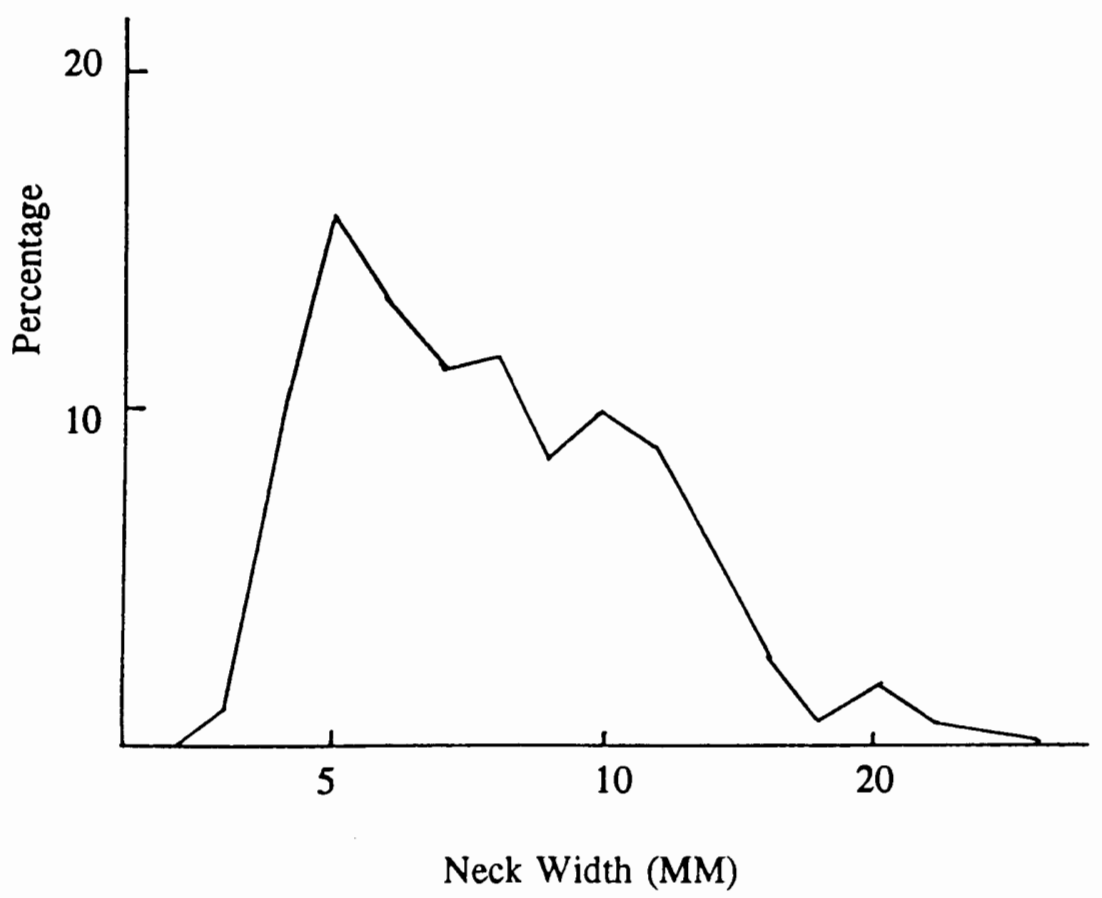

Figure 43. Neck width relative frequencies (\%) for 35MU9, both excavated and borrowed collections. $\mathrm{n}=300$. (Adapted from Pettigrew 1977:198, Figure 15.)

Based on comparison of relative frequency of diagnositic projectile point types from the Tualatin Valley and the Portland Basis sites, I have positioned the Ibach site the earliest of the 9 sites. The Heynderickx site data indicate occupation later than at the Ibach site but earlier than 35MU9. Since the earliest Merrybell level used by Pettigrew is dated at 120 B.C., all that can be said about the Tualatin Valley sites is that occupation there begins earlier than 120 B.C.

\section{TUALATIN VALLEY SITES IN THE HAGER'S GROVE CHRONOLOGY}

At Hager's Grove in Salem, Pettigrew (1980) excavated two sites (35MA7 and 35MA9) which, according to C-14 dates, were occupied episodically over a 3500-year span. This excavation is a prime example of how point typologies resist easy transference from one 
location to another, for when Pettigrew attempted to apply his Portland Basin point type definitions to the Hager's Grove points, he had to adjust definitions to accomodate a somewhat different array of point variations. (I noted these changes in Chapter IV. They are also listed in Pettigrew 1980:87.)

The reason I expanded my analysis to include Hager's Grove points are threefold: 1) to use the refinements Pettigrew made to his original typology to better translate his point descriptions into typing points accurately, 2) to compare point types frequencies found at Hager's Grove with those further north at the Ibach and Heynderickx sites, and 3) to ascertain what chronological information could be linked to specific point types as revealed through stratigraphic information lacking for the Portland Basin sites. I address these points in the following paragraphs.

One of the modifications made by Pettigrew was to split Type 12 into $12 \mathrm{a}$ and $12 \mathrm{~b}$ variants, with Type $12 \mathrm{~b}$ labeled broad-necked (and therefore probably equal to or greater than $7.5 \mathrm{~mm}$, although this is not stated) and Type 12a narrow-necked (less than $7.5 \mathrm{~mm}$ ). Confirmation that Type 12 in the Portland Basin is not the Type 12 I found in the Tualatin Valley collections is found in Pettigrew's statement (1980:63), "Type 12b was not defined on the Lower Columbia River..." All Type 12 points at 35MA7 and 35MA9 are the broadnecked variant, as are all the Type 12 points in the Ibach and Heynderickx collections. Therefore, by placing the Tualatin Valley sites earlier than 35MU9, I supposed correctly that the Type 12 anomalies might be explained by a neck width size difference not yet (in 1977) recognized by Pettigrew. The question then becomes how old is the Type $12 \mathrm{~b}$ point (a triangular-bladed side-notched point). Pettigrew (1980:63) excavated a cluster of points containing Types 7 and 12b above a living floor and suggests their association with a feature 
dated to circa A.D. 810 and 730. This would imply that narrow-necked Type 7 is a contemporary of Type $12 \mathrm{~b}$.

Although detailed point comparisons are hampered by the small sample sizes ( 32 identifiable points at 35MA7; 28 identifiable at 35MA9) and by the somewhat muddled cultural deposit in 35MA9 (Pettigrew 1980:17, 60), some statements can be made:

1) Type 6 (undifferentiated at Hager's Grove into the subtypes devised for the Portland Basin typology) is present in high frequencies at both sites, representing $19 \%$ of identifiable points at one site and $29 \%$ at the other. In comparison, in the Tualatin Valley, Type 6 accounts for $55 \%$ of the Ibach points and $18 \%$ of the Heynderickx points. In contrast, Type 6 (all subtypes) never makes up more than $7 \%$ of the points in any of the Portland Basin sites excavated by Pettigrew.

2) Projectile point type trends among the 3 identified occupation periods (A, B, and C) at the two Hager's Grove sites show Types 1-5 (broad-necked) and Type 6 (unstemmed) most frequent in the earliest level, and the narrow-necked types (7-10) predominating in the latest component (p. 65).

3) In contrast to Portland Basin sites where, in 6 out of 7 sites, ccs accounted for no less than $89 \%$ of the points and obsidian no more than $10 \%$ of the points, the percentages for Hager's Grove are: $35 \mathrm{MA} 7: 53 \%$ ccs, $45 \%$ obsidian, $3 \%$ basalt; 35MA9: $50 \%$ ccs, $42 \%$ obsidian, $3 \%$ basalt and $6 \%$ other. Pettigrew (p. 65) states that ccs is the most frequent raw material in the early occupation level and that its proportion decreases with time, while obsidian shows the opposite trend. By comparison, the proportion of ccs points to obsidian and basalt in the Ibach collection is 60:26:14 (Table III) and in the Heynderickx collection, 78:20:2 (Table II). 
4) Pettigrew identifies neck width frequency modes for both sites at $4 \mathrm{~mm}, 9 \mathrm{~mm}$ and

$11 \mathrm{~mm}$ (although he suspects sampling error accounts for the dip at $10 \mathrm{~mm}$ ).

Certainly, these are narrower neck-width values than for either the Ibach or

Heynderickx points, as presented in the previous section.

\section{TUALATIN VALLEY SITES IN THE FLANAGAN SITE CHRONOLOGY}

\section{Toepel's Seriation Process}

Whereas Pettigrew designed his seriation of projectile point types to produce an intersite chronology, Toepel (1985) presents an intrasite seriation of projectile point types spanning a 6000 year period of occupation at the Flanagan site just west of Eugene. The field work was done in several seasons. To provide a stratigraphic basis of projectile point types, she first compared vertical distributions of point types for all points excavated in a 1975 test pit and the 1976 and 1978 units with the vertical distributions of point types for only the 1978 block, "which was presumed to have more internal consistency because the depth of the cultural deposit was less variable in this area than within the site as a whole" (p. 119). She found not only that the distribution patterns between the two excavation groupings were comparable, but also that point types could be collapsed into their series types without altering distribution patterns over the 12 levels in the site. (This means SS1, SS2 and SS3 types could be lumped into a Small Stemless Series, for example.)

Toepel uses radiocarbon dates (bolstered by other artifactual analyses) to frame a chronology ranging from 6000 B.P. to 200 B.P., and the point types correlated with this time frame are discussed below. It should be kept in mind, however, that of the $221 \times 1$ meter units excavated in the 1978 field season, only $9(41 \%)$ were excavated below Level 8 to 
culturally sterile soil (p. 39). This means that the lowest and earliest four strata are underrepresented in the point total.

\section{Flanagan Site Projectile Point Type Patterns}

The seriation of projectile point types reveals the following chronological sequence, from oldest to youngest: Heavy Broad-necked Series, Heavy Stemless Series, Moderate Broad-necked Series, Narrow-necked Series, and Small Stemless Series (Table XVII). Toepel groups the stratigraphic levels into Early, Middle and Late components. The Heavy Broadnecked and Heavy Stemless series are most common in the early component (4000-6000 B.P.). In the middle component (2000-4000 B.P.) Moderate Broad-necked is most common, but the Narrow-necked and Small Stemless series are also present. By the late component (2000-200 B.P.) the Narrow-necked and Small Stemless series dominate.

Toepel notes the site disturbance at the Flanagan site, namely historic plowing, rodent activity and human prehistoric ground disturbances, such as the building of earth ovens. She attributes some of the perceived messiness of the chronological tiering of the point types to these earth-moving factors (p. 121). In particular, she attributes the presence of small points in the earliest levels to this phenomenon. It is possible, given the discussion in Chapter II, that variation in dart point neck widths may account for this perceived displacement. 
TABLE XVII

DISTRIBUTION OF PROJECTILE POINT SERIES BY SITE COMPONENT $(\mathrm{N}=226)$

Projectile

Component

Point Series

Late

Middle

(Levels 1 - 4)

(Levels 5 - 8)

Early

(Levels 9 - 12)

\section{Block Area:}

Small Stemless Series $(n=14)$

Narrow-necked Series $(n=62)$

Moderate Broad-necked Series $(n=5)$

Heavy Stemless Series $(n=4)$

Heavy Broad-necked Series $(n=5)$

$\begin{array}{ccc}83 \% & 17 \% & - \\ 73 \% & 25 \% & 2 \% \\ - & 60 \% & 40 \% \\ - & 50 \% & 50 \% \\ - & 20 \% & 80 \%\end{array}$

\section{All Units:}

Small Stemless Series $(n=34)$

Narrow-necked Series $(n=157)$

Mod. Broad-necked Series $(n=13)$

Heavy Stemless Series $(n=8)$

Heavy Broad-necked Series $(n=14)$

$80 \%$

$78 \%$

$31 \%$

$-$

$14 \%$
$20 \%$

$21 \%$

$54 \%$

$75 \%$

$36 \%$
$1 \%$

$15 \%$

$25 \%$

$50 \%$

(Adapted from Toepel 1985:124, Table 15.)

\section{Tualatin Valley Sites in the Flanagan Site Chronology}

To see how the Ibach and Heynderickx collections could fit into the chronology set up by Toepel, I had to develop a different perspective of looking at the point types over time. I first assumed that the Heynderickx and Ibach points each represented one component and then, in order to fit those collections into one of the Flanagan site time periods, I needed to know the percentages of point types within each component. Using information from Toepel's Table 15 (p. 124), which is the same as my Table XVII, I computed the frequencies and percentages of each point series within each component both for the 1978 block and all units together (Table XVIII). In order to compare the Tualatin Valley point frequencies to the FIanagan frequencies, I next prepared the same point series information for the Heynderickx and Ibach collections (Table XIX). 
TABLE XVIII

DISTRIBUTION OF FLANAGAN PROJECTILE POINT SERIES PER SITE COMPONENT

\begin{tabular}{|c|c|c|c|c|c|c|}
\hline \multirow{2}{*}{$\begin{array}{l}\text { Projectile } \\
\text { Point Series }\end{array}$} & \multicolumn{2}{|l|}{ Late } & \multicolumn{3}{|c|}{ Component } & Early \\
\hline & \# & $\%$ & \# & $\%$ & \# & $\%$ \\
\hline \multicolumn{7}{|l|}{1978 Block Area: } \\
\hline Small Stemless Series $(n=14)$ & 12 & 21 & 2 & 8 & - & - \\
\hline Narrow-necked Series $(n=62)$ & 45 & 79 & 16 & 67 & 1 & 11 \\
\hline Mod. Broad-necked Series $(n=5)$ & - & - & 3 & 12 & 2 & 22 \\
\hline Heavy Stemless Series $(n=4)$ & - & - & 2 & 8 & 2 & 22 \\
\hline \multirow[t]{3}{*}{ Heavy Broad-necked Series $(n=5)$} & - & - & 1 & 4 & 4 & 44 \\
\hline & $==$ & $==$ & $==$ & $==$ & $==$ & $==$ \\
\hline & 57 & 100 & 24 & 99 & 9 & 99 \\
\hline
\end{tabular}

All Units:

Small Stemless Series $(n=34)$

Narrow-necked Series $(n=157)$

$27 \quad 17$

$122 \quad 79$

Mod. Broad-necked Series $(n=13)$

Heavy Stemless $(n=8)$

Heavy Broad-necked Series $(n=14)$

$4 \quad 3$

$\begin{array}{cccc}7 & 12 & - & - \\ 33 & 57 & 2 & 15 \\ 7 & 12 & 2 & 15 \\ 6 & 10 & 2 & 15 \\ 5 & 9 & 7 & 54 \\ == & = & = & = \\ 58 & 100 & 13 & 99 * *\end{array}$

*This component underrepresented in the excavation, especially in the 1978 block area. **Percentage not exactly 100 due to rounding.

(Adapted from Toepel 1985:124, Table 15.)

TABLE XIX

TUALATIN VALLEY PROJECTILE POINTS IN FLANAGAN SITE TYPOLOGY

Projectile Point Series

$\begin{array}{lll}\text { Ibach } & & \text { Heynderickx } \\ \# & \% & \#\end{array}$

Small Stemless Series

Narrow-necked Series

Moderate Broad-necked Series

Heavy Stemless Series

34

Heavy Broad-necked Series

$\begin{array}{cccc}3 & 4 & 3 & 3 \\ 4 & 6 & 47 & 42 \\ 5 & 6 & 14 & 12 \\ 40 & 50 & 19 & 17 \\ 27 & 35 & 31 & 27 \\ == & == & == & == \\ 79 & 101^{*} & 118 & 101^{*}\end{array}$

*Percentage not exactly 100 due to rounding. 
In comparing the Ibach and Heynderickx relative frequencies to those for Flanagan (i.e., comparing Table XVIII with Table XIX), I come up with questionable results, as neither Tualatin Valley site easily fits into any of the three Flanagan site component configurations. The Tualatin Valley sites by far contain higher percentages of the Heavy Stemless points than the Flanagan site. Although in the above tables Toepel ranks Heavy Stemless points slightly later than the Heavy Broad-necked based on overall size, she notes that she considers both on a chronological par (p. 110).

I conclude that the Tualatin Valley sites are probably multi-componented or show occupation over thousands of years, especially the Heynderickx site with its large proportions of both early and late types. Based on the above percentages, I think both sites have strong Early component occupation (4000-6000 B.P.), with the Ibach site appearing to be earlier than the Heynderickx site. Eighty-five percent of the Ibach points are made up of the Heavy Stemless and Heavy Broad-necked Series, whereas the figure is $44 \%$ for the Heynderickx site. Only $10 \%$ of the Ibach site is composed of the smaller point series as compared to $45 \%$ for the Heynderickx site.

\section{CONCLUSION}

The objective of this thesis project has been to establish when human occupation occurred at two sites in the Tualatin Valley, a section of the Willamette Valley which has not received either extensive or intensive archaeological investigations over the last 25 years. Although other parts of the Willamette Valley have sites firmly dated as early as 8000 years ago, archaeological work in the Tualatin Valley had yielded no radiocarbon dates to pinpoint occupation times and too few chronologically diagnostic artifacts for relative dating with other sites. The Ibach and Heynderickx collections, however, provided large enough samples of a 
diagnostic artifact -- the projectile point -- to use in a frequency seriation comparison with nearby sites dated by radiocarbon means.

The results of using the sequence comparisons between the undated Tualatin Valley collections and the Portland Basin and Flanagan sites suggest that both the Ibach and Heynderickx sites predate the earliest Portland Basin site (the Merrybell site, dated to before 120 B.C.), and comparison with the Flanagan site components supports occupation at both sites at least as early as $4000-6000$ B.P. In addition, the analysis suggests that the Heynderickx site has both early and late components, whereas the Ibach site evidences a primarily early occupation.

These findings are significant in that although the potential for early sites existed for the Tualatin Valley, until now it had not been demonstrated. Two cautions regarding the results derived from my analysis need to be addressed. One is the reminder that while inferring chronologies from frequency seriations is a valid technique for dating collections or unstratified deposits, it is at best a working hypothesis contingent on corroborating evidence from other independent sources, such as radiocarbon or obsidian hydration dates.

Furthermore, the underlying assumption is that artifact types in a seriation reflect only relative age and not spatial or functional factors. In the case of projectile points, which is commonly the only extant remnant of more complex tools, there is continuing debate over how they were hafted, what they were used for, and how old they are. Flenniken (1986), for example, contends that morphological projectile point types assumed to represent different ages may in fact simply represent one point type in different stages of repair.

What is needed to quell the uncertainty is data from other sources. For instance, obsidian hydration analysis could be used to date the point itself. A point may also be dated by its association with a radiocarbon-dated feature, which is what Pettigrew (1980:63) was 
able to do at one of the Hager's Grove sites. (There he found two projectile point types -one presumed to be an earlier style than the other -- associated with the same dated feature.) Even a series of distinct, undisturbed, single component, clearly dated sites throughout the Tualatin Valley as well as the greater Willamette Valley would permit finer chronlogical inferences from projectile point seriations.

Finally, the other caution is that there are projectile points in the Heynderickx and Ibach collections that appear to be older than the chronological framework of either the Portland Basin typology or the Flanagan site typology. Several points in the Tualatin Valley collections look like the points associated with the Windust and Cascade phases of the Columbia Plateau dating from approximately 8000 B.C. to 3000 B.C. (Leonhardy and Rice 1970, Rice 1972) and those found at Cascadia Cave dating from 6000 B.C. to 2000 B.C. (Newman 1966), as well as those found at other apparently early sites, such as the Geertz site (Woodward 1972), the Burnett site (Burnett 1991), and at the mouth of the Columbia River (Minor 1984).

As noted earlier, the typologies of Pettigrew and Toepel do not draw attention to these early historical point types. Although Pettigrew's approach to defining projectile point types in his typology would accomodate such a type description, his Portland Basin sites are apparently too recent to contain any of these points. Toepel's typology, with its focus on overall size and shape attributes, masks such type distinctions as it did in my analysis.

The next step, which is beyond the scope of this thesis, would be to examine the points from early sites in western Washington and Oregon and the Cascades and compare the Tualatin Valley points to them. This broadening of the range of research would suffice until such time that further archaeological fieldwork produces firmer dates for Tualatin Valley sites. 


\section{REFERENCES CITED}

Allen, John E., Marjorie Burns and Sam C. Sargent. 1986. Cataclysms on the Columbia. Timber Press. Portland, Oregon.

Baker, W.E. and A.V. Kidder. 1937. A Spear-Thrower From Oklahoma. American Antiquity 3:5:51.

Balster, C.A. and R.B. Parsons. 1968. Geomorphology and soils, Willamette Valley, Oregon. Oregon State University Agricultural Experiment Station Special Report 265.

Brown, James A. 1982. On the Structure of Artifact Typologies. In Essays on Archaeological Typology, Robert Whallon and James A. Brown, ed. Center for American Archeology Press. Evanston.

Burnett, Robert M. 1991. The Burnett Site: A Cascade Phase Camp on the Lower Willamette River. M.A. Thesis, Department of Anthropology, Portland State University.

Connolly, Thomas J. and Paul W. Baxter. 1986. New Evidence on a "Traditional" Topic in Pacific Northwest Prehistory. In Contributions to the Archaeology of Oregon, 19831986, edited by Kenneth M. Ames. Association of Oregon Archaeologists Occasional Papers 3:141.

Cole, David L. 1965. Archaeological Survey of the Scoggin Creek Reservoir. Museum of Natural History, Eugene, Oregon. Submitted to the National Park Service.

Corliss, David W. 1972. Neck width of Projectile Points: an Index of Culture Continuity and Change. Occasional Papers of the Idaho State University Museum 29. Pocatello.

Cowgill, George L. 1982. Cluster of Objects and Associations between Variables: Two Approaches to Archaeological Classification. In Essays on Archaeological Typology, Robert Whallon and James A. Brown, ed. Center for American Archeology Press. Evanston.

Davis, Wilbur A. 1970. Scoggin Creek Archaeology, 1969 Final Report. Department of Anthroplogy, Oregon State University. Submitted to National Park Service.

Decker, Doyle D. and Wilbur A. Davis. 1976. Survey of Impacts on Prehistoric Resources Tualatin Project, Second Phase. Department of Anthropology, Oregon State University. Submitted to the National Park Service. 
Doran, J. E. and F. R. Hodson. 1975. Mathematics and Computers in Archaeology. Harvard University Press. Cambridge.

Ellis, David V. 1989. Draft Report to Northwest Nautural Gas South Mist Feeder Project: Investigations at the Pumpkin Ridge Site (35WN34). Ms. in possession of author.

Ellis, David V. and John L. Fagan. 1990. Archaeological Testing of the Horse Oak Site (35WN19), Washington County, Oregon. Archaeological Investigations Northwest Report No. 7. Portland, Oregon.

Fanenga, Franklin. 1953. The Weights of Chipped Stone Points: a Clue to Their Functions. Southwestern Journal of Anthropology 9:309-323.

Flenniken, Jeffrey J. and Anan W. Raymond. 1986. Morphological Projectile Point Typology: Replication Experimentation and Technological Analysis. American Antiquity 51:603-614.

Forbis, Richard G. 1960. The Old Women's Buffalo Jump, Alberta Ec-Pl 1. Contributions to Anthropology. National Museum of Canada, Bulletin No. 180.

Frison, George. 1974. The Casper Site. Academic Press, New York.

Gilsen, Leland. 1990. Oregon Radio-carbon Database. Oregon State Historic Preservation Office.

Green, George L. 1982. Soil Survey of Washington County, Oregon. Soil Conservation Service, U.S. Department of Agriculture, in cooperation with the U.S. Department of Agriculture, Forest Service, and the Oregon Agricultural Experiment Station.

Hibbs, Charles, Jr. and David V. Ellis. 1988. An Inventory of Cultural Resources and An Evaluation of the Effects of the Proposed South Mist Feeder Gas Pipeline, Located between the Unpper Nehalem River Valley and the Tualatin Valley in Northwestern Oregon. 3 vols. Report prepared by Charles Hibbs and Associates for the Northwest Natural Gas Company, Portland, Oregon.

Hoffman, C. Marshall. 1985. Projectile Point Maintenance and Typology: Assessment with Factor Analysis and Canonical Correlation. In For Concordance in Archaeological Analysis, Christopher Carr, ed. Westport Publishers, Inc. Kansas City.

Jenkins, Paul C. and Deborah L. Soper. 1989. A Cultural Resource Inventory of the Tualatin Wetlands Protection District. Coastal Magnetic Search \& Survey Report No. 41. Gresham, Oregon.

Leonhardy, Frank C., and David G. Rice. 1970. A Proposed Culture Typology for the Lower Snake River Region, Southeastern Washington. Northwest Anbthropological Research Notes No. 4. 
Lohse, Ernest S. 1985. Rufus Woods Lake Projectile Point Chronology. In Summary of Results, Chief Joseph Dam Cultural Resources Project, Washington, S. K. Campbell, ed. Office of Public Archaeology, University of Washington. Seattle.

Newman, Thomas M. 1966. Cascadia Cave. Occasional Papers of the Idaho State Museum, Number 18. Pocatello, Idaho.

Pettigrew, Richard M. 1977. A Prehistoric Culture Sequence in the Portland Basin of the Lower Columbia Valley. Unpublished Ph.D. Dissertation, Department of Anthropology, Univeristy of Oregon.

Pettigrew, Richard M. 1980. Archaeological Investigations at Hager's Grove, Salem, Oregon. University of Oregon Anthropological Papers 19.

Rice, David G. 1972. The Windust Phase in Lower Snake River Region Prehistory. Report of Investigations No. 50. Laboratory of Anthropology, Washington State University.

Spaulding, Albert C. 1977. On Growth and Form in Archaeology: Multivariate Analysis. Journal of Anthropological Research 33:1-15.

Thomas, David H. 1978. Arrowheads and Atlatl Darts: How the Stones Got the Shaft. American Antiquity 43:461-472.

Thomas, David H. 1981. How to Classify the Projectile Points from Monitor Valley, Nevada. Journal of California and Great Basin Anthropology 3(1):7-43.

Thomas, David H. 1989. Archaeology. Second Edition. Holt, Rinehart and Winston, Inc. Fort Worth, Texas.

Toepel, Katherine A. 1985. The Flanagan Site: 6,000 Years of Occupation in the Upper Willamette Valley, Oregon. Unpublished Ph.D. Dissertation, Department of Anthropology, University of Oregon.

Warner, Irene and George Warner. 1975. Trojan III - 35CO1; Archaeological Report Covering the Third and Final Season of Salvage Excavation of the Trojan Site. Oregon Archaeological Society Report No. 7. Portland.

Wiggin, Roger. 1979. Functional Analysis of Great Basin Projectile Points. Unpublished M.A. Thesis, Department of Anthropology, Portland State University.

Woodward, John A. 1972. The Geertz Site: an Early Campsite in Western Oregon. Tebiwa 15:55-62.

Zenk, Henry B. 1976. Contributions to Tualatin Ethnography: Subsistence and Ethnobiology. Unpublished M.A. Thesis, Department of Anthropology, Portland State University. Portland. 


\section{APPENDIX A}

\section{SAMPLE PROJECTILE POINT WORKSHEET WITH DEFINITIONS}

Created to type a point in either Pettigrew's Portland Basin typology or Toepel's Flanagan site typology. 
Page 1 of 2

PROJECTILE POINT WORKSHEET: Tualatin Valley

Catalogue Number:

Collection:

QUALITATIVE ATTRIBUTES: [circle selection(s) after each colon]

1. Material: ces basalt obsidian other:

2. Condition: complete

breakage: tip blademargin barb stem base

3. Serration: yes slight no

4. Point Outline: stemless: triangular [if stemless, go next to 8]

leaf-shaped

lanceolate

stemmed

indeterminate

5. Blade Margins: straight excurvate incurvate indeterminate

6. Blade-Stem Juncture: shoulder

notching: side corner basal
indeterminate

7. Stem Shape: expanding contracting straight indeterminate

8. BasalEdge Shape: $\begin{aligned} & \text { straight } \\ & \text { concave }\end{aligned}$ pointed notched slanted indeterminate

9. EdgeGrinding:yes no indeterminate

$\begin{array}{llll}\text { 10. Blade Cross-section: } & \text { plano-convex } & \text { biplano } & \text { bitriangular } \\ \text { plano-triangular } & \text { biconvex } & \text { convex-triangular }\end{array}$ 
Catalogue Number:

Collection:

QUANTITATIVE ATTRIBUTES: [12 - 16 in millimeters]

12. $\mathrm{L}_{\mathrm{t}}$

13. $\mathrm{W}_{\mathrm{m}}$

14. $\mathrm{W}_{\mathrm{b}}$

15. $\mathrm{W}_{\mathrm{n}}$

16. $\mathrm{T}_{\mathrm{m}}$

17. $\mathrm{Wt}$

gm

REMARKS:

POINT OUTLINE: 


\section{DEFINITIONS FOR PROJECTILE POINT WORKSHEET AND TABLES}

\section{QUALITATIVE:}

\section{RAW MATERIAL [Matrl]}

ccs: Cryptocrystalline silica. A general term for the cryptocrystalline varieties of silica stones, such as, chalcedony, jasper, chert, agate.

bas: Basalt. A type of extrusive lava, either fine-grained or vesicular.

obs: Obsidian. A term used here to denote obsidian, a volcanic glass, and other obsidian-like material such as ignimbrite, which is a welded volcanic tuff.

oth: Other. Category for stone not fitting any of the above. (In this collection of points, only one petrified wood specimen fit this group.)

\section{SERRATION [Serr]}

Y: Yes. The lateral blade margin shows a pattern of deep notches, producing a saw-like edge with pronounced "teeth."

S: $\quad$ Slight. The lateral blade margin shows a pattern of fine, shallow indentations.

N: No. The lateral blade margin shows no pattern of notching.

\section{BLADE MARGINS [Mrgn]}

S: $\quad$ Straight. The lateral blade margin forms a flat line.

E: Excurvate. The lateral blade margin forms a convex curve relative to the longitudinal axis of the blade.

I: Incurvate. The lateral blade margin forms a concave curve relative to the longitudinal axis of the blade.

-: Indeterminate. Condition precludes description.

\section{BLADE CROSS-SECTION [X-sect]}

pc: Plano-convex. Blade cross-section is flat on one face and curved on the other.

pt: Plano-triangular. Blade cross-section is flat on one face and sharply tapered on the other.

bp: Biplano. Blade cross-section is flat on both surfaces with relatively steep edges.

bc: Biconvex. Blade cross-section is curved on both surfaces.

bt: Bitriangular. The blade cross-section is sharply tapered on both surfaces.

ct: Convex-triangular. The blade cross-section is curved on one surface and sharply tapered on the other. 
SHAPE [Shape]

Descriptive subdivisions for overall shape of stemless points (i.e., points with no measurable necks):

tri: Triangular. The maximum width is at the proximal end.

lea: Leaf-shaped. The maximum width is in the proximal $1 / 3$ of the point.

lan: Lanceolate. The maximum width is in the middle $1 / 3$ of the point.

-: Indeterminate. Condition precludes placement into any of the above categories.

BLADE-STEM JUNCTURE [Junct]

Applicable to stemmed points.

S: $\quad$ Shouldered. The neck is formed by a very wide corner notch. The juncture of the shoulder and blade margin does not project below a horizontal line running through the neck of the projectile point and perpendicular to the longitudinal axis.

N: Notched. Neck is formed by a narrower notch.

si: $\quad$ Side notch. The neck is formed by a deep lateral notch that creates an expanding stem.; maximum stem width is about the same as maximum point width.

co: Corner notch. The neck is formed by removal of part of the corner of the point; the juncture of the shoulder and blade margin projects below the neck.

ba: Basal notch. The neck is formed by removal of part of the base of the point; the juncture of the shoulder and blade margin projects below the neck.

-: Indeterminate. Condition precludes assignment to a notched subcategory.

-: Indeterminate. Condition precludes description.

\section{BASAL EDGE SHAPE [Base]}

st: Straight. The basal edge is horizontal, i.e. perpendicular to the longitudinal axis of the projectile point.

cv: Concave. The basal edge forms a rounded indentation.

cx: Convex. The basal edge bulges proximally.

ea: Earred. The basal edge has a wide central notch that separates the basal corners of the stem.

pt: $\quad$ Pointed. The basal edge ends in a sharp termination.

nt: Notched. The basal edge is primarily horizontal with a central indentation.

sl: $\quad$ Slanted. The basal edge is straight but not perpendicular to the longitudinal axis.

-: Indeterminate. Condition precludes description. 
EDGE GRINDING [Grd]

Y: Yes. The lateral margins of the hafted area have been dulled.

N: No. The lateral margins of the hafted area have not been dulled.

-: Indeterminate. Condition precludes description.

BREAKAGE [Brkge]

--: $\quad$ The projectile point is whole.

T,M,Br,S,Bs:

When the projectile point shows breakage, broken areas are noted. For stemmed points, these are Tip, blade Margin, Barb, and Stem. Broken areas for stemless points are Tip, blade Margin, and Base.

\section{QUANTITATIVE:}

All measurements -- except weight -- in millimeters. An asterisk $\left(^{*}\right)$

following an entry denotes an estimated value for a measurement on a broken point when the missing portion is estimated to be 2 millimeters or less. A plus sign $(+)$ denotes the actual measurement of a point with breakage too extensive for estimating. .

L total: Total length.

W max: $\quad$ Maximum width.

W base: Basal width. Stemmed: if any part of stem is wider than neck, widest part is basal width; if not, width of proximal end is basal width. Stemless: if the base is not clearly delineated, basal width is measured approximately 1 millimeter distal from the most proximal margin.

W neck: $\quad$ Neck width. Measured at the narrowest constriction.

T : Maximum thickness of point.

Wt: Weight in grams.

\section{DERIVED MEASUREMENTS:}

A symbol following one of these ratios marks one that has an estimated $(*)$ or broken $(+)$ measurement.

$\mathbf{W}_{\mathrm{b}}-\mathbf{W}_{\mathbf{n}}$ : Neck width subtracted from basal width.

$\mathbf{W}_{\mathrm{b}} / \mathbf{W}_{\mathrm{m}}$ : Basal width divided by maximum width.

$\mathbf{T} / \mathbf{W}_{\mathrm{m}}$ : Thickness divided by maximum width. 


\section{APPENDIX B}

\section{TABLES OF PROJECTILE POINT ATTRIBUTES AND TYPES}

Data derived from projectile point worksheets of Ibach and Heyndericx collections. Definitions of attributes are in Appendix A. A (-) or blank space in column means breakage precludes description or measurement. 
IBACH STEMED PROJECTILE POINTS

\begin{tabular}{|c|c|c|c|c|c|c|c|c|c|c|c|c|c|c|c|c|c|c|}
\hline Acc. No. & Matrl & Serr & Junct & stem & Base & Grd & $x-\sec t$ & Brkge & L total & $W \max$ & $W$ bose & $W$ neck & $\mathbf{T}$ & wt & wb- $m$ & Wo/n & $\begin{array}{c}\text { Toepel } \\
\text { Type }\end{array}$ & $\begin{array}{l}\text { Petti } \\
\text { Type }\end{array}$ \\
\hline$\cdots$ & $\cdots$ & $\cdots \cdot$ & $\cdots$ & $\cdots$ & $\cdots$ & $\cdots$ & $\cdots$ & $\cdots$ & $\ldots$ & $\cdots$ & $\cdots \cdots$ & $\cdots$ & $\cdots \cdot$ & $\cdots$ & $\cdots$ & $\ldots$ & ....... & $\cdots$ \\
\hline $33-1.28$ & ccs & N & N. & - & - & - & $b c$ & TMS & $36.2+$ & $26.1+$ & & 15.0 & 8.7 & 10.1 & & & HB & $1 / 4$ \\
\hline $83-1.71$ & obs & $\mathbf{M}$ & $\cdot$ & - & - & - & $b c$ & $\mathbf{s}$ & $36.9+$ & 22.2 & & 16.2 & $7: 1$ & 5.1 & & & HB & $1 / 12$ \\
\hline $23-1.106$ & abs & $\mathbf{s}$ & $\mathbf{s}$ & - & - & - & $b c$ & IBrs & $35.1+$ & 23.2 & & 12.7 & 6.2 & 4.9 & & & HB & $2 / 5 / 12$ \\
\hline $83-1.116$ & obs & $N$ & $N$ & - & - & $\cdot$ & $b c$ & TBrS & $46.1+$ & $26.2+$ & & 12.0 & 5.9 & 5.5 & & & HB & $1 / 4$ \\
\hline $3-1.5$ & ccs & N & $N=i$ & E & st & N & $b c$ & IMS & 41.0 . & $21.2 *$ & 20.0 . & 13.4 & 6.6 & 6.1 & $6.6{ }^{*}$ & $.94 *$ & HB1 & 12 \\
\hline $83 \cdot 1.59$ & ccs & N & $N=i$ & E & $c x$ & N & ct & $\mathbf{I}$ & $34.0 *$ & 22.9 & 22.0 & 20.7 & 7.5 & 4.8 & 1.3 & .96 & HBI & 12 \\
\hline $33-1.2$ & ccs & N & N co & $\mathbf{E}$ & st & N & bc & Is & 46.0 . & 24.1 & 16.0 . & 13.5 & 7.2 & 7.9 & 2.5 & $.66 *$ & H82 & 1 \\
\hline $33-1.4$ & ccs & $N$ & $\mathbf{s}$ & $\mathbf{s}$ & $c x$ & N & $c t$ & -. & 37.9 & 20.1 & 13.6 & 13.6 & 8.2 & 6.4 & 0.0 & .68 & H82 & 5 \\
\hline $83-1.18$ & ccs & N & $n-$ & $\mathbf{E}$ & - & - & bt & BrS & $39.4+$ & $18.0 *$ & $11.0+$ & 10.1 & 5.9 & 3.5 & $.9+$ & $.61+$ & HB2 & $1 / 12$ \\
\hline $83-1.29$ & ccs & $N$ & $N$ si & E & st & N & $b c$ & TMBr & 29.0 & 22.0 . & 19.4 & 15.2 & 7.5 & 5.1 & 4.2 & .88 . & HB2 2 & 1 \\
\hline $83-1.30$ & ces & N & $\mathbf{s}$ & E & st & $N$ & $b c$ & -. & 54.0 & 28.2 & 14.9 & 14.6 & 8.7 & 14.4 & .3 & .53 & HB2 & 2 \\
\hline $83-1.47$ & ccs & N & N co & E & st & $n$ & $b c$ & $\mathbf{s}$ & 42.3 & 18.8 & 11.4 * & 10.2 & 4.5 & 3.0 & 1.2 . & .61. & HB2 & 1 \\
\hline $33-1.58$ & ccs & N & N co & $E$ & $c x$ & N & $c t$ & TM & 59.5 . & 27.9 & 19.8 & 16.2 & 12.9 & 18.1 & 3.6 & .71 & HB2 & 1 \\
\hline $83-1.62$ & ccs & $N$ & $\mathbf{s}$ & E & $c x$ & $N$ & ct & $M$ & 30.5 & 18.0 & 15.9 & 14.2 & 6.0 & 3.7 & 1.7 & .88 & HB2 & 2 \\
\hline $83-1.83$ & ccs & N & $\mathbf{s}$ & $\mathbf{s}$ & st & $N$ & $b c$ & -. & 24.0 & 14.8 & 9.4 & 9.4 & 5.2 & 1.3 & .0 & .64 & H82 & 5 \\
\hline $83-1.117$ & obs & N & N co & E & - & - & $b c$ & s & 38.0 . & 22.0 & $14.0 *$ & 11.1 & 7.0 & 5.6 & 2.9 . & $.64 *$ & HB2 & 1 \\
\hline $83 \cdot 1.121$ & abs & N & $N \mathrm{si}$ & E & st & N & $b c$ & ז. & 25.5 & 14.3 & 12.1 & 9.9 & 5.0 & 2.3 & 2.2 & .85 & HB2 & 12 \\
\hline-1.23 & bas & N & $\mathbf{s}$ & c & $c x$ & N & $b c$ & is & 60.4. & 27.0 & 5.5 & 18.1 & 6.8 & 10.0 & -12.6 & .20 & HB3 & 5 \\
\hline $83-1.45$ & obs & $\mathbf{N}$ & $\mathbf{s}$ & c & $\cdot$ & N & PC & $\mathbf{s}$ & 32.6 & 20.3 & $7.2 *$ & 11.8 & 5.9 & 3.4 & -4.6 & .35 & HB3 & 5 \\
\hline $83-1.50$ & ccs & N & $\mathbf{s}$ & c & $c x$ & $N$ & bc & is & $35.8+$ & 18.8 & $10.0 *$ & 13.4 & 8.0 & 6.2 & -3.4 & $.53 *$ & HB3 & 5 \\
\hline $83-1.60$ & ccs & $\mathbf{N}$ & $\mathbf{s}$ & c & $\cdot$ & - & pt & $\mathbf{s}$ & $33.8+$ & 16.2 & $6.7+$ & 11.2 . & 4.5 & 2.6 & $-4.5+$ & $.41+$ & HB3 & 5 \\
\hline-1.65 & $\operatorname{ccs}$ & $\mathbf{N}$ & N co & c & $c x$ & N & $b c$ & $\mathrm{TMBr}$ & $43.4+$ & $28.0+$ & 14.8 & 17.2 & 10.1 & 11.6 & -2.4 & $.53+$ & MB3 & 4 \\
\hline $3-1.66$ & $\operatorname{ccs}$ & N & N co & C & - & N & pt & is & $34.5+$ & 20.1 & $6.1+$ & 9.8 & 7.9 & 4.2 & $-3.7+$ & $.30+$ & HB3 & 4 \\
\hline
\end{tabular}


IBACH STEMAED PROJECTILE POINTS

\begin{tabular}{|c|c|c|c|c|c|c|c|c|c|c|c|c|c|c|c|c|c|c|}
\hline Acc. Mo. & Matrl & Serr & Junct & stem & Base & Grd & $x-\sec t$ & Brkge & l total & $y \max$ & W bose & $W$ neck & $\mathbf{T}$ & we & $w b-4 n$ & wotum & $\begin{array}{c}\text { Toepel } \\
\text { Type }\end{array}$ & $\begin{array}{l}\text { Petti } \\
\text { Type }\end{array}$ \\
\hline$\cdots \cdots$ & $\cdots$ & $\cdots$ & $\cdots$ & $\cdots$ & $\cdots$ & $\cdots$ & $\cdots$ & $\cdots$ & $\cdots$ & $\cdots$ & ....... & $\cdots$ & $\cdots$ & $\cdots$ & ..... & ..... & ........ & ....... \\
\hline $83-1.84$ & obs & $N$ & $s$ & c & - & - & $b c$ & $\mathbf{s}$ & 32.4. & 17.3 & $8.2+$ & 10.0 & 5.1 & 2.5 & $-1.8+$ & .47 & HB3 & 5 \\
\hline $83-1.112$ & obs & $N$ & s & c & - & - & $b c$ & IMS & $51.0+$ & 25.7 & 10.6 & 14.3 & 7.2 & 9.4 & $-3.7+$ & $.41+$ & H83 & 5 \\
\hline $83-1.113$ & ccs & N & N co & c & - & - & $b c$ & TBrS & $37.1+$ & 29.0 & 8.9 & 16.1 & 8.2 & 9.2 & $-7.2+$ & $.31+$ & HB3 & 4 \\
\hline $83-1.124$ & obs & $N$ & s & c & $c x$ & $r$ & $b c$ & $T$ & $64.8^{\circ}$ & 23.9 & 12.7 & 16.8 & 7.1 & 11.6 & -4.1 & .53 & H83 & 5 \\
\hline $83-1.37$ & ccs & s & $\mathbf{s}$ & - & - & - & $b c$ & $\mathbf{s}$ & 28.2 & 17.8 & & 8.1 & 6.0 & 3.1 & & & MB & $2 / 5$ \\
\hline $83-1.73$ & obs & N & N si & $\mathbf{E}$ & st & N & $b c$ & IS & $36.4+$ & 16.7 & 15.2 . & 10.8 & 3.9 & 2.2 & $4.4 \%$ & .91 . & MB1 1 & 12 \\
\hline $83-1.82$ & ces & N & s & c & st & $n$ & $b c$ & $\cdots$ & 31.8 & 14.0 & 4.1 & 7.3 & 6.2 & 2.2 & -3.2 & .29 & MB3 & 10 \\
\hline $83-1.91$ & obs & N & $\mathbf{s}$ & c & st & $x$ & $b c$ & $\mathrm{Br}$ & 32.4 & 18.7 & 7.0 & 8.8 & 5.5 & 3.0 & -1.8 & .37 . & MB3 & 5 \\
\hline $83-1.120$ & obs & N & $\mathbf{s}$ & c & si & N & ct & $\cdots$ & 32.0 & 12.8 & 7.0 & 9.0 & 5.3 & 1.9 & -2.0 & .55 & MBS & 5 \\
\hline $83-1.125$ & obs & $N$ & $N=$ & - & - & - & $b c$ & IBrS & 14.7 & 13.8 & & 5.7 & 2.2 & .6 & & & NW & $7 / 9$ \\
\hline $83-1.133$ & obs & N & $N=$ & - & - & - & $b c$ & IBS & 16.5 & $17.0+$ & & 7.0 & 4.3 & .9 & & & NM & $7 / 9$ \\
\hline $83-1.97$ & ces & $\mathbf{s}$ & s & • & - & - & $b c$ & I.S & $21.2+$ & 9.1 & & 4.9 & 3.3 & .7 & & & NH2 & $8 / 10$ \\
\hline $83-1.99$ & $\operatorname{ccs}$ & $\cdot$ & N co & - & - & - & $b c$ & TBrS & $15.0+$ & 15.9 . & $4.0+$ & 5.0 & 4.4 & .8 & -1.0 & $.25+$ & NM2 & $7 / 9$ \\
\hline
\end{tabular}


MEYMDERICKX STEMHED PROJECTILE POINTS

\begin{tabular}{|c|c|c|c|c|c|c|c|c|c|c|c|c|c|c|c|c|c|c|}
\hline Acc. Mo. & Matrt & Serr & Junct & Stem & Base & Grd & $x-\sec t$ & Brkge & l total & $W \max$ & W bose & $w$ neck & $\mathbf{I}$ & we & wo- $1 \mathrm{n}$ & Wo/min & $\begin{array}{c}\text { Toepel } \\
\text { Iype }\end{array}$ & $\begin{array}{l}\text { Petti } \\
\text { Iype }\end{array}$ \\
\hline$\cdots$ & $\cdots$ & $\cdots$ & $\cdots$ & $\cdots$ & $\cdots$ & $\cdots$ & $\cdots \ldots$ & $\cdots \cdots$ & $\cdots \ldots$ & $\cdots$ & $\cdots \cdots$ & $\ldots \ldots$ & $\cdots \cdot$ & $\cdots$ & $\cdots$ & $\cdots$ & $\cdots$ & $\cdots$ \\
\hline $85-18.67 .27$ & obs & N & s & - & $\cdot$ & $\cdot$ & $b c$ & is & $41.8+$ & 24.0 & & 13.3 & 7.8 & 7.9 & & & HB & $2 / 5$ \\
\hline $85-18.66 .3$ & $\operatorname{ccs}$ & N & $N \leq \mathbf{i}$ & E & $c x$ & N & pt & $\cdots$ & 35.3 & 22.0 & 20.0 & 14.0 & 8.2 & 5.1 & 6.0 & .91 & H81 & 12 \\
\hline $85-18.67 .37$ & obs & $N$ & N si & E & cx & N & $b c$ & $\mathbf{T}$ & $34.0 *$ & 22.2 & 20.1 & 16.6 & 5.4 & 3.7 & 4.5 & .91 & HBI & 12 \\
\hline $85-18.66 .15$ & ccs & N & N co & E & $c x$ & N & pt & $\cdots$ & 48.3 & 25.0 & 12.1 & 11.8 & 7.7 & 6.1 & .3 & .48 & HB2 & 1 \\
\hline $85-18.66 .18$ & ces & N & N co & E & cx & N & $b c$ & 1 & 37.8 . & 21.6 & 15.2 & 11.8 & 6.8 & 5.2 & 3.4 & .70 & HB2 & 1 \\
\hline $85-18.66 .35$ & bes & $N$ & $\mathbf{s}$ & E & $c x$ & N & ct & $\cdots$ & 53.1 & 24.4 & 18.8 & 16.0 & 10.1 & 11.4 & 2.8 & .77 & H82 & 2 \\
\hline $85-18.67 .6$ & ccs & N & N co & E & st & N & $b c$ & $\cdots$ & 34.1 & 20.4 & 12.0 & 11.2 & 6.7 & 4.4 & .8 & .59 & HB2 & 1 \\
\hline $85-18.67 .9$ & ccs & $N$ & N co & E & si & N & $b c$ & $\cdots$ & 36.2 & 22.6 & 13.6 & 12.9 & 6.1 & 3.7 & .7 & .60 & HB2 & 1 \\
\hline $85-18.67 .13$ & ccs & $n$ & N co & E & st. & N & $b c$ & TBrS & $36.6+$ & $22.6+$ & $14.0 *$ & 12.7 & 4.1 & 2.9 & $1.3 *$ & $.63+$ & HB2 & 1 \\
\hline $85-18.67 .14$ & ces & $\mathbf{s}$ & N co & E & st & N & $b c$ & $\mathbf{T}$ & 41.0 & 15.5 & 9.8 & 9.1 & 5.2 & 3.1 & .7 & .63 & HB2 & 1 \\
\hline $85-18.67 .15$ & ces & N & N co & E & cx & N & $b c$ & $\cdots$ & 40.2 & 24.8 & 17.6 & 14.7 & 6.4 & 5.4 & 2.7 & .70 & HB2 & 1 \\
\hline $85-18.67 .23$ & ccs & N & N co & E & $8 t$ & N & $b c$ & Br & 48.9 & $25.6+$ & 10.4 & 9.4 & 7.5 & 6.7 & 1.0 & $.41+$ & HB2 & 1 \\
\hline 85 - 18.67 .30 & $\operatorname{ccs}$ & N & N co & E & st & N & $b c$ & TBr & 51.0. & $24.0+$ & 14.8 & 14.4 & 5.2 & 6.2 & .4 & $.62+$ & H82 & 1 \\
\hline $85-18.67 .32$ & obs & N & $\mathbf{s}$ & E & $\cdot$ & N & $b c$ & $\mathbf{s}$ & $33.3+$ & 22.0 & $15.2+$ & 14.8 & 7.9 & 5.7 & $.4+$ & $.69+$ & HB2 & 2 \\
\hline $85-18.68 .1$ & ccs & N & N bo & E & $c x$ & $\mathbf{N}$ & $b c$ & I8r & 62.1 & $31.9+$ & $15.6+$ & 14.6 & 6.8 & 10.3 & .8 & $.48+$ & HB2 & 1 \\
\hline $85-18.68 \cdot 4$ & ccs & N & N co & $E$ & cx & $r$ & $b c$ & IBrS & 101.0 & 39.5 & 25.3 & 17.1 & 11.1 & 44.7 & 8.2 & .64 & HB2 & 1 \\
\hline $85-18.66 .9$ & ces & M & $\mathbf{s}$ & c & st & N & bt & I & $55.2 *$ & 16.4 & 4.9 & 9.9 & 7.3 & 6.6 & -5.0 & .30 & HB3 & 5 \\
\hline $85-18.66 .13$ & ccs & N & s & c & $c x$ & N & $b c$ & $\mathbf{t}$ & 49.1 . & 20.8 & 5.8 & 10.1 & 9.1 & 6.5 & -4.3 & .28 & HB3 & 5 \\
\hline $85 \cdot 18.66 .19$ & bas & N & s & c & st & $N$ & $b c$ & $\cdots$ & 39.0 & 17.2 & 9.6 & 12.2 & 5.3 & 4.3 & -2.6 & .56 & HB3 & 5 \\
\hline $85-18.66 .24$ & ccs & N & $\mathbf{s}$ & c & cr & $Y$ & $b c$ & im & 34.0 & 12.5 & 10.9 & 11.0 & 6.0 & 2.5 & -.1 & .87 & HB3 & 5 \\
\hline $85-18.66 .25$ & $\operatorname{ccs}$ & N & $\mathbf{s}$ & C & - & - & $b c$ & $\mathbf{s}$ & $46.3+$ & 23.8 & $11.2+$ & 11.9 & 7.9 & 8.8 & $-.7+$ & $.47+$ & H83 & 5 \\
\hline $85-18.67 .2$ & $\operatorname{ces}$ & N & N co & c & st & N & pc & TBrS & $42.1 \%$ & 25.6 & 9.0 * & 11.2 & 8.1 & 8.1 & -2.2 & .35 . & H83 & 4 \\
\hline $85-18.67 .3$ & ccs & N & $\mathbf{s}$ & c & - & N & pc & IBrS & $44.8+$ & 27.5 . & $8.2+$ & 12.2 & 6.8 & 6.5 & $-6.0+$ & $.30+$ & H83 & 5 \\
\hline $85-18.67 .4$ & ccs & N & s & c & st & $r$ & $b c$ & $\cdots$ & 54.6 & 15.9 & 6.7 & 13.2 & 5.0 & 4.4 & -6.5 & .42 & H83 & \\
\hline
\end{tabular}


HEYHDERICKX STEMmEd PROJECTILE POINTS

\begin{tabular}{|c|c|c|c|c|c|c|c|c|c|c|c|c|c|c|c|c|c|c|}
\hline Acc. No. & Matrl & Serr & Junct & stem & Base & Grd & $x-\sec t$ & Brkge & L total & $W \max$ & $W$ bose & $W$ neck & $\mathbf{T}$ & wt & $w_{0}-w_{n}$ & $\mathrm{~Wb} / \mathrm{Wm}$ & $\begin{array}{l}\text { Toepel } \\
\text { Iype }\end{array}$ & $\begin{array}{l}\text { Petti } \\
\text { Type }\end{array}$ \\
\hline$\cdots$ & $\cdots$ & $\cdots$ & $\cdots \cdots$ & $\cdots$ & $\cdots$ & $\cdots$ & $\cdots \cdot$ & $\cdots$ & $\cdots+$ & $\cdots$ & $\cdots$ & $\cdots$ & $\cdots$ & $\cdots$ & $\cdots$ & $\cdots$ & ....... & $\cdots$ \\
\hline $85-18.67 .7$ & ces & $N$ & s & c & - & $N$ & $b c$ & is & $62.2+$ & 27.0 & $6.0+$ & 13.3 & 11.1 & 17.5 & $-9.3+$ & $.15+$ & HB3 & 5 \\
\hline $85-18.67 .10$ & $\operatorname{ccs}$ & N & s & C & $\cdot$ & $r$ & pt & s & 55.1 & 31.8 & 10.5 . & 15.2 & 9.1 & 14.1 & -4.7 & .33 & HB3 & 5 \\
\hline $85-18.67 .19$ & $\operatorname{ccs}$ & $N$ & $\mathbf{s}$ & C & - & N & pe & $\mathbf{s}$ & 45.9 & 23.4 & $4.0 *$ & 10.1 & 7.8 & 6.9 & -6.1. & .17 & M83 & 5 \\
\hline $85-18.67 .26$ & obs & $N$ & s & C & - & $r$ & ct & MS & 45.6 & $22.2=$ & 6.8 & 10.1 & 7.6 & 5.1 & -3.3 & $.31 \cdot$ & H83 & 5 \\
\hline $85-18.67 .28$ & obs & $\mathbf{N}$ & $\mathbf{s}$ & c & st & N & $b c$ & $\mathbf{T}$ & 49.3 * & 23.6 & 10.2 & 14.6 & 9.3 & 9.6 & -4.4 & .44 & H83 & 5 \\
\hline $85-18.67 .33$ & obs & N & $\mathbf{s}$ & c & $c v$ & $r$ & $b c$ & -. & 43.8 & 22.8 & 14.0 & 17.6 & 7.1 & 6.5 & -3.6 & .61 & H83 & 5 \\
\hline $85-18.68 .2$ & $\operatorname{ccs}$ & N & N co & c & $c x$ & N & $b c$ & Br & 57.9 & $29.6 *$ & 4.7 & 11.2 & 8.1 & 7.9 & -6.5 & $.16+$ & HB3 & 4 \\
\hline $85-18.66 .8$ & ccs & N & N co & $\cdot$ & - & - & $b c$ & is & $46.0+$ & 20.0 & & 7.7 & 7.4 & 6.4 & & & MB & $1 / 4$ \\
\hline $85 \cdot 18.67 .17$ & ccs & N & N - & - & $\cdot$ & $\cdot$ & $b c$ & is & $44.1+$ & 15.5 & & 7.6 . & 5.5 & 4.0 & & & MB & $1 / 4$ \\
\hline $85-18.67 .40$ & obs & N & N co & - & - & $\cdot$ & $b c$ & is & $33.3+$ & 16.8 & & 7.8 & 4.9 & 1.9 & & & MB & $1 / 4$ \\
\hline $85-18.66 .21$ & ecs & N & N co & E & . & N & be & IMS & $25.6+$ & 13.2 . & 8.6 & 8.2 & 7.5 & 1.9 & .4 & $.65+$ & MB2 & 1 \\
\hline $85-18.69 .22$ & ccs & N & N co & E & - & N & PC & s & $23.9+$ & 21.6 & 9.0 . & 8.3 & 4.2 & 2.0 & $.7+$ & $.42+$ & MB2 & 1 \\
\hline $85-18.69 .24$ & ccs & $r$ & N - & E & - & $\cdot$ & $b c$ & BrS & $25.0+$ & 19.6 * & & 8.1. & 4.8 & 1.2 & & & MB2 & 1 \\
\hline $85-18.69 .29$ & ccs & N & s & E & cv & N & $b c$ & $\cdots$ & 23.2 & 14.2 & 8.6 & 7.9 & 3.6 & .8 & .7 & .61 & MB2 & 2 \\
\hline $85-18.66 .7$ & $\operatorname{ccs}$ & N & s & c & cr & N & $b c$ & -. & 27.2 & 12.0 & 4.5 & 9.0 & 5.2 & 1.5 & -4.5 & .38 & MB3 & 5 \\
\hline $85-18.66 .10$ & ccs & $N$ & N co & c & st & N & $b c$ & is & 26.7 & 17.1 & $5.7{ }^{\circ}$ & 8.1 & 5.7 & 2.1 & -2.4 & .33 & M83 & 4 \\
\hline $85-18.66 .11$ & ccs & $N$ & $\mathbf{s}$ & c & cr & N & $b c$ & $\mathbf{T}$ & 27.1 . & 14.2 & 5.6 & 7.5 & 5.2 & 1.3 & -1.9 & .39 & H83 & 5 \\
\hline $85-18.66 .20$ & $\operatorname{ccs}$ & N & s & C & $c x$ & $r$ & $b c$ & $\cdots$ & 30.6 & 15.6 & 4.4 & 8.9 & 6.1 & 3.2 & -4.5 & .28 & M83 & 5 \\
\hline $85-18.66 .22$ & ccs & N & s & c & - & - & $b c$ & MS & $42.0+$ & 21.6 & $6.4+$ & 7.9 & 7.1 & 6.9 & $-1.5+$ & $.30+$ & MB3 & 5 \\
\hline $85-18.67 .38$ & obs & N & $\mathbf{s}$ & C & st & $Y$ & $b c$ & $\mathbf{T}$ & 31.3 . & 18.0 & 5.0 & 8.6 & 6.5 & 3.3 & -3.6 & .28 & M83 & 5 \\
\hline $85-18.69 .23$ & $\operatorname{ccs}$ & N & $\mathbf{s}$ & C & st & N & $b c$ & $\cdots$ & 22.8 & 12.0 & 5.7 & 7.9 & 3.1 & .8 & -2.2 & .47 & MB3 & 5 \\
\hline $85-18.66 .32$ & ccs & s & N co & $\cdot$ & - & $\cdot$ & pC & s & 17.8 & 13.0 & & 5.4 & 3.5 & .7 & & & NN & $7 / 9$ \\
\hline $85-18.67 .39$ & obs & N & $\mathbf{s}$ & $\cdot$ & - & $\cdot$ & $b c$ & $\mathbf{s}$ & $30.2+$ & 15.6 & & 7.0 & 6.0 & 2.5 & & & MN & $8 / 10$ \\
\hline
\end{tabular}


HEYNDERICKX STEMEO PROJECTILE POINTS

\begin{tabular}{|c|c|c|c|c|c|c|c|c|c|c|c|c|c|c|c|c|c|c|}
\hline Acc. No. & Matrl & Serr & Junct & Stem & Base & Grd & $x-\sec t$ & Brkge & L total & $W \max$ & $W$ bose & weck & $T$ & we & Wo- Wn & Wo/un & $\begin{array}{c}\text { Toepel } \\
\text { Type }\end{array}$ & $\begin{array}{l}\text { Petti } \\
\text { Type }\end{array}$ \\
\hline . & $\cdots$ & $\cdots$ & $\cdots$ & $\cdots$ & $\cdots$ & $\cdots$ & $\cdots \cdots$ & $\cdots$ & ........ & $\cdots$ & $\cdots \cdots$ & $\cdots \cdots$ & $\cdots$ & $\cdots$ & $\cdots$ & $\cdots$ & $\cdots$ & $\cdots$ \\
\hline $85-18.69 .9$ & ccs & N & N & $\cdot$ & $\cdot$ & $\cdot$ & $b c$ & TBrS & $9.0+$ & $12.8+$ & & 4.2 & 2.8 & .4 & & & NM & $7 / 9$ \\
\hline $85-18.69 .11$ & $\operatorname{ccs}$ & s & $M$ & • & - & - & $b c$ & TBrS & $12.1+$ & $13.2+$ & & 4.9 & 2.6 & .3 & & & NM & $7 / 9$ \\
\hline $85-18.69 .12$ & ccs & $\mathbf{s}$ & $N=$ & $\cdot$ & $\cdot$ & $\cdot$ & $b c$ & s & $12.9+$ & 17.1 & & 6.2 & 3.3 & .6 & & & NN & $7 / 9$ \\
\hline $85-18.69 .27$ & ccs & N & $N \cdot$ & - & - & $\cdot$ & pC & TBrs & $11.3+$ & 16.0 . & & 4.5 & 3.1 & .3 & & & NN & $7 / 9$ \\
\hline $85-18.69 .34$ & obs & $\mathbf{s}$ & N - & $\cdot$ & $\cdot$ & - & pC & Brs & $15.9+$ & $11.1{ }^{\circ}$ & & 4.1 & 2.0 & .3 & & & NN & $7 / 9$ \\
\hline $85-18.69 .37$ & obs & $\mathbf{s}$ & N - & $\cdot$ & - & - & $b c$ & $\mathbf{s}$ & $18.5+$ & 14.6 & & 5.1 & 3.1 & .5 & & & NN & $7 / 9$ \\
\hline $85 \cdot 18.69 .41$ & obs & N & $N \cdot$ & $\cdot$ & $\cdot$ & $\cdot$ & $b c$ & BrS & $14.8+$ & $11.0+$ & & 3.9 & 2.8 & .3 & & & NN & $7 / 9$ \\
\hline $85-18.66 .28$ & ccs & N & $\mathbf{s}$ & c & $8 t$ & N & $b c$ & $\mathbf{T}$ & 27.6 * & 9.1 & 2.7 & 5.0 & 3.9 & .8 & -2.3 & .30 & NM2 & 10 \\
\hline $85-18.66 .30$ & ccs & N & N co & E & st & N & $b c$ & IBrS & $22.0+$ & $11.1+$ & $6.5 *$ & 5.9 & 4.1 & .7 & $.6 *$ & $.59+$ & HW2 & 7 \\
\hline $85 \cdot 18.66 .31$ & obs & N & N co & s & st & N & pC & TBr & 14.6 . & 10.9 & 4.4 & 4.4 & 2.1 & .2 & 0.0 & $.40+$ & NM2 & 9 \\
\hline $85-18.66 .33$ & ces & N & $\mathbf{s}$ & c & $c x$ & N & $b c$ & $8 r$ & 20.8 & $13.1 *$ & 3.4 & 5.8 & 4.2 & .9 & -2.6 & .26 & NM2 & 10 \\
\hline $85-18.66 .36$ & obs & N & N co & E & si & N & $b c$ & Br & 19.2 & $15.8 *$ & 7.6 & 6.2 & 3.8 & .7 & 1.4 & $.48 *$ & MN2 & 7 \\
\hline $85-18.67 .20$ & ccs & $n$ & $\mathbf{s}$ & C & pt & $r$ & bc & $\cdots$ & 31.6 & 9.3 & 2.2 & 4.6 & 4.3 & 1.1 & -2.4 & .24 & NM2 & 10 \\
\hline $85-18.67 .21$ & $\operatorname{ccs}$ & s & N co & E & sl & N & DC & $\cdots$ & 27.6 & 16.5 & 7.4 & 6.9 & 3.3 & 1.0 & .5 & .45 & NH2 & 7 \\
\hline $85-18.67 .41$ & $\operatorname{ccs}$ & s & N co & E & - & $n$ & $p C$ & $\mathbf{s}$ & $28.6+$ & 13.6 & $8.1+$ & 6.6 & 4.4 & 1.5 & $1.5+$ & $.60+$ & NM2 & 7 \\
\hline $85-18.69 .2$ & $\operatorname{ccs}$ & N & $\mathbf{s}$ & C & $c x$ & $r$ & PC & $\mathbf{T}$ & 23.1 . & 12.1 & 3.0 & 4.9 & 2.9 & .6 & -1.9 & .25 & NH2 & 10 \\
\hline $85-18.69 .4$ & ccs & N & $\mathbf{s}$ & $\mathbf{s}$ & st & $N$ & $b c$ & Brs & 19.8 & $12.9 *$ & 6.4 & 6.4 & 4.0 & .7 & 0.0 & .50 & MK2 & 10 \\
\hline $85: 18.69 .5$ & $\operatorname{ccs}$ & N & N co & E & $c x$ & N & ct & IBr & 21.0 & 10.0 & 4.0 & 3.5 & 3.2 & .6 & .5 & .40 & MN2 & 7 \\
\hline $85-18.69 \cdot 6$ & ccs & $n$ & N co & s & cx & N & bc & $\mathrm{TBr}$ & 19.2 & $11.8+$ & 4.1 & 4.1 & 3.6 & .4 & 0.0 & $.35+$ & NH2 & 9 \\
\hline $85-18.69 .7$ & ccs & N & $\mathbf{s}$ & c & $\cdot$ & N & be & IBrS & 19.5 & $14.5 *$ & $4.0+$ & 5.2 & 3.0 & .4 & $-1.2+$ & $.28+$ & MM2 & 10 \\
\hline $85-18.69 .8$ & $\operatorname{ccs}$ & s & N co & E & $c x$ & N & $b c$ & $\cdots$ & 20.2 & 12.4 & 5.8 & 5.5 & 3.6 & .6 & .3 & .47 & MM2 & 7 \\
\hline $85-18.69 .16$ & ces & $\mathbf{s}$ & N co & s & $c x$ & N & bc & TBrS & 16.1 & 12.2 & 4.0 & 4.0 & 3.2 & .4 & 0.0 & .33 & MN2 & 9 \\
\hline $85-18.69 .17$ & ccs & N & N co & E & $\cdot$ & N & $b c$ & Brs & $17.9+$ & $14.6+$ & 5.0 & 4.5 & 2.9 & .5 & $.5+$ & $.34+$ & MN2 & 7 \\
\hline $85-18.69 .18$ & ccs & N & $\mathbf{N} \cdot$ & E & $c x$ & N & $b c$ & BrS & 25.0 & $14.1+$ & $5.0 *$ & 4.4 & 3.3 & .8 & $.6 *$ & $.35+$ & MN2 & 7 \\
\hline $85 \cdot 18.69 .20$ & ces & N & N co & c & $c x$ & N & $b c$ & IBr & $18.3+$ & $12.6+$ & 3.4 & 4.2 & 3.4 & .6 & $\cdot .8$ & $.27+$ & MW2 & 9 \\
\hline $85-18.69 .31$ & obs & N & N co & C & $c x$ & N & bc & $\cdots$ & 14.8 & 13.8 & 2.8 & 4.3 & 2.8 & .3 & -1.5 & .20 & NM2 & 9 \\
\hline $85=18.69 .32$ & $\operatorname{ccs}$ & N & N co & $\mathbf{s}$ & st & N & $b c$ & $\mathrm{TBr}$ & $18.3 *$ & $15.0^{\circ}$ & 6.1 & 6.1 & 2.6 & .4 & 0.0 & .41 & NM2 & 9 \\
\hline $85-18.69 .33$ & obs & N & N co & E & $\cdot$ & N & $b c$ & IMBrS & $13.8+$ & $15.0^{*}$ & $5.4+$ & 5.0 & 3.2 & .5 & $.4+$ & $.36+$ & MM2 & 7 \\
\hline $85-18.69 .35$ & $\operatorname{ccs}$ & $\mathbf{s}$ & N co & C & $c x$ & $\mathbf{N}$ & pt & $T$ & $18.4{ }^{*}$ & 10.4 & 2.2 & 4.6 & 3.0 & .3 & -2.4 & .21 & NN2 & 9 \\
\hline
\end{tabular}


HEYMDERICKX STEMMEO PROJECTILE POINTS

Acc. No.

\section{Acc. No.}

$85-18.69 .36$

$85-18.69 .39$

$85-18.69 .42$

$85 \cdot 18.69 .44$

$85-18.69 .45$

$85-18.69 .46$

$85-18.67 .5$

$85 \cdot 18.67 .22$

85-18.69. 1

$85 \cdot 18.69 .3$

$85 \cdot 18.69 .19$

$85 \cdot 18.69 .21$

$85-18.69 .26$

$85-18.69 .28$

$85 \cdot 18.69 .30$

$85 \cdot 18.69 .40$
Matrl Serr Junct Stem Base Grd X-sect Brkge $L$ total

\begin{tabular}{|c|c|c|c|c|c|c|c|}
\hline ccs & N & N co & S & se & M & $p C$ & $\cdots$ \\
\hline obs & S & N co & c & $c x$ & N & $b c$ & -. \\
\hline obs & N & S & E & - & N & $b c$ & Brs \\
\hline obs & $\gamma$ & N co & E & $c x$ & N & $b c$ & BrS \\
\hline ccs & $n$ & N co & S & 81 & $N$ & $b c$ & $\mathrm{Br}$ \\
\hline ccs & $N$ & N co & $E$ & - & $N$ & $p c$ & Brs \\
\hline
\end{tabular}

$24.0 \quad 15.9$

$\begin{array}{llll}19.1 & 13.0 & 2.8 & 4.0\end{array}$

$22.0+10.3+6.0 * 5.4$

$23.9 \quad 11.0 * 5.0 * 4.2$

$18.4 \quad 13.3+4.8 \quad 4.8$

$14.1+12.1 * 5.5+4.9$

$\begin{array}{lll}\text { ccs } & \text { N } & \text { N co } \\ \operatorname{ccs} & \text { N } & \text { S } \\ \operatorname{ccs} & \text { N } & \text { S } \\ \text { ccs } & \text { N } & \text { S } \\ \operatorname{ccs} & \text { N } & \text { N ba } \\ \operatorname{ccs} & \text { N } & \text { S } \\ \operatorname{ccs} & \text { N } & \text { S } \\ \operatorname{ccs} & \text { N } & \text { N co } \\ \operatorname{ccs} & \text { S } & \text { N co } \\ \text { obs } & \text { N } & \text { S }\end{array}$

\begin{tabular}{|c|c|c|c|}
\hline & $N$ & $b c$ & 5 \\
\hline$c x$ & $N$ & pt & .. \\
\hline pt & $N$ & PC & In \\
\hline st & $N$ & pt & $\boldsymbol{T}$ \\
\hline st & $N$ & $b c$ & $\mathrm{TBr}$ \\
\hline st & N & $b c$ & $\mathrm{Br}$ \\
\hline sl & N & $c t$ & .. \\
\hline$c x$ & N & $b c$ & $\mathrm{Br}$ \\
\hline - & N & $b c$ & $\mathbf{S}$ \\
\hline$c x$ & $Y$ & $b c$ & $\cdots$ \\
\hline
\end{tabular}

$\begin{array}{llll}35.4+15.6 & 2.5 * & 4.0 \\ 30.3 & 11.9 & 2.3 & 3.9 \\ 25.1 * 13.9 & 2.0 & 6.4 \\ 21.0 * 11.2 & 2.1 & 6.5 \\ 22.2+14.0 * & 1.9 & 2.4 \\ 16.9-12.5 * & 2.1 & 4.8 \\ 20.0 & 10.8 & 2.1 & 4.1 \\ 41.0 & 17.2 * & 3.0 & 5.4 \\ 19.0 & 12.2 & 2.2 * & 4.3 \\ 14.6 & 11.6 & 2.0 & 4.5\end{array}$

Toepel Petti

Iype Iype

\begin{tabular}{|c|c|c|c|}
\hline I & wt & wh- In & $\mathrm{m} / \mathrm{mm}$ \\
\hline & & & \\
\hline
\end{tabular}

$\begin{array}{cccccc}2.5 & .8 & 0.0 & .36 & \text { NH2 } & 9 \\ 4.1 & .7 & -1.2 & .22 & \text { NH2 } & 9 \\ 3.8 & .7 & .6 * & .58+ & \text { NH2 } & 8 \\ 3.0 & .5 & .8 * & .45 * & \text { HN2 } & 7 \\ 3.1 & .4 & 0.0 & .36+ & \text { NM2 } & 9 \\ 2.0 & .3 & .6+ & .45+ & \text { NH2 } & 7\end{array}$

\begin{tabular}{|c|c|c|c|c|c|}
\hline 4.2 & 2.2 & -1.5 & .16 & WN3 & 9 \\
\hline 4.6 & 1.4 & -1.6 & .19 & NM3 & 10 \\
\hline 3.4 & .7 & -4.4 & .14 & NH3 & 10 \\
\hline 4.1 & .8 & -4.4 & .19 & NM3 & 10 \\
\hline 2.8 & .5 & $\cdot .5$ & $.16 *$ & NM3 & 9 \\
\hline 3.4 & .4 & -2.7 & .17 & MN3 & 10 \\
\hline 4.2 & .6 & -2.0 & .19 & NM3 & 10 \\
\hline 3.8 & 1.8 & -2.4 & .17 & NM3 & 9 \\
\hline 3.4 & .5 & -2.1 & .18 & NM3 & 9 \\
\hline 2.9 & .2 & -2.5 & .17 & NM3 & 10 \\
\hline
\end{tabular}


IBACH STEMLESS PROJECTILE POINTS

\begin{tabular}{|c|c|c|c|c|c|c|c|c|c|c|c|c|c|c|c|c|}
\hline Accessiun Mo. & Matrl & Serr & Shape & Base & Grd & $x-\sec t$ & Brkge & L total & $U \max$ & $u$ bose & $\mathbf{T}$ & wt & Wo/Ln & $r / \ln$ & $\begin{array}{c}\text { Toepel } \\
\text { Type }\end{array}$ & $\begin{array}{l}\text { Petti } \\
\text { Iype }\end{array}$ \\
\hline$\cdots$ & $\cdots$ & $\cdots$ & $\cdots$ & $\cdots$ & $\cdots$ & $\cdots$ & $\cdots$ & ........ & $\cdots$ & $\cdots$ & $\ldots$ & $\cdots$ & $\cdots$ & $\cdots$ & $\cdots$ & $\cdots$ \\
\hline 83-1. 1 & ccs & N & leo & st & $r$ & $b c$ & T & 60.2 . & 21.8 & 8.9 & 9.0 & 10.5 & .41 & .61 & HS2 & 68 \\
\hline $83-1,13$ & ces & N & les & st & N & bc & $\mathbf{T}$ & $32.0+$ & 19.7 & 11.0 & 6.9 & 3.9 & .56 & .35 & HS2 & 6 \\
\hline $83-1.14$ & ces & $n$ & len & $c x$ & N & be & $\cdots$ & 55.0 & 19.8 & 9.0 & 9.4 & 10.1 & .45 & .47 & HS2 & 6 \\
\hline $83-1.41$ & obs & N & Ian & cr & $\cdot$ & ct & $\cdots$ & 36.3 & 14.0 & 9.9 & 5.7 & 2.8 & .71 & .41 & HS2 & 6 \\
\hline $83-1.43$ & ccs & N & lea & st & $n$ & $b c$ & $\cdots$ & 32.9 & 16.8 & 6.1 & 5.8 & 2.6 & .41 & .39 & HS2 & $6 a$ \\
\hline $83-1.72$ & ccs & N & lea & $c x$ & $r$ & $c t$ & $\mathbf{T}$ & $41.0+$ & 22.9 & 10.7 & 6.9 & 7.1 & .47 & .30 & HS2 & 6 \\
\hline 83-1. 75 & $\operatorname{ccs}$ & N & lea & $c x$ & $\cdot$ & $c t$ & IM & $34.2+$ & 20.1 & 11.0 & 9.0 & 6.5 & .55 & .45 & HS2 & 6 \\
\hline $83 \cdot 1.100$ & obs & s & lea & $c x$ & N & $b c$ & B & $32.0^{\circ}$ & 16.1 & 8.0 . & 6.1 & 2.5 & .50 & .38 & HS2 & 6 \\
\hline $83-1.122$ & abs & $\mathbf{s}$ & leo & $\cdot$ & N & bc & TMBs & $30.5+$ & 26.0 & $7.8+$ & 6.0 & 5.5 & $.30+$ & .23 & HS2 & 6 \\
\hline $83-1 . \quad 3$ & bas & N & Ian & $c x$ & N & $b c$ & $\mathbf{T}$ & $53.0+$ & 27.4 & 7.6 & 9.1 & 13.1 & .27 & .33 & HS3 & 6 \\
\hline $83-1.7$ & bas & N & Ian & st & $\cdot$ & bc & $\cdots$ & 48.1 & 23.9 & 3.1 & 7.4 & 9.2 & .13 & .31 & MS3 & 60 \\
\hline $83-1.8$ & bas & N & Ion & cv & $Y$ & $b c$ & $T$ & $45.6+$ & 27.6 & 9.3 & 7.9 & 11.2 & .36 & .29 & HS3 & 6 \\
\hline $83-1.17$ & bas & N & lea & $c x$ & $\cdot$ & $c t$ & Bs & 64.5 & 26.0 & $4.2 *$ & 6.6 & 12.1 & .16 & .25 & HS3 & 6 \\
\hline $83-1.19$ & ces & N & Ian & pt & $r$ & $b c$ & $T$ & 48.0 & 17.1 & 2.0 & 8.0 & 5.8 & .12 & .67 & HS3 & $6 b$ \\
\hline $83-1.24$ & ccs & N & - & pt & $N$ & be & TM & $26.6+$ & 15.8 & 3.5 & 7.0 & 2.7 & .22 & .64 & HS3 & 6 \\
\hline $83-1.26$ & ccs & N & Ion & $c x$ & N & $b c$ & $\mathbf{T}$ & $27.7+$ & 18.8 & 5.0 & 6.0 & 3.2 & .27 & .32 & HS3 & 6 \\
\hline $83-1.31$ & ccs & N & $\operatorname{lan}$ & $c x$ & N & $p c$ & IBS & $41.9+$ & 19.8 & $5.0 *$ & 7.5 & 5.0 & $.25 *$ & .38 & HS3 & 68 \\
\hline $83-1.33$ & ccs & N & Ian & $c x$ & N & be & TBs & 29.4 & 12.9 & $4.2 *$ & 6.8 & 2.2 & $.33 *$ & .53 & HS3 & 6a \\
\hline $83-1.34$ & bas & N & $\operatorname{lan}$ & cr & $r$ & $b c$ & $\cdots$ & 50.8 & 29.9 & 9.6 & 7.8 & 10.6 & .32 & .26 & HS3 & 6 \\
\hline $23-1.35$ & bas & N & Ian & pt & N & bc & $T$ & 76.4 . & 29.1 & 4.0 & 7.9 & 18.1 & .14 & .27 & HS3 & 6 \\
\hline $83-1.42$ & bas & N & Ion & $c x$ & $Y$ & $b c$ & $\mathbf{T}$ & 49.9 - & 27.5 & 5.0 & 10.0 & 11.8 & .18 & .36 & HS3 & 6 \\
\hline $83-1.48$ & bas & $\mathbf{s}$ & Ian & pt & N & ct & $\boldsymbol{T}$ & $97.6 *$ & 22.9 & 5.0 & 8.2 & 21.5 & .22 & .36 & HS3 & $6 b$ \\
\hline $83-1.54$ & bas & s & Ian & pt & $r$ & bc & $\mathbf{T}$ & $64.4+$ & 29.8 & 4.2 & 8.0 & 15.8 & .14 & .27 & MS3 & 6 \\
\hline 83-1. 56 & ccs & N & $\operatorname{lan}$ & $c x$ & N & bc & IBs & $28.3+$ & 16.2 & $4.9^{\circ}$ & 5.8 & 3.1 & $.30 *$ & .36 & HS3 & 6 \\
\hline $83-1.67$ & bas & N & $\operatorname{lan}$ & si & N & $\mathbf{p c}$ & $\mathbf{T}$ & 53.3 . & 20.8 & 7.0 & 6.2 & 7.3 & .34 & .30 & NS3 & 6 \\
\hline $83-1 \cdot 70$ & ccs & N & Ion & st & N & bc & $\mathbf{T}$ & $35.2+$ & 20.5 & 8.0 & 6.5 & 5.0 & .39 & .32 & HS3 & 6 \\
\hline $83-1.74$ & ccs & N & Ian & $c x$ & $\cdot$ & $b c$ & TBS & $37.2+$ & 22.1 & $6.0 *$ & 6.9 & 6.1 & $.27 *$ & .31 & HS3 & 6 \\
\hline
\end{tabular}


IBACH STEMLESS PROJECTILE POINTS

\begin{tabular}{|c|c|c|c|c|c|c|c|c|c|c|c|c|c|c|c|c|}
\hline Accession No. & Matrl & Serr & Shape & Base & Grd & $x-\sec t$ & Brkge & L total & $y \max$ & 4 base & $\mathbf{T}$ & Wt & 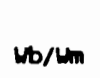 & $\mathrm{T} / \mathrm{Lm}$ & $\begin{array}{c}\text { Toepel } \\
\text { Type }\end{array}$ & $\begin{array}{r}\text { Petti } \\
\text { Iype }\end{array}$ \\
\hline 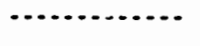 & $\cdots$ & $\cdots$ & $\cdots$ & $\cdots$ & $\cdots$ & $\cdots$ & $\ldots$ & ....... & $\cdots$ & $\cdots \cdots$ & $\cdots .$. & $\cdots$ & $\cdots$ & $\cdots$ & ......... & $\cdots$ \\
\hline $83 \cdot 1.76$ & bas & $\mathbf{s}$ & Ion & $c x$ & $r$ & $b c$ & IM & $56.2+$ & 31.9 & 8.0 & 9.3 & 19.1 & .25 & .29 * & HS3 & 6 \\
\hline $83-1.81$ & bas & N & Ian & pe & $\cdot$ & $b c$ & $T$ & $63.8 *$ & 23.8 & 5.0 & 7.8 & 12.4 & .21 & .33 & HS3 & $6 b$ \\
\hline $83-1.86$ & $\operatorname{ccs}$ & N & $\tan$ & st & $N$ & ct & $\boldsymbol{T}$ & $26.8 *$ & 12.1 & 4.2 & 5.2 & 1.4 & .35 & .43 & KS3 & $6 b$ \\
\hline 83-1. 95 & $\operatorname{ccs}$ & - & $\cdot$ & $c x$ & $r$ & pe & TM & $22.1+$ & $19.8+$ & 5.0 & 5.2 & 2.2 & $.25 *$ & $.26+$ & HS3 & 6 \\
\hline $83-1.102$ & ces & $N$ & Ion & $c x$ & $r$ & $b c$ & TBs & 36.1 . & 16.9 & 6.9 & 5.2 & 2.7 & .29 & .31 & HS3 & 6 \\
\hline $83-1.103$ & $\operatorname{ccs}$ & $\mathbf{s}$ & $\cdot$ & st & $\cdot$ & bt & TM & $26.1+$ & 11.9 & 3.3 & 5.8 & 1.7 & .28 & .49 & HS3 & $6 b$ \\
\hline $83-1.107$ & obs & $r$ & $\operatorname{lan}$ & - & $r$ & $c t$ & TBs & $60.8+$ & 23.5 & $9.0^{*}$ & 9.3 & 13.7 & .38 & .40 & HS3 & 6 \\
\hline $83 \cdot 1.109$ & obs & N & Ian & $\cdot$ & - & $b c$ & MBs & 65.2 . & $25.8+$ & 8.0 & 9.8 & 14.4 & $.31+$ & $.38+$ & HS3 & 6 \\
\hline $83-1.116$ & $\operatorname{ccs}$ & s & $\tan$ & $c x$ & $N$ & ct & rBs & 36.7 . & 17.0 & 5.7 & 7.2 & 4.0 & .36 & .42 & HS3 & 6 \\
\hline $83-1.118$ & obs & $\cdot$ & $\cdot$ & $c x$ & - & pt & TH & 33.7 & 23.0 & 6.5 & 8.0 & 6.4 & .28 & .35 & HS3 & 6 \\
\hline $83-1.119$ & $\operatorname{ccs}$ & $\gamma$ & $\operatorname{lon}$ & pt & $\cdot$ & ct & $\mathbf{T}$ & $30.1+$ & 14.8 & 2.0 & 6.9 & 2.3 & .14 & .47 & HS3 & $6 b$ \\
\hline $83-1.126$ & obs & N & Ion & $c x$ & - & $b c$ & 8 & $41.4+$ & 19.8 & $5.0 *$ & 7.0 & 4.6 & .25 & .35 & NS3 & 6 \\
\hline $83-1.127$ & obs & N & Ian & - & N & $b c$ & IBS & 40.0 & 21.1 & $5.2+$ & 5.9 & 5.3 & $.25+$ & .28 & HS3 & 6 \\
\hline 83-1. 44 & ces & N & Ion & st & $r$ & $b c$ & $\cdots$ & 33.2 & 12.6 & 3.8 & 4.9 & 1.7 & .31 & .60 & ss3 & $6 b$ \\
\hline $83-1.85$ & ccs & N & Ian & $c x$ & $\mathbf{N}$ & $D C$ & $\cdots$ & 26.8 & 13.8 & 6.1 & 2.8 & 1.1 & .30 & .20 & ss3 & $6 a$ \\
\hline $83 \cdot 1.128$ & obs & N & Ian & pt & $N$ & $b c$ & $\cdots$ & 29.0 & 13.1 & 1.9 & 6.1 & 1.3 & .15 & .31 & ss3 & $6 b$ \\
\hline
\end{tabular}


MEYMDERICKX SIEMLESS PROJECTILE POINTS

\begin{tabular}{|c|c|c|c|c|c|c|c|c|c|c|c|c|c|c|c|c|}
\hline Accession No. & Matrl & Serr & Shape & Base & Grd & $x-\sec t$ & Brkge & L total & $y \max$ & $\checkmark$ base & $\mathbf{I}$ & ve & Wh/ & $T / m n$ & $\begin{array}{c}\text { Toepel } \\
\text { Type }\end{array}$ & $\begin{array}{r}\text { Petti } \\
\text { Type }\end{array}$ \\
\hline , n & $\cdots$ & $\cdots$ & $\cdots$ & $\cdots$ & $\cdots$ & $\cdots$ & $\cdots$ & ........ & $\cdots$ & $\cdots \cdots$ & $\cdots$ & $\cdots$ & $\cdots$ & $\cdots$ & $\ldots \ldots$ & $\ldots$ \\
\hline $85-18.66 .1$ & $\operatorname{ccs}$ & N & lea & - & N & $b c$ & MBs & 43.6 & 16.7 & $12.0 *$ & 5.5 & 3.8 & $.72 *$ & .33 & HS2 & 6 \\
\hline $85-18.66 .4$ & $\operatorname{ccs}$ & $N$ & les & cx & N & bt & $\cdot-$ & 43.1 & 15.9 & 6.5 & 7.7 & 4.5 & .41 & .48 & HS2 & $6 b$ \\
\hline $85-18.66 .16$ & $\operatorname{ccs}$ & $N$ & lea & cx & N & $b c$ & IM & $45.0 *$ & 20.7 & 13.7 & 7.0 & 5.9 & .66 & .34 & HS2 & 6 \\
\hline $85-18.67 .25$ & ccs & $N$ & lea & $c x$ & N & DC & Bs & 52.8 & 19.8 & 12.3 & 5.1 & 5.6 & $.62 *$ & .26 & HS2 & 6 \\
\hline $85 \cdot 18.67 .29$ & $\operatorname{ccs}$ & N & lea & cx & N & $b c$ & $\mathbf{T}$ & $45.8+$ & 17.3 & 10.9 & 6.9 & 5.6 & .63 & .40 & KS2 & 6 \\
\hline $85-18.67 .31$ & obs & $N$ & les & cx & N & $b c$ & $\cdots$ & 36.4 & 19.0 & 8.2 & 6.1 & 4.5 & .43 & .32 & HS2 & 6 \\
\hline $85-.18 .67 .34$ & pund & $N$ & lea & st & N & $b c$ & In & $52.5 *$ & 17.9 & 7.2 & 8.9 & 9.2 & .40 & .50 & HS2 & $6 a$ \\
\hline $85 \cdot 18.67 .35$ & ccs & N & lea & $c x$ & N & bc & $T$ & $46.3{ }^{\circ}$ & 23.2 & 16.3 & 7.0 & 6.8 & .70 & .30 & HS2 & 6 \\
\hline $85-18.68 .3$ & $\operatorname{ccs}$ & N & lea & st & N & $b c$ & $\mathbf{T}$ & $50.7 *$ & 22.8 & 15.2 & 7.5 & 8.0 & .67 & .33 & HS2 & 6 \\
\hline $85-18.68 .7$ & $\operatorname{ccs}$ & N & lea & cx & N & bc & $\cdots$ & 90.4 & 36.7 & 23.0 & 8.9 & 29.7 & .63 & .24 & HS2 & 6 \\
\hline $85-18.66 .12$ & $\operatorname{ccs}$ & s & Ian & st & N & pt & $\mathrm{T}$ & $37.1 *$ & 13.9 & 5.0 & 7.0 & 2.9 & .36 & .50 & HS3 & $6 a$ \\
\hline $85-18.66 .17$ & $\operatorname{ccs}$ & $N$ & $\operatorname{lan}$ & pt & $r$ & bt & $\cdots$ & 41.8 & 12.2 & 4.6 & 7.0 & 3.4 & .38 & .57 & MS3 & $6 b$ \\
\hline $85-18.66 .26$ & $\operatorname{ccs}$ & N & $\operatorname{lon}$ & st & N & $b c$ & TM & $53.5 *$ & 17.9 & 7.0 & 8.1 & 8.0 & .39 & .45 & HS3 & 60 \\
\hline $85-18.66 .36$ & abs & N & $\operatorname{lan}$ & cr & r & bc & $\cdots$ & 56.9 & 22.3 & 7.2 & 9.1 & 10.9 & .32 & .41 & HS3 & 6 \\
\hline $85 \cdot 18.66 .37$ & ccs & $N$ & $\tan$ & pt & N & ct & $\cdots$ & 52.2 & 20.3 & 5.3 & 8.9 & 7.4 & .26 & .46 & HS3 & $6 b$ \\
\hline $85-18.67 .1$ & $\operatorname{ccs}$ & $N$ & $\operatorname{lon}$ & pt & r & pc & IM & $39.4+$ & 16.2 & 3.2 & 5.9 & 3.8 & .20 & .36 & HS3 & $6 b$ \\
\hline $85-18.67 .8$ & $\operatorname{ccs}$ & $N$ & Ian & st & N & pt & $\cdots$ & 43.0 & 15.8 & 4.6 & 8.2 & 5.0 & .29 & .52 & HS3 & $6 b$ \\
\hline $85-18.67 .11$ & ccs & N & lan & pt & N & $b c$ & $\cdot-$ & 44.0 & 20.9 & 4.7 & 7.2 & 6.3 & .22 & .34 & HS3 & 6 \\
\hline $85 \cdot 18.67 .18$ & ccs & M & Ian & $c x$ & $r$ & $b c$ & $\cdots$ & 31.9 & 13.6 & 5.0 & 5.2 & 2.1 & .37 & .38 & HS3 & $6 b$ \\
\hline $85-18.69 .38$ & obs & N & tri & st & N & PC & $\cdots$ & 16.0 & 11.2 & 11.2 & 2.1 & .3 & 1.00 & .19 & SSi & 14 \\
\hline $85-18.69 .43$ & obs & $\mathbf{s}$ & tri & st & N & $p c$ & $\cdots$ & 14.1 & 10.2 & 10.2 & 1.8 & .2 & 1.00 & .18 & SS1 & 14 \\
\hline $85-18.69 .25$ & $\operatorname{ccs}$ & s & lea & cx & N & $b c$ & $\mathbf{T}$ & $21.4 *$ & 11.6 & 7.3 & 3.2 & .8 & .63 & .28 & SS2 & $6 d$ \\
\hline
\end{tabular}


IBACH PROJECTILE POINT FRAGMEMTS

Accession Mo. Frogment type Matrl Serr Mrgn $X$-sect $L$ total waximum I wt.

\begin{tabular}{|c|c|c|c|c|c|c|c|c|c|}
\hline $83-1.6$ & Bl ade & bas & N & E & $b c$ & 41.1 & 27.8 & 12.2 & 12.8 \\
\hline $83-1.9$ & Blade & ces & M & E & $c t$ & 29.2 & 16.6 & 6.9 & 2.3 \\
\hline $83-1.21$ & Bl ade & ces & N & E & be & 51.4 & 19.8 & 9.8 & 7.5 \\
\hline $83-1.39$ & Bl ade & ccs & N & $E$ & $p c$ & 23.0 & 24.0 & 8.3 & 3.9 \\
\hline $83 \cdot 1.40$ & Bl ade & $\operatorname{ccs}$ & N & E & be & 32.8 & 15.5 & 7.7 & 3.6 \\
\hline $83-1.49$ & Bl ade & $\operatorname{ccs}$ & $r$ & E & $b c$ & 59.9 & 23.2 & 8.9 & 13.2 \\
\hline $83-1.52$ & Bl ade & $\operatorname{ccs}$ & M & $\mathbf{s}$ & bt & 68.2 & 32.9 & 11.9 & 22.7 \\
\hline $83-1.57$ & Blade & ecs & N & $\mathbf{s}$ & bt & 33.3 & 16.8 & 6.0 & 3.1 \\
\hline $83-1.61$ & Bl ade & $\operatorname{ccs}$ & $r$ & $\mathbf{s}$ & DC & 37.0 & 21.0 & 5.9 & 3.9 \\
\hline $83-1.63$ & Bl ode & $\operatorname{ccs}$ & N & E & $b c$ & 30.1 & 20.0 & 7.1 & 3.5 \\
\hline 83.1 .77 & Bl sode & $\operatorname{ccs}$ & N & E & $b c$ & 46.8 & 22.0 & 8.8 & 10.5 \\
\hline 83.1 .80 & Bl ade & $\operatorname{ccs}$ & N & E & $\not c$ & 48.9 & 28.4 & 8.2 & 11.6 \\
\hline $83 \cdot 1.89$ & Blade & $\operatorname{ccs}$ & $r$ & s & $b c$ & 22.3 & 17.2 & 6.0 & 2.0 \\
\hline $83-1.93$ & Bl ade & $\operatorname{ccs}$ & N & s & $b c$ & 31.0 & 18.9 & 5.4 & 2.8 \\
\hline $83-1.106$ & Bl ade & abs & N & E & be & 06.5 & 24.1 & 9.3 & 15.8 \\
\hline $83 \cdot 1.110$ & Blode & obs & N & E & $b c$ & 46.8 & 32.9 & 7.0 & 9.8 \\
\hline $83-1.115$ & Blade & $\operatorname{ccs}$ & $r$ & SE & $b c$ & 39.8 & 15.3 & 4.1 & 2.6 \\
\hline $83-1.123$ & B I ade & abs & N & E & pt & 35.1 & 15.8 & 4.9 & 2.7 \\
\hline $83 \cdot 1.132$ & Blade & obs & $r$ & SE & pt & 34.8 & 19.1 & 6.0 & 3.7 \\
\hline $83-1.134$ & Blade & obs & N & $\mathbf{E}$ & $b c$ & 6.9 & 21.1 & 5.1 & 1.2 \\
\hline $83-1.87$ & Haft & $\operatorname{ccs}$ & $\cdot$ & $\cdot$ & ct & 29.3 & 20.1 & 8.8 & 4.0 \\
\hline $83-1.27$ & Mid-section & bas & $\mathbf{s}$ & - & bc & 26.6 & 25.2 & 6.2 & 4.5 \\
\hline $83-1.38$ & Mid-section & ccs & $N$ & $\mathbf{E}$ & bc & 39.5 & 15.8 & 5.7 & 3.9 \\
\hline $83-1.64$ & Mid-section & $\operatorname{ccs}$ & $r$ & $\cdot$ & be & 24.9 & 16.8 & 7.2 & 3.6 \\
\hline $83-1.72$ & Mid-section & ccs & $N$ & $\cdot$ & be & 28.9 & 19.0 & 6.4 & 3.2 \\
\hline $83-1.78$ & Mid-section & $\operatorname{ccs}$ & N & E & $b c$ & 27.0 & 18.0 & 4.0 & 2.5 \\
\hline $83-1.96$ & Mid-section & $\operatorname{ccs}$ & $\mu$ & $\cdot$ & $b c$ & 17.1 & 16.2 & 5.8 & 1.7 \\
\hline $83-1.98$ & Mid-section & ccs & $r$ & $\cdot$ & $b c$ & 22.4 & 18.0 & 5.2 & 2.6 \\
\hline
\end{tabular}


HEYMOERICKX PROJECTILE POINT FRAGMENTS

\begin{tabular}{|c|c|c|c|c|c|c|c|c|c|}
\hline Accession Ho. & Fragment type & Matrl & Serr & Mrgn & $x-\sec t$ & L total & $u$ & $I$ maximm & we \\
\hline . & $\cdots+\ldots$ & $\cdots$ & $\cdots$ & $\cdots$ & 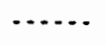 & ......... & $\cdots$ & $\cdots$ & \\
\hline $85-18.66 .2$ & Blade & $\operatorname{ccs}$ & N & E & $b c$ & 38.9 & 14.8 & 6.4 & 3.7 \\
\hline $85-18.66 .29$ & Blade & $\operatorname{ccs}$ & s & s & $b c$ & 22.8 & 11.3 & 3.1 & .6 \\
\hline $85-18.67 .36$ & Blade & $\operatorname{ccs}$ & N & E & $b c$ & 36.4 & 22.0 & 6.1 & 4.9 \\
\hline $85-18.69 .10$ & Blade & $\cos$ & N & s & $b c$ & 21.2 & 13.9 & 3.9 & .8 \\
\hline $85-18.69 .15$ & Blade & ces & r & - & pc & 18.2 & 8.6 & 2.2 & .3 \\
\hline
\end{tabular}

